\title{
Electrospun one-dimensional nanostructures: a new horizon for gas sensing materials
}

\author{
Muhammad Imran ${ }^{1}$, Nunzio Motta ${ }^{1}$ and Mahnaz Shafiei ${ }^{* 1,2}$
}

\section{Review}

\section{Address:}

${ }^{1}$ Institute for Future Environments and School of Chemistry, Physics, and Mechanical Engineering, Queensland University of Technology (QUT), Brisbane, QLD 4001, Australia and ${ }^{2}$ Faculty of Science, Engineering and Technology, Swinburne University of Technology, Hawthorn, VIC 3122, Australia

Email:

Mahnaz Shafiei - mshafiei@swin.edu.au

* Corresponding author

Keywords:

1D nanostructures; conductometric devices; electrospinning; gas sensors; optical sensors; resonators

\author{
Beilstein J. Nanotechnol. 2018, 9, 2128-2170. \\ doi:10.3762/bjnano.9.202 \\ Received: 10 January 2018 \\ Accepted: 23 July 2018 \\ Published: 13 August 2018 \\ Associate Editor: P. Leiderer \\ (C) 2018 Imran et al.; licensee Beilstein-Institut. \\ License and terms: see end of document.
}

\begin{abstract}
Electrospun one-dimensional (1D) nanostructures are rapidly emerging as key enabling components in gas sensing due to their unique electrical, optical, magnetic, thermal, mechanical and chemical properties. 1D nanostructures have found applications in numerous areas, including healthcare, energy storage, biotechnology, environmental monitoring, and defence/security. Their enhanced specific surface area, superior mechanical properties, nanoporosity and improved surface characteristics (in particular, uniformity and stability) have made them important active materials for gas sensing applications. Such highly sensitive and selective elements can be embedded in sensor nodes for internet-of-things applications or in mobile systems for continuous monitoring of air pollutants and greenhouse gases as well as for monitoring the well-being and health in everyday life. Herein, we review recent developments of gas sensors based on electrospun 1D nanostructures in different sensing platforms, including optical, conductometric and acoustic resonators. After explaining the principle of electrospinning, we classify sensors based on the type of materials used as an active sensing layer, including polymers, metal oxide semiconductors, graphene, and their composites or their functionalized forms. The material properties of these electrospun fibers and their sensing performance toward different analytes are explained in detail and correlated to the benefits and limitations for every approach.
\end{abstract}

\section{Review}

\section{Introduction}

The monitoring and control of air pollutants, toxic gases and explosives has become increasingly important for human wellness [1], security [2,3] as well as for the environment [4-11] in the last few decades. For instance, exposure to low concentra- tions of $\mathrm{CO}, \mathrm{CO}_{2}, \mathrm{NH}_{3}, \mathrm{NO}_{2}, \mathrm{CH}_{4}$ and/or $\mathrm{H}_{2} \mathrm{~S}$, even in the range of a few parts per million ( $\mathrm{ppm}$ ), can cause suffocation, nervous system disorders, and/or asthma followed by death. Gas sensors are the primary devices used for the detection and moni- 
toring of these pollutants. Employing nanotechnology in sensor applications has significantly improved the performance of such devices, providing enhanced sensitivity, selectivity, low power consumption and high integration flexibility. To date, many different gas sensing technologies have been developed. The predominant approaches to utilization are based on changes in the electrical conductance, optical properties, electrochemical potential or resonant frequency of the device [12-33].

Different types of nanostructures, including those based on metal oxides (MOx), organic and inorganic materials and carbon nanostructures, have shown promising sensing performance due to their unique characteristics, such as high surfaceto-volume ratio, high surface active sites, high specific surface area and reactivity $[12,13]$. Among these nanostructured materials, one-dimensional (1D) materials are known to be highly suitable candidates due to their higher surface energy, increased number of reactive sites, effective charge carrier transport, and larger surface-to-volume ratio [34]. The large surfacearea-to-volume ratio of nanofibers (NFs), hollow nanofibers (HNFs), nanotubes (NTs) and nanowires (NWs) with micro/ mesoporous surfaces results in improved adsorption and better reaction kinetics of gas-sensitive materials.

Nanofibers can be produced by many different approaches. For example, by use of a molten-salt method, wet (or liquid) chemistry, nanocarving, self-catalyst growth, template-assisted (or sacrificial template) synthesis, chemical vapour deposition, thermal evaporation, spray pyrolysis or electrospinning [34-36]. Among these techniques, electrospinning is one of the most versatile and robust techniques for synthesis of functional nanofibers with unique structure and diverse properties [37-40]. The diameter of these functional fibers range between submicrometre to nanometre. The versatility of electrospinning has led to many publications in the field. The number of publications on electrospun fiber-based gas sensors has increased rapidly since the application of electrospinning to sample preparation. The number of patents and publications per year on electrospun 1D nanomaterials from 2000 until 2017 is shown in Figure 1.

A nanofiber film has a surface area approximately twice that of a continuous thin film. This property means that nanofibers are excellent candidates for gas sensing applications. Moreover, nanofibers derived from a variety of materials, such as polymers, metals, metal-oxides and composites, are fabricated in various assemblies (e.g., as mixed nanocomposites, doublelayers, core-shell or hollow forms) using the electrospinning technique [37]. These electrospun nanofibers exhibit enhanced specific surface area, superior mechanical properties, nanoporosity and improved surface characteristics [37,40]. Such porous nanostructures provide a fundamental property that enhances the effective analyte adsorption and increases sensitivity. Therefore, the remarkable specific surface area and high porosity ( $\approx 70-90 \%)$ [41] due to the presence of small and large pores means that electrospun nanofibers are highly attractive as ultrasensitive sensors [42].

To date, many excellent review articles on the fabrication, alignment and application of electrospun nanofibers have been published $[32,37,39,40]$. However, to the best of our knowledge, a modern, comprehensive review on gas sensing applications of the electrospun 1D nanostructures (NFs, HNFs, NTs, and NWs) employing different types of materials integrated with different sensing principles does not exist. In 2009, Ding et al. [32] published a review article on gas sensors based on electrospun nanofibers, but since then, many reports on the development of the gas sensors employing electrospun nanofibers have

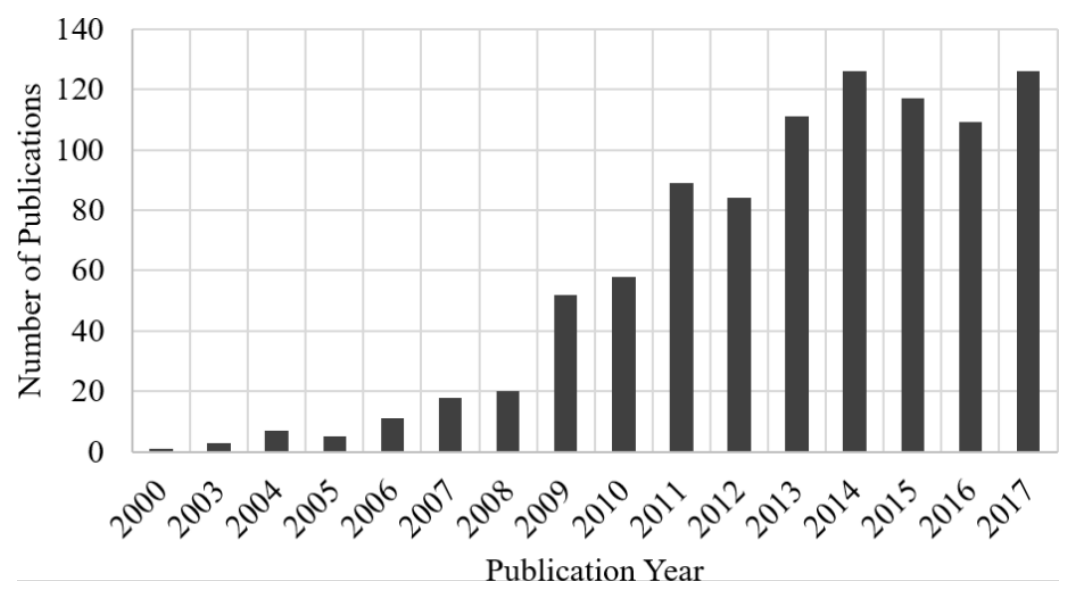

Figure 1: The annual number of patents and journal article publications on the topic of electrospun 1D nanomaterials used for gas sensing (Source: SciFinder ${ }^{\circledR}$ searched on May 14, 2017). 
been published. Recently, Choi et al. [43] reported a review on chemiresistive and optical sensors employing only semiconducting metal oxides and their functionalization by catalytic nanoparticles. Herein, we will comprehensively review and summarize the fabrication of electrospun 1D nanostructures based on diverse range of materials (including polymers, metal oxide semiconductors, graphene, and their composites or their functionalized forms) and their gas sensing performance in all available sensing architectures (including conductometric, acoustic resonators and optical). In addition, we provide concluding remarks and an outlook on this rapidly evolving research field on gas sensors based on electrospun 1D nanostructures.

\section{Electrospinning}

The electrostatic effect was first described in 1600 by Willian Gilbert $[44,45]$ through a series of experiments using an electrically charged piece of amber. He noticed that a water droplet attained a conical profile in the proximity of charged amber and, if the charge was strong enough, tiny droplets would evolve from the larger water droplet. Gilbert's experiments laid the foundation for electrospinning as well as electrospraying.

Electrospinning is a simple, robust and low-cost technique to generate polymer and composite fibers ranging from nanometres to a few micrometres in diameter [46,47]. In electrospinning, a high voltage source is used to produce fine fibers from a polymer solution or melt. A typical solution electrospinning setup comprises five major components: a metallic needle with a blunt tip, a syringe for containing the electrospun solution, a syringe pump to control the solution feeding rate, a direct current (DC) high voltage (HV) source, and a grounded conductive collector. Electrospinning is based on the electrostatic effect on a high viscosity fluid. In electrospinning, a hemispherical droplet of the polymer solution, suspended at the end of a capillary tube, is subjected to an electric force. Electric charges accumulate at the surface of the droplet and tend to elongate the droplet into a cone shape, where surface tension reduces the surface area by keeping it in a spherical shape. When the charged repulsive expansion exceeds surface tension based contraction, a charged jet of the solution is ejected from the tip of the Taylor cone and travels toward the target surface [48]. This charged jet exhibits chaotic motion as it travels toward the target. During the evolution of the electrospinning technique to modern times, Reneker and co-workers $[49,50]$ have made a remarkable contribution by producing a diverse range of electrospun NFs of various morphologies, sizes and for various applications [51-55]. More recently, Deitzel et al. [56] and Shafiei et al. [57] developed a method to dampen the chaotic motion of the charged jet using electrostatic rings with a better control of the deposition area that is crucial for depositing 1D nanostruc- tures on miniature sensing platforms (i.e., micro-electromechanical systems (MEMs)).

The electrospinning process is governed by various parameters such as viscosity, conductivity, molecular weight of fiber components, surface tension of polymer solution, electric potential, working distance, and flow rate. Each parameter significantly influences the morphology of the electrospun fibers, yet by their proper manipulation nanofibers with desired morphology and diameter are obtained. Bhardwaj et al. [58] and several other researchers summarized these parameters and their effect on fiber diameter and morphology for current electrospinning practices [58-62].

\section{Nanostructure morphologies generated by electrospinning}

Recently, a great deal of attention and research effort has been devoted to the development of electrospun fibers incorporated with functional nanoparticles (NPs) [39,40]. This practice significantly improves the performance of electrospun fibers/mats. In addition, the electrospun fibers/mats may reduce corrosion and/or oxidation in NPs, especially those with anisotropic structure [40]. Depending on the type of polymer and NPs, electrospun fibers incorporated with NPs are optimized for specific applications. This approach shows good potential for applications involving the self-assembly of anisotropic NPs to generate new functional devices [63].

There are two major methods for producing electrospun NP fibers [40]: (i) "indirect synthesis", that requires some post-processing methods after electrospinning and (ii) "direct synthesis" of electrospun NP fibers during the electrospinning process. In the direct method, the composite fibers are electrospun from one single solution that contains the NPs. NP fibers formed in this way are not notably deformed or affected during the electrospinning process and their functionality remains viable in the final product [40]. To make the electrospinning of fibers containing NPs simple and easy, the NPs should be uniformly distributed within the solution. The properties of an electrospun hybrid fiber are tuned by controlling the density and distribution of the NPs in the fibers. Based on the type of NP (0D dots, $1 \mathrm{D}$ - wires, $2 \mathrm{D}$ - plates), the nanofibers can be classified as:

- 0D NPs-electrospun fibers containing quantum dots or zero-dimensional particles,

- 1D NPs-electrospun fibers containing wires or similar elongated morphologies,

- 2D NPs-electrospun fibers containing plate-like or layered morphology particles and

- other organic or biological NPs-electrospun fibers [40]. 
Recently, Shafiei et al. [57] reported electrospun ultrafine fibers with $\mathrm{MoO}_{3}$ nanoparticles embedded in poly(ethylene oxide) (PEO) polymer by using the direct method. The fibers are deposited directly onto a controlled and selective deposition area using a multifield electrospinning setup as shown in Figure 2. The scanning transmission electron microscopy (STEM) image confirms the uniform distribution of $\mathrm{MoO}_{3} \mathrm{NPs}$ inside the electrospun fibers. Similarly, $\mathrm{CuO}$ NPs are embedded in polyurethane (PU) nanofibers using electrospinning [64] These nanoparticles embedded in polymer nanofibers could be promising materials for room temperature gas sensing. Furthermore, graphene oxide (GO) sheets have also been incorporated with electrospun polyacrylonitrile (PAN) fibers [65-67]. The fibers reinforced with GO show better mechanical, electrical and thermal properties than the fibers without GO. These graph- ene-based composite electrospun fibers have been used for biosensor applications $[65,68]$.

Hybrid nanofibers with various morphologies, including mixed nanocomposite, dual-layer, core-shell and hollow nanofibers, are produced using different modified spinnerets [69-74]. Lin et al. [69] produced bi-component polymer fibers, showing the synergistic effects of the two different polymers, for the production of a new material using a microfluidic device as shown in Figure 3 . These fibers are normally categorized by their crosssectional structure such as: side-by-side, sheath-core and segmented-pie types. The nature of composite fibers produced in this way depends on their mutual interaction during electrospinning. Polymer solutions can either remain immiscible following a laminar flow or disperse to form a uniform homogeneous
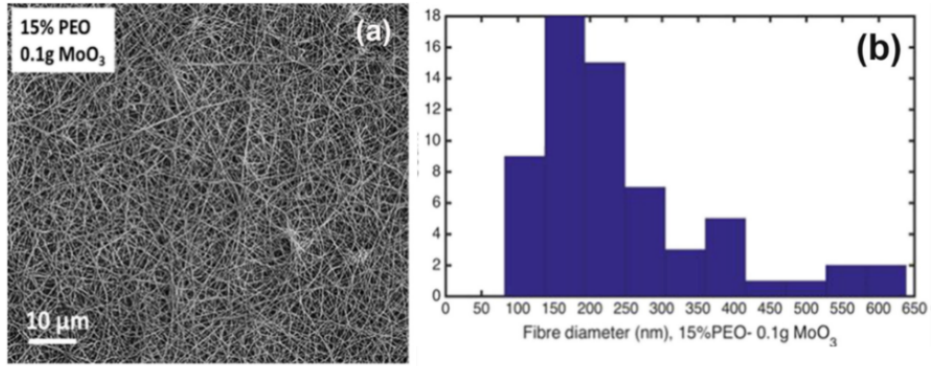

(c)

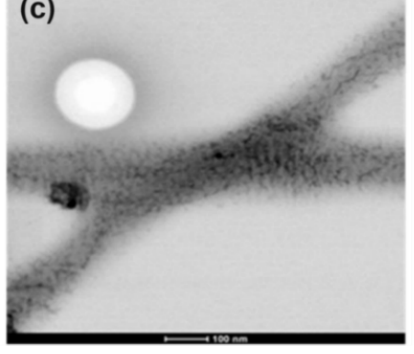

(d)

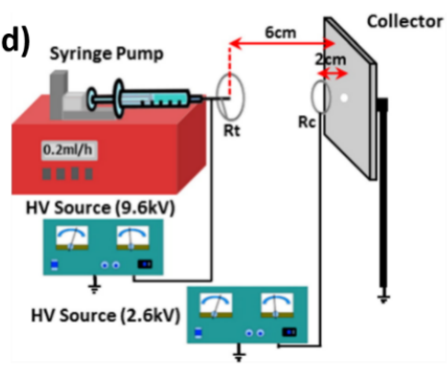

Figure 2: (a) SEM image; (b) size distribution of fiber diameters and (c) STEM image of electrospun nanofibers from a solution of $15 \%$ PEO with $0.1 \mathrm{~g}$ of $\mathrm{MoO}_{3}$ powder. (d) Schematic diagram of a multifield electrospinning setup. Reproduced with permission from [57], copyright 2017 Elsevier.

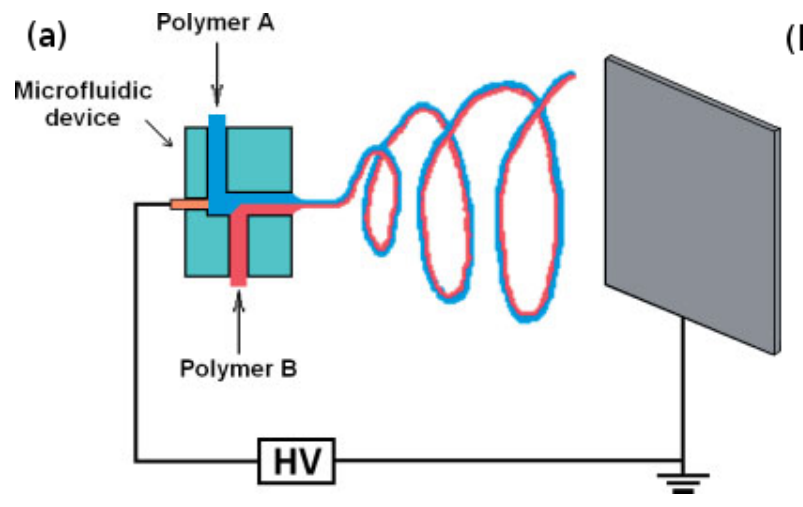

(b)

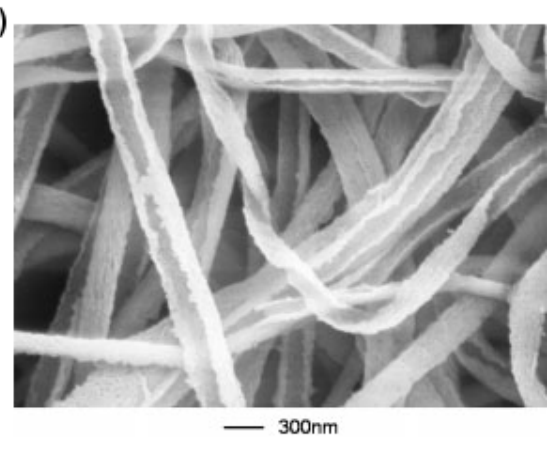

Figure 3: (a) Side-by-side electrospinning apparatus and (b) SEM image of poly(acrylonitrile)/polyurethane (PAN/PU) fibers. Reproduced with permission from [69], copyright 2005 Wiley. 
solution. The former gives rise to bi-component nanofibers, while the latter produces blended polymer fibers.

Dual-layer $\mathrm{TiO}_{2} / \mathrm{SnO}_{2}$ nanofibers have been reported by Liu et al. [72] using two syringes containing different solutions linked to a common spinneret. Each solution must have the same viscosity for uniform distribution in the final product. The resulting fibers from this technique are shown in Figure 4. Similarly, titania hollow fibers have been synthesized by Li et al. using a coaxial spinneret $[73,74]$. Titania hollow fibers can be produced by co-electrospinning a poly(vinyl pyrrolidone) (PVP) solution containing a titanium alkoxide $\left(\mathrm{Ti}(\mathrm{OiPr})_{4}\right)$ and mineral oil. The mineral oil is removed at a later stage by calcination. In the same way, the interior of a hollow fiber is decorated by oildispersible nanoparticles using a silica capillary inside a stainless steel needle. The electrospinning setup and resulting hollow fibers are shown in Figure 5.

Choi et al. [75] synthesized macroporous $\mathrm{WO}_{3} \mathrm{NTs}$ using coaxial electrospinning combined with sacrificial templating. A porous structure using colloidal polystyrene (PS) particles in a solution with a $\mathrm{W}$ precursor and poly(vinyl pyrrolidone) was produced and a mineral oil was used to define the core. The PS particles and mineral oil are later removed by calcination. A schematic diagram of the electrospinning setup and resulting nanotubes are shown in Figure 6.
Fan et al. [76] developed a new fabrication strategy for synthesis of $\mathrm{SnO}_{2}$ NFs with a branch-on-stem morphology using electrospinning, oxygen plasma etching, sputtering and annealing. Electrospun PVP NFs were first etched with oxygen plasma to make a hierarchical template. Afterwards, a $\mathrm{SnO}_{2}$ film is deposited by sputtering and the PVP template is removed by annealing. The morphology of the NFs is dependent on sputtering time, resulting in uniformly distributed branches all over stem. Jun et al. [77] developed polypyrrole (PPy)-coated $\mathrm{SnO}_{2}$ tube-in-tube structures using single-nozzle electrospinning with a phase separation solvent method (Figure 7).

Liang et al. [78] reported a new method to synthesize electrospun hollow NFs using a two-step method. The $\mathrm{In}_{2} \mathrm{O}_{3}$ NFs are first produced by electrospinning and then are corroded by using $10 \% \mathrm{HNO}_{3}$ to obtain hollow $\mathrm{In}_{2} \mathrm{O}_{3} \mathrm{NFs}$. The morphology of $\mathrm{In}_{2} \mathrm{O}_{3}$ nanostructures is also transformed from NFs to nanotubes (NTs) in a single capillary electrospinning process by changing the heating rate during the calcination process [79].

Similarly, $\mathrm{In}_{2} \mathrm{O}_{3}$ NFs are converted into nanoribbons (NRbs) by changing the experimental parameters [80]. The rapid evaporation of solvent and the concentration of the precursor are important parameters for the formation process of $\mathrm{In}_{2} \mathrm{O}_{3} \mathrm{NRbs}$. The $\mathrm{In}_{2} \mathrm{O}_{3} \mathrm{NFs}$ have an average diameter of $180 \mathrm{~nm}$, whereas the $\mathrm{NRbs}$ have an average width of $1 \mu \mathrm{m}$ and thickness of $150 \mathrm{~nm}$.
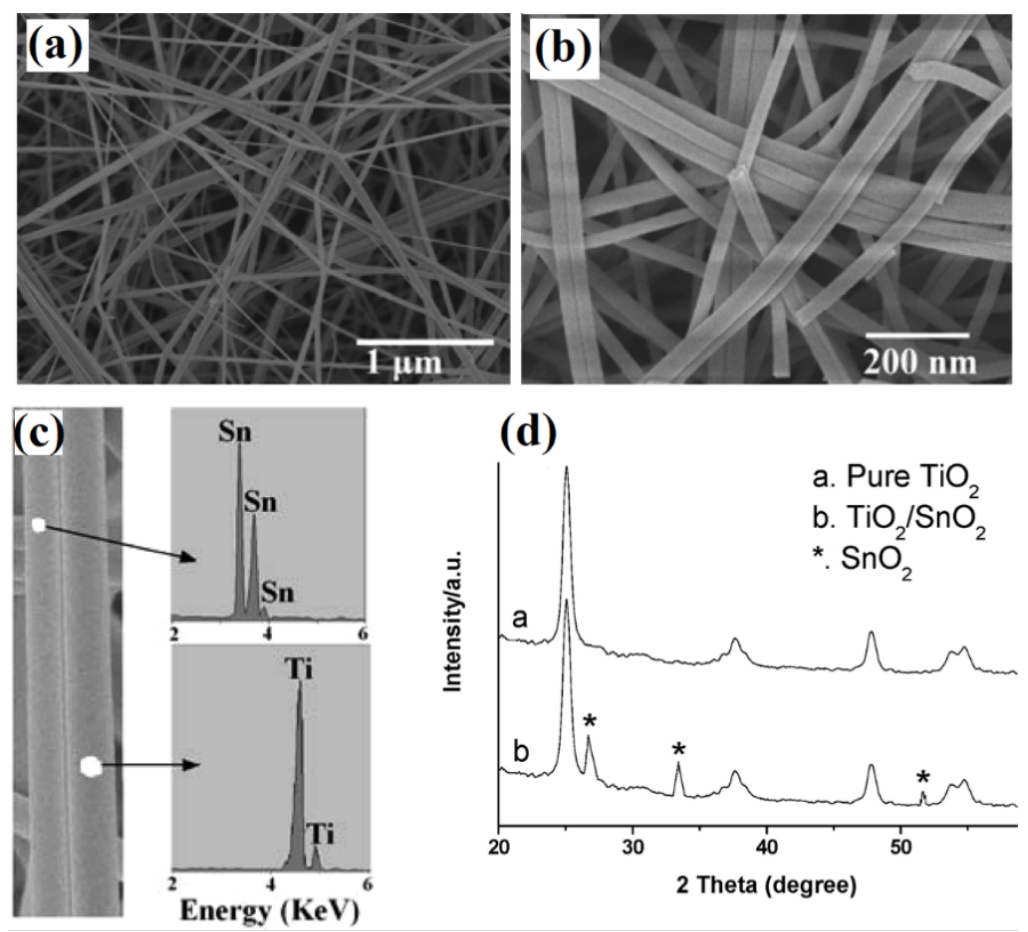

Figure 4: (a, b) Typical SEM images of the electrospun bi-component $\mathrm{TiO}_{2} / \mathrm{SnO}_{2}$ nanofibers; (c) EDS microanalysis of selected areas of the nanofiber, and (d) XRD diffraction patterns of the electrospun nanofibers. Reproduced with permission from [72], copyright 2007 ACS. 

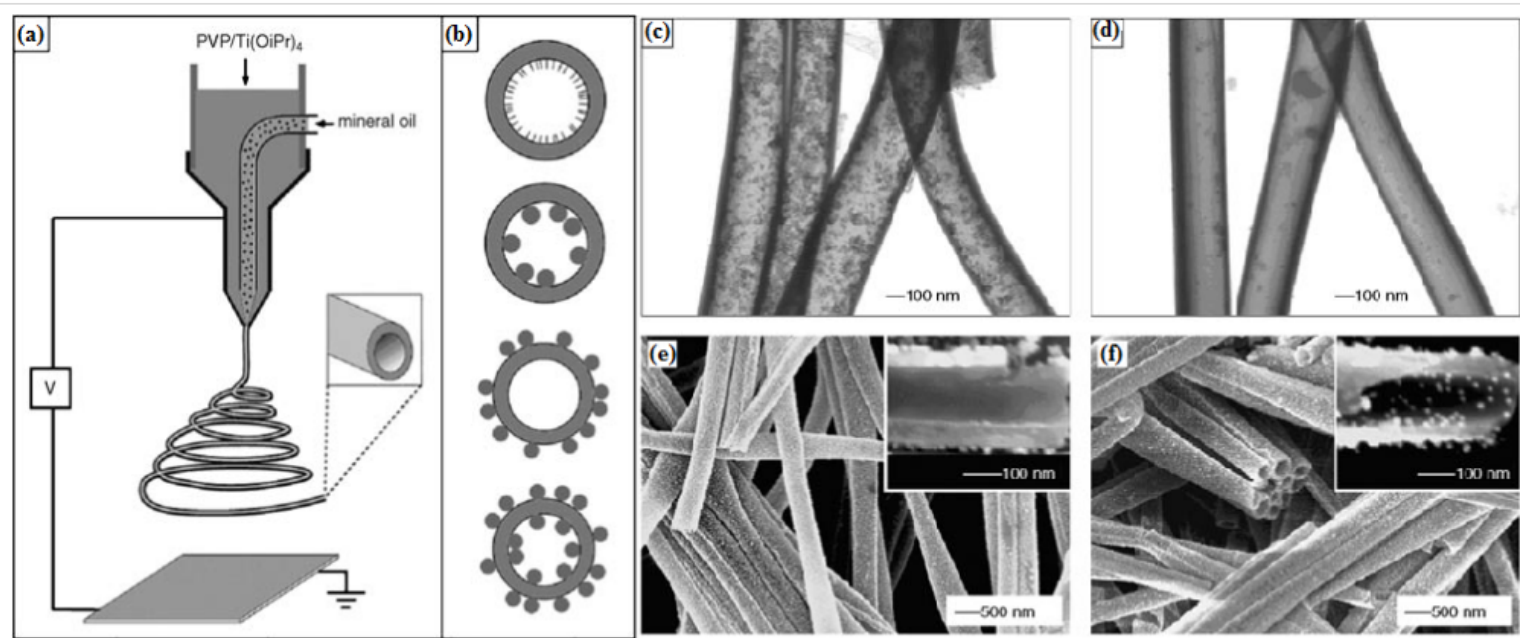

Figure 5: (a) Schematic illustration of the setup using a dual-capillary spinneret to directly electrospin hollow nanofibers with functionalized surfaces; (b) schematic drawings showing cross sections of hollow nanofibers whose surfaces are derivatized with functional molecules (the top plate) and nanoparticles (NPs) (the other plates). TEM images of hollow titania nanofibers immersed in an oil-based ferrofluid overnight. The hollow fibers are prepared by co-electrospinning, either with (c) or without (d) octadecyltrichlorosilane (OTS) added to the mineral oil. (e) SEM image of hollow fibers for which inner and outer surfaces are derivatized with $\mathrm{CH}_{3}$ - and $\mathrm{NH}_{2}$-terminated silanes, respectively, and then immersed in citrate-stabilized Au colloids. Note that the Au colloids are selectively adsorbed onto the outer surfaces. (f) SEM image of hollow fibers with inner and outer surfaces treated with an $\mathrm{NH}_{2}$-terminated silane, followed by incubation with Au colloids. In this case, the Au colloids are adsorbed on both surfaces. Reproduced with permission from [73], copyright 2005 Wiley.
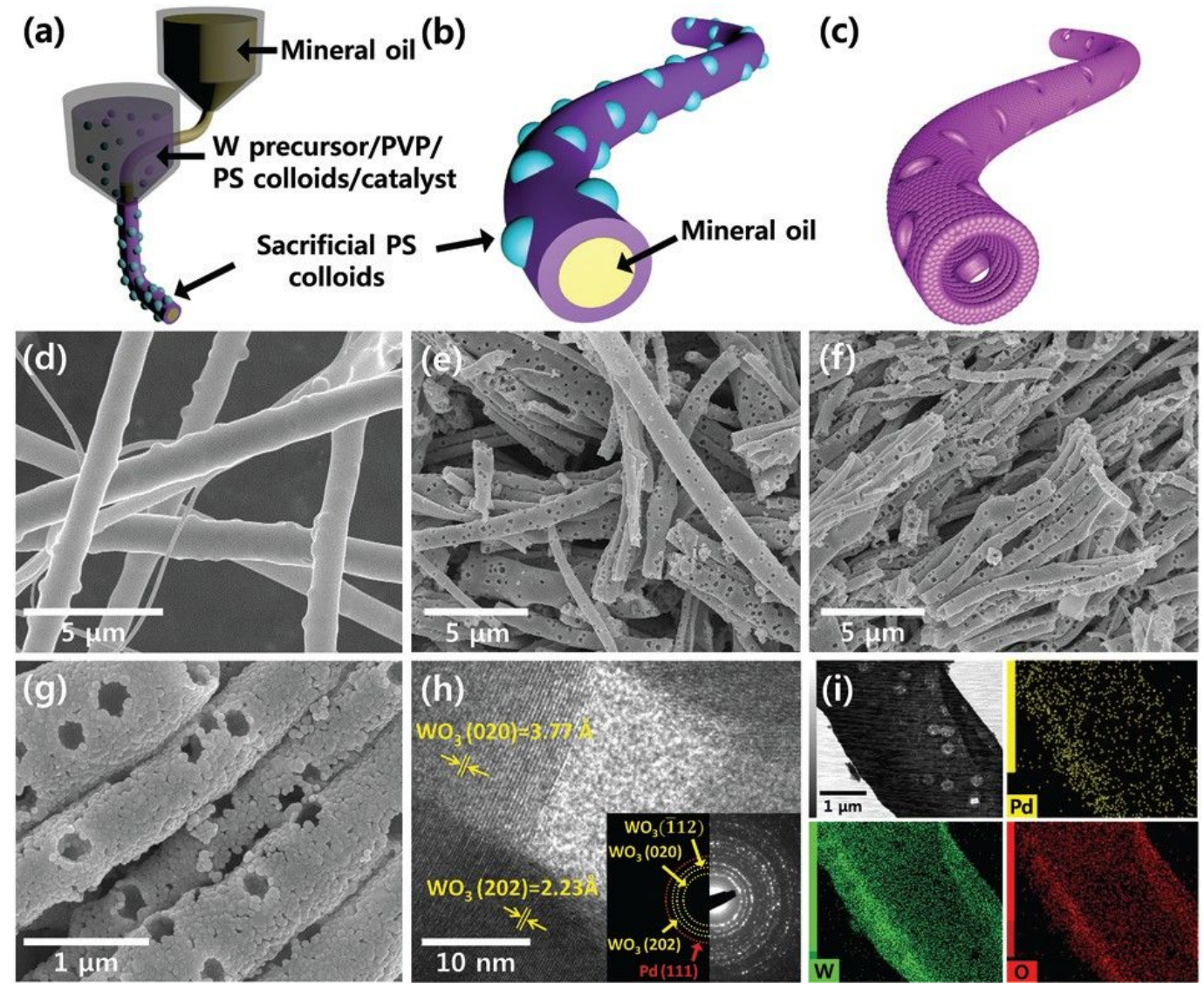

Figure 6: $(a-c)$ Schematic illustrations of coaxial electrospinning using mineral oil in the core and composite solution in the shell. (d-i) SEM and TEM images of W precursor/PVP composite nanotubes decorated with PS colloid templates, and Pd-loaded macroporous WO $\mathrm{WT}_{3} \mathrm{NT}$. Reproduced with permission from [75], copyright 2016 Royal Society of Chemistry. 


\section{(a)}
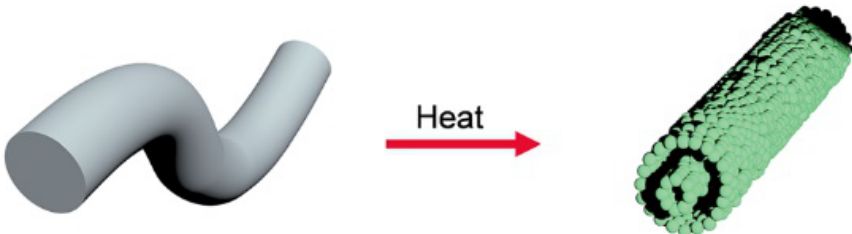

Electrospun nanofiber
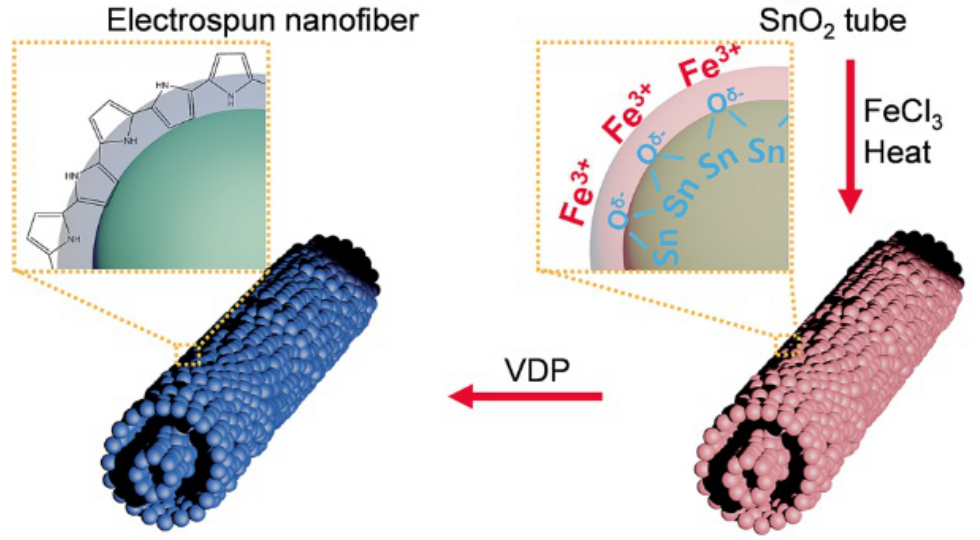

PPy@SnO ${ }_{2}$ tube in tube

$\mathrm{FeCl}_{3}$ soaked $\mathrm{SnO}_{2}$ tube in tube
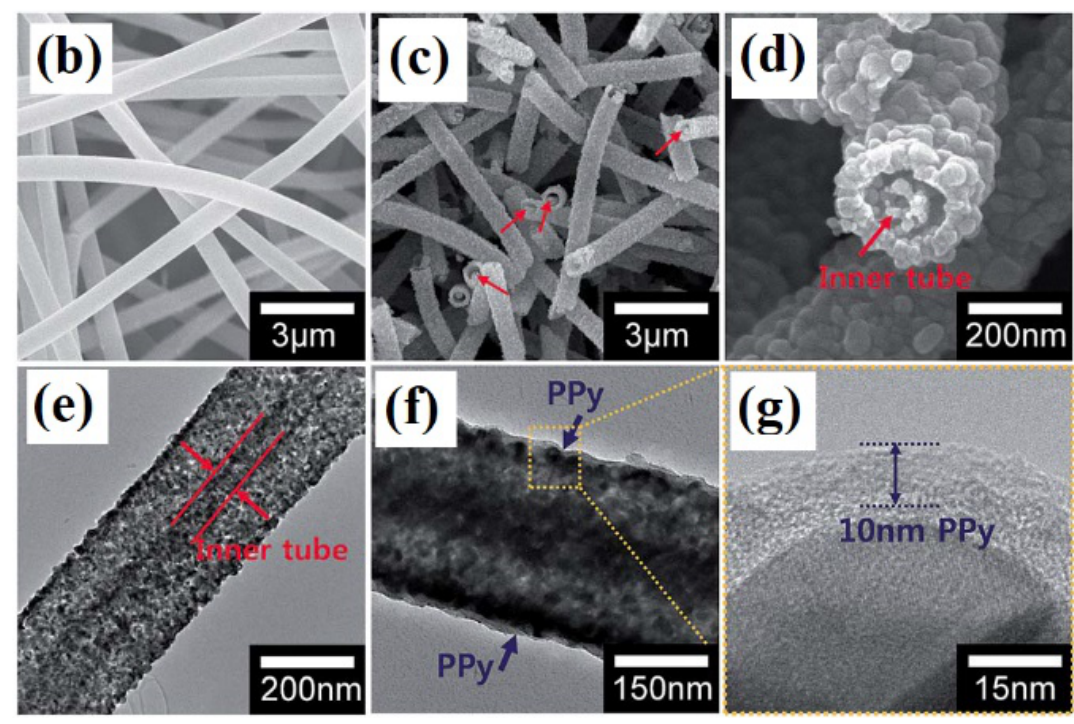

Figure 7: (a) Schematic diagram of the sequential fabrication of a PPy@ $\mathrm{SnO}_{2}$ tube-in-tube structure. (b) FE-SEM image of the electrospun nanofibers. (c, d) Low- and high-resolution FE-SEM images of the tube-in-tube $\mathrm{SnO}_{2}$. (e) Low-resolution TEM images of the tube-in-tube SnO 2 . (f, g) Low- and high-resolution TEM images of the tube-in-tube PPy/SnO 2 . Reproduced with permission from [77], copyright 2017 Royal Society of Chemistry.

Li et al. [80] found that just by increasing the ethanol concentration in the solvent mixture by keeping the precursor concentration constant, mixed NFs and NRbs are obtained. These mixed morphologies are further completely converted into nanoribbons by increasing the polymer concentration and salt content [80].

\section{Gas sensors based on electrospun nanostructures}

Gas sensors are devices specifically used to detect and discriminate between many different gases in the presence of other gases within low concentration ranges between a few parts per million ( $\mathrm{ppm}$ ) to parts per billion ( $\mathrm{ppb}$ ). The performance parameters of these gas sensors, including sensitivity, selectivity, response and recovery time, stability, reproducibility and reversibility, are strongly influenced by the properties of the sensing materials [12-14]. Chemical sensors are widely used for biomedical, healthcare, security and environmental applications. Table S1 in Supporting Information File 1 presents a summary of the different types of electrospun nanofibers reported to date that are used for gas sensors [4-11,32,81-89]. The following section discusses the details of these developed gas sensors 
based on the type of sensing platform and then by sub-categories of material(s) used to fabricate the electrospun nanofibers as the sensing layer. These materials include:

- metal oxide (MOx) semiconductors (e.g., $\mathrm{SnO}_{2}, \mathrm{TiO}_{2}$, $\left.\mathrm{SiO}_{2}\right)[83,84]$,

- doped MOx semiconductors [4-11],

- composite materials made of MOx semiconducting materials (e.g., $\mathrm{ZnO}-\mathrm{In}_{2} \mathrm{O}_{3}$ ) [86],

- conducting polymer-based gas sensors (e.g., polypyrrole (PPy), polyaniline (PANI), polythiophene (PTh) and their derivatives) $[32,87,88,90]$,

- MOx nanofibers surface functionalized by metal nanoparticles [75] and

- graphene sheets incorporated with MOx nanofibers [89].

\subsection{Conductometric gas sensors}

Nanostructure-based conductometric sensors have found widespread commercial applications $[91,92]$ due to their simplicity and enhanced gas sensing performance (high sensitivity, fast response/recovery and low operating temperature) and low cost. A typical conductometric gas sensor consists of an active sensing layer in which conductivity changes upon exposure to the target gas. The adsorption of gas molecules on the sensing layer leads to redox reactions by serving as an electron donor or acceptor which depends on the reductive or oxidative nature of the target gas compared to molecular oxygen. As the charge carrier concentration changes due to gas adsorption or desorption, the resistance of the sensing layer changes. To date, many types of nanomaterials in different structures have been synthesized and employed in conductometric devices for gas sensing applications [12,34,92].

4.1.1 Pure semiconducting metal oxides: Several types of electrospun metal oxide (MOx) semiconductors have been used for gas sensing applications. These semiconductors include titanium dioxide $\left(\mathrm{TiO}_{2}\right)$ [93-95], tungsten trioxide $\left(\mathrm{WO}_{3}\right)$ [27,96110], copper oxide (CuO) [111], $\mathrm{NiO}$ [112], $\mathrm{Co}_{3} \mathrm{O}_{4}$ [113,114], iron oxide $\left(\mathrm{Fe}_{2} \mathrm{O}_{3}\right)$ [115,116], tin dioxide $\left(\mathrm{SnO}_{2}\right)$ [76,117-123], zinc oxide $(\mathrm{ZnO})$ [124-130], and indium oxide $\left(\operatorname{In}_{2} \mathrm{O}_{3}\right)$ [78,80,131-138]. Table S2 in Supporting Information File 1 summarizes the sensing performance of these electrospun pure MOx nanofibers.

Pure metal oxides have an intrinsic response towards a specific analyte gas that is remarkably dependent on grain size and specific surface area. A high response is expected for nanofibers with smaller grain size, smaller crystallite size, high porosity and larger surface area $[130,139,140]$. For example, the sensitivity of $\mathrm{In}_{2} \mathrm{O}_{3}$ nano/microtubes was improved by controlling the grain size via adjusting the calcination temperature [132]
The sensitivity increases as grain size is reduced with a corresponding increase in surface area. Grain sizes of 10,15 and $23 \mathrm{~nm}$ were obtained for $\mathrm{In}_{2} \mathrm{O}_{3}$ NTs calcined at $400{ }^{\circ} \mathrm{C}, 600{ }^{\circ} \mathrm{C}$ and $800{ }^{\circ} \mathrm{C}$. The $\operatorname{In}_{2} \mathrm{O}_{3}$ NTs sample calcined at $400{ }^{\circ} \mathrm{C}$ shows the highest performance for $\mathrm{HCHO}$ gas compared with its counterparts. The crystallite size can also be controlled by solution composition and polymer content followed by annealing and calcination [83]. A very low detection limit (9.7 ppb $\left.\mathrm{NO}_{x}\right)$ with an optimal response time $(20 \mathrm{~s})$ is achieved with nanocrystalline $(5-10 \mathrm{~nm}) \mathrm{SnO}_{2}$ NTs at room temperature [141]. Similar behaviour is exhibited by p-type $\mathrm{NiO}$ and $\mathrm{CuO}$ toward $\mathrm{CO}$ and $\mathrm{NO}_{2}[111,112]$. The gas sensing behaviour also depends on the connectivity of the grains in highly crystalline nanofiber $[113,114]$.

An opposite trend for crystal size is reported by Landau et al. [142] and Choi et al. [111] who obtained a higher response toward $\mathrm{CO}$ and $\mathrm{NO}_{2}$ with larger grain fibers. Moreover, the interparticle distance is also a key parameter in gas sensing properties. Less connected particles in $\mathrm{Cr}_{2} \mathrm{O}_{3}$ and $\mathrm{Co}_{3} \mathrm{O}_{4}$ nanofibers show a reduced gas sensing response [113]. Sensors calcined at $750{ }^{\circ} \mathrm{C}$ (grain size $36 \pm 4 \mathrm{~nm}$ ) showed $10-25 \%$ and $25-65 \%$ more sensitivity toward $\mathrm{CO}$ and $\mathrm{NO}_{2}$, respectively, than those calcined at $450{ }^{\circ} \mathrm{C}$ (grain size $17 \pm 2 \mathrm{~nm}$ ). The response of the NFs increases with an increase in surface area. $\mathrm{TiO}_{2}$ hollow fibers (HFs), of average diameter 200-2000 nm, exhibited higher response to $\mathrm{CO}$ at room temperature compared with solid fibers because gas molecules interact with the inner and outer diameters of the HFs. Moreover, the $\mathrm{In}_{2} \mathrm{O}_{3}$ and $\mathrm{ZnO}$ NTs with smaller diameter $(\approx 50-100 \mathrm{~nm})$ and thinner walls $(\approx 10 \mathrm{~nm})$ exhibited enhanced response compared with larger diameter NTs $(\approx 500 \mathrm{~nm})$ toward formaldehyde, $\mathrm{CO}$ and $\mathrm{NO}_{2}$ [126-128,133,143].

$\mathrm{WO}_{3}$ NTs with an average diameter of $200 \mathrm{~nm}$ showed a response of 45.2 toward $100 \mathrm{ppm}$ of acetone at $250{ }^{\circ} \mathrm{C}$ compared with solid NFs with average diameter of $275 \mathrm{~nm}$. These latter NFs give a response of 60.2 at $270{ }^{\circ} \mathrm{C}$. The response time of $\mathrm{WO}_{3}$ NTs $(5 \mathrm{~s})$ is smaller than $\mathrm{WO}_{3}$ NFs $(6-13 \mathrm{~s})$ but the recovery time is longer (22 s) than $\mathrm{WO}_{3} \mathrm{NFs}(4-9 \mathrm{~s})$ because of different desorption rates in NTs compared with NFs $[102,110]$. A similar trend is shown by $\operatorname{In}_{2} \mathrm{O}_{3}$ NWs and NTs with similar response times but a longer recovery time for NTs compared with their counterparts [79,133]. Moreover, smaller diameter $\mathrm{In}_{2} \mathrm{O}_{3}$ NTs $(\approx 100 \mathrm{~nm})$ exhibited a higher response toward HCHO than larger diameter NTs $(\approx 500 \mathrm{~nm}$ or $1 \mu \mathrm{m})$ [133].

The gas sensing response is also improved without tuning the microstructure of nanofibers just by the introduction of UV irradiation $[105,144,145]$. The response of $\mathrm{TiO}_{2}$ nanofibers is enhanced from $1.8 / 25 \mathrm{ppm}$ to $18 / 25 \mathrm{ppm}$ of hydrogen, whereas the 
response/recovery time reduced from $12.3 / 22.5 \mathrm{~s}$ to $2 / 6.9 \mathrm{~s}$ [145].

4.1.2 Doped semiconducting metal oxide: The intrinsic response of pure metal oxide 1D nanostructures can be tuned by changing the crystallite size, crystallinity and surface area. In general, these material parameters are modified by controlling the precursor concentration and/or calcination temperature [130]. The most effective approach to improve the gas sensing response of pure MOx 1D nanostructures is by functionalizing with different catalytic metals, MOx or noble metals [11,146]. Doping changes the reaction kinetics and electronic characteristics as well as the structural properties, including size and topology of the MOx 1D nanostructures, which leads to a change in their chemical sensing behaviour. [8,147-150]. Yamazoe et al.[151,152] explained the two types of functionalization mechanisms occurring in metal oxides as chemical sensitization and electronic sensitization. Traditionally, the doping is done by noble metals like Au [109,146,153-156], Ag [157-161], Pt [162-168], or Pd [75,107,148,169-176]. Moreover, noble metals can catalyse the gas sensing response of pure MOx NFs [86].

$\mathrm{SnO}_{2}$ is a widely-used metal oxide material for gas sensing applications because of its low cost and high chemical stability. However, wide application of $\mathrm{SnO}_{2}$-based gas sensors is limited by low sensitivity, slow response, lack of selectivity and the effects of aging. $\mathrm{SnO}_{2} \mathrm{NFs} / \mathrm{NTs}$ have been doped by alkaline earth (Ae) metals [86], lanthanides (Yb, Sr, Ce) [4,8,177], rare earth metals (Pr) [7], transition metals (Fe, Y, Ni) [5,178,179], copper [180], Pd [172] and $\mathrm{Al}$ [181]. In addition, NPs have been doped with Pt [153], Ag [157], $\mathrm{Ca}^{2+} / \mathrm{Au}[146,153,154]$ and $\mathrm{LaOCl}[182]$.

Doping with Ae metals exhibits an advantage in grain growth control [86]. For example, after thermal treatment, nanoparticle/ nanograins show necked connections for each type of Ae-doped $\mathrm{SnO}_{2}$ NF. Therefore, a conduction channel can be established within each aggregate due to the space-charge layer region around each neck; this leads to fast capture and migration of electrons, and subsequently, enhanced gas sensing performance. The response of $\mathrm{Sr} / \mathrm{SnO}_{2} \mathrm{NTs}$ is $54.23 \%$ to $2000 \mathrm{ppm} \mathrm{NH}_{3}$, a value that is higher than other sensors due to the tubular structure. A lower detection limit of $10 \mathrm{ppm}$, faster response time of $6 \mathrm{~s}$ for $2000 \mathrm{ppm}$ and $16 \mathrm{~s}$ for $10 \mathrm{ppm}$ as well as improved reversibility was measured for $\mathrm{Sr} / \mathrm{SnO}_{2} \mathrm{NT}$ s toward $\mathrm{NH}_{3}$ gas at room temperature as compared with the pristine $\mathrm{SnO}_{2} \mathrm{NFs}$.

Similarly, $\mathrm{SnO}_{2} \mathrm{NFs}$ doped with $\mathrm{Ca}^{2+} / \mathrm{Au}$ exhibit a higher response (62) to $100 \mathrm{ppm}$ of acetone at lower temperature $\left(180^{\circ} \mathrm{C}\right)$ with response and recovery times of $8 \mathrm{~s}$ and $5 \mathrm{~s}$ for
$100 \mathrm{ppm}$ of acetone [146]. $\mathrm{SnO}_{2}$ NTs have also been functionalized by bio-inspired Pt particles ( $2 \mathrm{~nm}$ diameter) at $0.16 \mathrm{wt} \%$ and Au particles ( $2.7 \mathrm{~nm}$ diameter) at $0.08 \mathrm{wt} \%$ using a protein nanocage by single-nozzle electrospinning [183] as shown schematically in Figure 8a. The diameter of the $\mathrm{SnO}_{2}$ NTs, as shown in SEM micrographs (Figure $8 \mathrm{~b}-\mathrm{d}$ ), is $250-350 \mathrm{~nm}$ with a wall thickness of $40 \mathrm{~nm}$. The elemental distribution for each NT is shown in Figure 8g,j. Pt-loaded $\mathrm{SnO}_{2}$ NTs exhibit a response of 92 toward $5 \mathrm{ppm}$ of acetone compared to pure $\mathrm{SnO}_{2}$ NFs which respond 4.8 at 5 ppm acetone. $\mathrm{SnO}_{2}$ NTs show a response of 11 at 5 ppm acetone while Au-loaded $\mathrm{SnO}_{2}$ NTs show a higher response of 34 toward 5 ppm of hydrogen sulphide $\left(\mathrm{H}_{2} \mathrm{~S}\right)$. In comparison, dense $\mathrm{SnO}_{2}$ NFs show a response of 2.6 at $5 \mathrm{ppm} \mathrm{H}_{2} \mathrm{~S}$ and pristine $\mathrm{SnO}_{2}$ NTs show a response of 4.7 at $5 \mathrm{ppm} \mathrm{H}_{2} \mathrm{~S}$, respectively (Figure 8k,1) [183].

Similarly, a very low concentration of acetone (120 ppb) can be detected with a fast response/recovery time (11/6s) using thinwalled wrinkled layer $\mathrm{SnO}_{2}$ NTs functionalized with Pt by a controlled phase separation technique [163]. The selectivity of $\mathrm{SnO}_{2} \mathrm{NFs}$ is also improved by doping with rare earth metals, e.g., $\mathrm{Pr}^{2+}, \mathrm{Sr}^{2+}$, and $\mathrm{Y}[5,7,177]$. Many ethanol sensors have similar cross-sensitivity between ethanol and acetone. The sensitivity of a $\mathrm{SnO}_{2}$ gas sensor has been selectively increased from $\approx 10.8$ to $\approx 18.9$ toward $100 \mathrm{ppm}$ of ethanol and the sensitivity toward $100 \mathrm{ppm}$ acetone has been reduced from $\approx 8.9$ to $\approx 3.9$ by doping with $\mathrm{Sr}^{2+}$, resulting in a good discrimination between ethanol and acetone. The effect is obtained by inhibiting the growth of $\mathrm{SnO}_{2}$ grains resulting from substitution of $\mathrm{Sn}^{2+}$ with $\mathrm{Sr}^{2+}$ and enhanced surface area and reaction sites for analyte gas [177].

Al-doped $\mathrm{SnO}_{2}$ NTs exhibit a high response to low concentrations of formaldehyde by $\mathrm{Sn}^{4+}$ by $\mathrm{Al}^{3+}$ in a $\mathrm{SnO}_{2}$ lattice as well as increase in oxygen vacancies [184]. Pure and 8Al-Sn NTs (i.e., the $\mathrm{Al} /(\mathrm{Al}+\mathrm{Sn})$ ratio is $8 \%)$ have nearly the same average diameter (120 nm inner diameter and $200 \mathrm{~nm}$ outer diameter) which suggests that $\mathrm{Al}$ doping has an insignificant effect on the morphology of $\mathrm{SnO}_{2}$ NTs. The optimum temperature for sensing response of Al-doped $\mathrm{SnO}_{2} \mathrm{NTs}$ is $240{ }^{\circ} \mathrm{C}$. The maximum response obtained from $8 \mathrm{Al}-\mathrm{Sn}$ NTs toward $1000 \mathrm{ppb}$ formaldehyde is as high as 7.82 at $240{ }^{\circ} \mathrm{C}$. This response for $8 \mathrm{Al}-\mathrm{Sn}$ is 4.1 times higher than that of pure $\mathrm{SnO}_{2}$ [184]. Al- and Co-doped $\mathrm{SnO}_{2}$ NFs (average diameter $80-120 \mathrm{~nm}$ ) have also been evaluated for hydrogen sensing $[181,185,186]$. These Co-doped $\mathrm{SnO}_{2} \mathrm{NFs}$ show a response of 24 toward $100 \mathrm{ppm}$ of hydrogen at $330{ }^{\circ} \mathrm{C}$ with a response and recovery time of $2 \mathrm{~s}$ and less than $3 \mathrm{~s}$, respectively [186].

Ni-doped $\mathrm{SnO}_{2}$ NFs are converted from solid to hollow NFs by tuning the heating rate. When the heating rate is as low as 
(a)

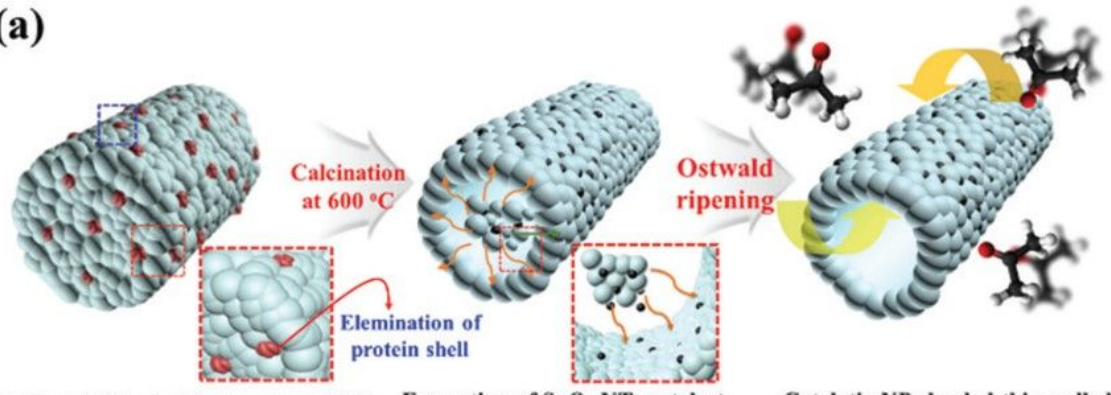

Catalyst-AF loaded Sn precursor/PVP Formation of $\mathrm{SnO}_{2}$ NTs-catalyst- Catalytic NPs loaded thin-walled
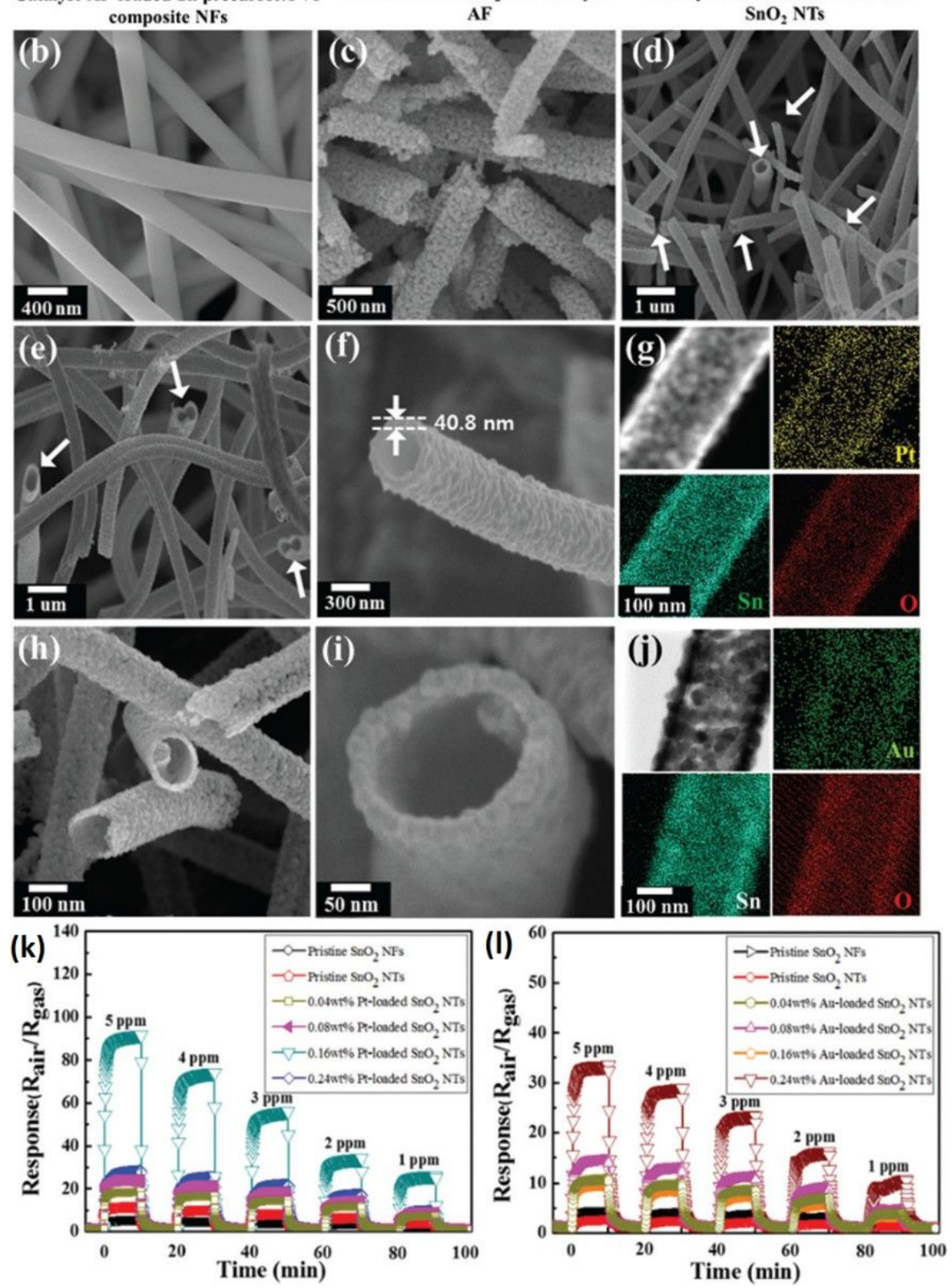

Figure 8: (a) Schematic illustration of the processing steps for $\mathrm{SnO}_{2} \mathrm{NT}$ s functionalized by bio-inspired catalysts (e.g., Pt-loaded SnO 2 NTs and

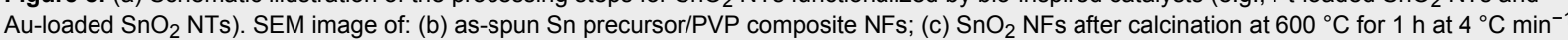
heating rate; (d) thin-walled $\mathrm{SnO}_{2} \mathrm{NTs}$ at $10{ }^{\circ} \mathrm{C} \mathrm{min}{ }^{-1}$ heating rate; (e) Pt-loaded $\mathrm{SnO}_{2} \mathrm{NTs}$; and (f) cross-sectional Pt-loaded SnO $\mathrm{NTs}_{2}$. (g) EDX elemental mapping of Pt-loaded $\mathrm{SnO}_{2}$ NTs. SEM image of: (h) Au-loaded $\mathrm{SnO}_{2}$ NTs and (i) cross-sectional Au-loaded SnO 2 NTs. (j) EDX elemental mapping of Au-loaded $\mathrm{SnO}_{2} \mathrm{NTs}$; (k) dynamic acetone sensing transition in a concentration range of $1-5 \mathrm{ppm}$ at $350{ }^{\circ} \mathrm{C}$ and (I) dynamic $\mathrm{H}_{2} \mathrm{~S}$ sensing transition in a concentration range of $1-5 \mathrm{ppm}$ at $300^{\circ} \mathrm{C}$. Reproduced with permission from [183], copyright 2015 Royal Society of Chemistry. 
$2{ }^{\circ} \mathrm{C} / \mathrm{min}, \mathrm{SnO}_{2} \mathrm{NFs}$ with solid cores are formed. Increasing the heating rate to $5{ }^{\circ} \mathrm{C} / \mathrm{min}$, a fraction of $\mathrm{SnO}_{2} \mathrm{NFs}$ with hollow cores was formed. When the heating rate is as high as $10{ }^{\circ} \mathrm{C} / \mathrm{min}$, most of the $\mathrm{SnO}_{2} \mathrm{NFs}$ are hollow. Ni-doped $\mathrm{SnO}_{2}$ NFs show diameters in the range $120 \mathrm{~nm}$ to $200 \mathrm{~nm}$. The maximum response to acetone for these NFs is at $340{ }^{\circ} \mathrm{C}$. By increasing the doping concentration of $\mathrm{Ni}$ in the range $0-10$ atom $\%$, response values are increased from 11.8 to 64.9 due to an increase in oxygen vacancies. The response and the recovery time are about $7 \mathrm{~s}$ and $30 \mathrm{~s}$, respectively [179].

$\mathrm{WO}_{3}$ NFs/NTs functionalized by Pt [168,187], Pd [107,188], $\mathrm{Cu}$ [101], $\mathrm{Ru}$ [189], $\mathrm{Rh}_{2} \mathrm{O}_{3}$ [106], $\mathrm{Au}$ NPs [109], $\mathrm{RuO}_{2}$ NPs [189], $\mathrm{La}_{2} \mathrm{O}_{3}$ [104] as well as Pd-loaded $\mathrm{ZnO}$ nanocubes [1] have been extensively applied for sensing of acetone, ethanol, toluene, formaldehyde and volatile organic compounds (VOCs). $\mathrm{WO}_{3}$ NFs functionalized by Au NPs exhibit improved VOC sensing properties. Noble metals onto metal oxide NFs reduce the activation energy, thus increasing their efficiency [109]. The average diameter of as-spun fibers is $412 \mathrm{~nm}$ which, after annealing, reduces to $315 \mathrm{~nm}$. The fiber diameter increases with increasing $\mathrm{Au}$ content. The average diameters of the $\mathrm{WO}_{3}-\mathrm{Au}$ $0.01 \mathrm{M}$, and $\mathrm{WO}_{3}-\mathrm{Au}-0.1 \mathrm{M}$ composite $\mathrm{NFs}$ are $350 \mathrm{~nm}$, and $370 \mathrm{~nm}$, respectively. Au NPs act as nucleation sites (seed) on the surface that promote the $\mathrm{WO}_{3}$ crystal growth. The highest response toward $100 \mathrm{ppm}$ of n-butanol is 7.3 for pure $\mathrm{WO}_{3}$ at $300{ }^{\circ} \mathrm{C}, 34.7$ for $\mathrm{WO}_{3}-\mathrm{Au}-0.01 \mathrm{M}$ and 152.7 for $\mathrm{WO}_{3}-\mathrm{Au}-0.1 \mathrm{M}$ at $250{ }^{\circ} \mathrm{C}$. $\mathrm{WO}_{3}-\mathrm{Au}-0.1 \mathrm{M}$ shows the highest voltage change when exposed to n-butanol [109].

Highly porous Pt- and Pd-doped $\mathrm{WO}_{3}$ NTs are synthesized using layer-by-layer (LBL) self-assembly of tungsten as well as catalyst precursor on PMMA electrospun nanofibers. Pristine $\mathrm{WO}_{3}$ NTs exhibit a high response $\left(R_{\mathrm{gas}} / R_{\text {air }}\right)$ of 63.59 to $5 \mathrm{ppm}$ $\mathrm{NO}$ at $350{ }^{\circ} \mathrm{C}$. On the other hand, a high response of 2.24 for the Pt- $\mathrm{WO}_{3}$ NTs and 2.35 for the $\mathrm{Pd}-\mathrm{WO}_{3}$ NTs toward 5 ppm toluene at $400{ }^{\circ} \mathrm{C}$ is measured. A negligible NO response (1.25 for the Pt- $\mathrm{WO}_{3} \mathrm{NTs}$ and 1.04 for the Pd- $\mathrm{WO}_{3} \mathrm{NTs}$ at $5 \mathrm{ppm}$ ) at $400{ }^{\circ} \mathrm{C}$ was found.

One problem associated with surface functionalization of NPs $(3-50 \mathrm{~nm})$ is their agglomeration. Traditional functionalization methods have limited ability to uniformly disperse NPs. A solution could be the encapsulation of NPs in polar proteins that could repel each other resulting in uniform dispersion over the entire surface area. Kim et al. [75,189-191] reported protein (apoferritin) encapsulated catalytic/noble metal NP functionalized MOx NFs with superior sensitivity and fast response in a high humidity environment ( $95 \%$ relative humidity $(\mathrm{RH})$ ). $\mathrm{WO}_{3}$ NFs functionalized by $\mathrm{RuO}_{2}$ [189] and $\mathrm{Rh}_{2} \mathrm{O}_{3}$ [106] NPs show improved response toward acetone at $350{ }^{\circ} \mathrm{C}$. The fibers have an average diameter in the range $250-300 \mathrm{~nm}$ with no significant morphology change at different concentrations of Ru nanoparticles. The gas sensing response for different concentrations of acetone was in the range of $0.1-5 \mathrm{ppm}$ at $350{ }^{\circ} \mathrm{C}$. The highest response (78.61) was for $\mathrm{Ru} 0.090 \mathrm{wt} \%$, that is $7.4 \%$ more than $\mathrm{Rh}_{2} \mathrm{O}_{3}$ (41.2) and the pristine $\mathrm{WO}_{3}$ (10.61). The fibers show maximum response at $350{ }^{\circ} \mathrm{C}$. For selectivity tests, response to acetone is four times higher than the interfering gasses. The response and recovery time of $0.090 \mathrm{wt} \%$-functionalized $\mathrm{WO}_{3}$ NFs is $7.9 \mathrm{~s}$ and $244 \mathrm{~s}$, respectively [189].

$\mathrm{WO}_{3}$ NFs have also been functionalized by MOF-driven metalembedded metal oxide catalysts and have been evaluated for toluene sensing [1]. $\mathrm{WO}_{3} \mathrm{NFs}$ are functionalized by Pd-loaded $\mathrm{ZnO}$ nanocubes that result in multi-heterojunction $\mathrm{Pd}-\mathrm{ZnO}$ and $\mathrm{ZnO}-\mathrm{WO}_{3}$ interfaces. The as-spun Pd@ZnO-WO $\mathrm{WFs}_{3}$ have average diameter in the range $500-950 \mathrm{~nm}$ that reduces to 400-850 nm after calcination. A schematic shown in Figure 9a provides an interpretation of the SEM and TEM micrographs in Figure 9b-g. Figure 9c shows the Pd@ZIF-8 particles embedded in the $\mathrm{WO}_{3} \mathrm{NFs}$. The highest response is obtained at $350{ }^{\circ} \mathrm{C}$ using Pd@ZnO- $\mathrm{WO}_{3} \mathrm{NFs}$ at a doping level of 0.136 wt \% Pd@ZnO. Similarly, hollow $\mathrm{SnO}_{2}$ NTs have also been sensitized by MOFs. A Zn-based zeolite imidazole framework $(\operatorname{Pd} @ Z I F-8, \approx 80 \mathrm{~nm})$ embedded with Pd NPs $(\approx 2 \mathrm{~nm})$ was used as a catalyst-loading platform for the efficient functionalization of a PdO@ZnO complex catalyst onto $\mathrm{SnO}_{2}$ NTs. Dual sensitized PdO@ZnO hollow $\mathrm{SnO}_{2}$ NTs (PdO@ZnO-SnO 2 NTs) exhibited high response $\left(R_{\text {air }} / R_{\text {gas }}=5.06\right)$ toward 1 ppm acetone at $400{ }^{\circ} \mathrm{C}$ with high selectivity, and fast response (20 s) and recovery (64 s) time under a highly humid atmosphere (95\% RH) [192].

Gas sensing experiments were performed at an optimum temperature of $350{ }^{\circ} \mathrm{C}$ for detection of toluene in the concentration range of $1-5 \mathrm{ppm}$. The response of $\mathrm{Pd} @ \mathrm{ZnO}-\mathrm{WO}_{3}$ NFs is $\left(R_{\text {air }} / R_{\text {gas }}=22.22\right.$ to $\left.1 \mathrm{ppm}\right)$ as compared with pristine $\mathrm{WO}_{3}\left(R_{\mathrm{air}} / R_{\mathrm{gas}}=1.10\right), \mathrm{ZnO}-\mathrm{WO}_{3} \mathrm{NFs}\left(R_{\mathrm{air}} / R_{\mathrm{gas}}=1.16\right)$, $\mathrm{Pd}($ polyol $)-\mathrm{WO}_{3} \mathrm{NFs}\left(R_{\mathrm{air}} / R_{\mathrm{gas}}=5.31\right)$, and $\mathrm{Pd}($ polyol) $-\mathrm{ZnO}-\mathrm{WO}_{3} \mathrm{NFs}\left(R_{\mathrm{air}} / R_{\mathrm{gas}}=5.47\right)$ as shown in Figure $9 \mathrm{~h}$. The response time of $\mathrm{Pd} @ \mathrm{ZnO}-\mathrm{WO}_{3} \mathrm{NFs}$ is $<20$ s compared with pristine $\mathrm{WO}_{3}$ (44 s), $\mathrm{ZnO}-\mathrm{WO}_{3}$ (36 s), $\mathrm{Pd}\left(\right.$ polyol)- $-\mathrm{WO}_{3}$ NFs (44 s), and Pd(polyol)-ZnO-- $\mathrm{WO}_{3}$ NFs (32 s) (Figure 9i). The lowest concentration detected by $\mathrm{Pd} @ \mathrm{ZnO}-\mathrm{WO}_{3} \mathrm{NFs}$ is $100 \mathrm{ppb}$ with a sensitivity of $R_{\mathrm{air}} / R_{\mathrm{gas}}=4.37$ at $350{ }^{\circ} \mathrm{C}$ (Figure 9j) [1,107].

$\mathrm{ZnO}$ is one of the most extensively used metal oxides for gas sensing applications [33]. ZnO-based 1D nanostructured materials have been doped by Ce [11,193], Pr [6], Er [194], La [190,195], Pt [190], Cu [190,196], Mn [197], Co [198], Al 

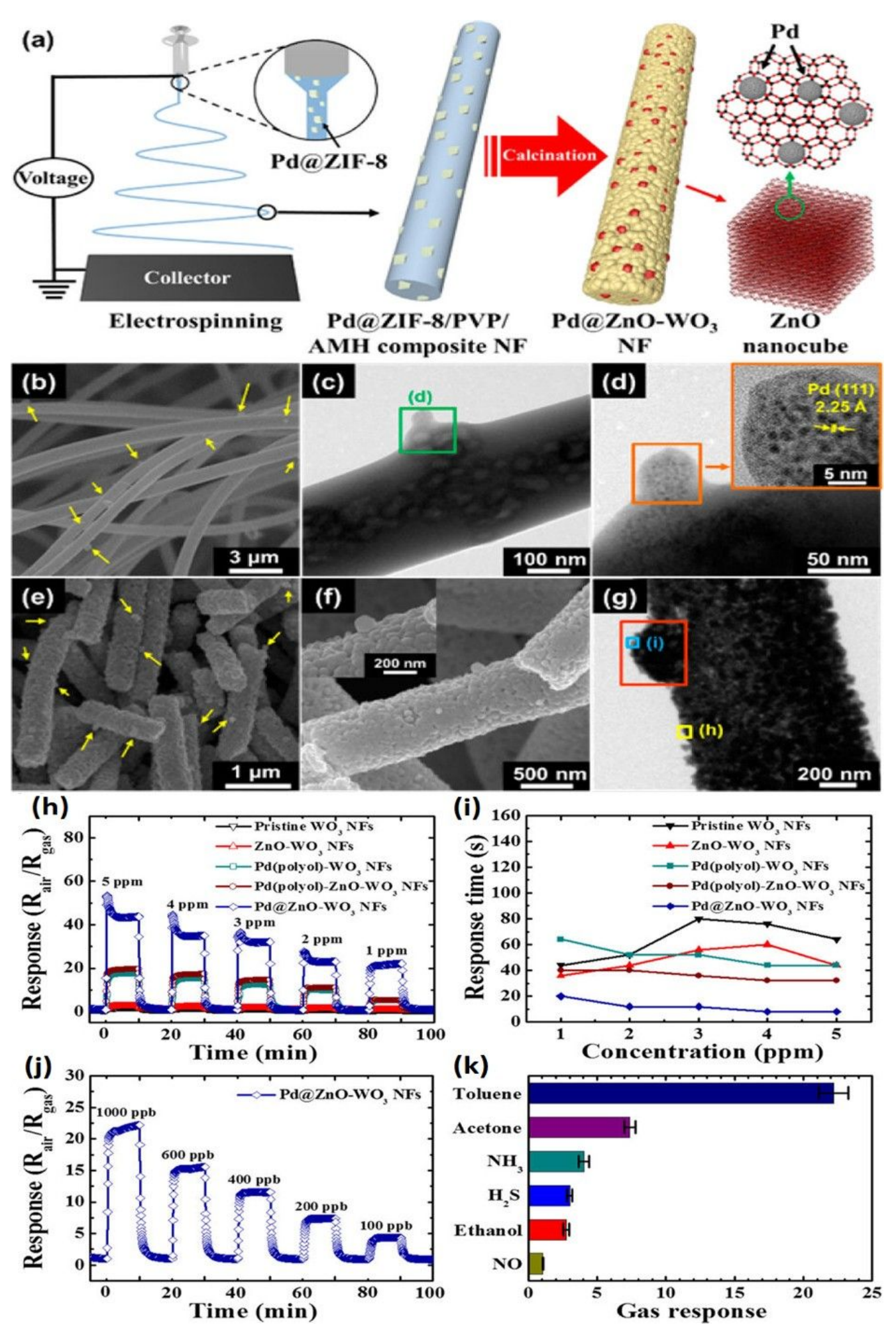

Figure 9: (a) Schematic illustration of synthetic process for the Pd@ZnO-WO $\mathrm{WF}_{3} \mathrm{NFs}$; (b) SEM image of as-spun ammonium metatungstate hydrate (AMH)/PVP/Pd@ZIF-8 NFs; (c,d) TEM images of AMH/PVP/Pd@ZIF-8 NFs and (inset) HRTEM image; (e,f) SEM images of Pd@ZnO-WO 3 NFs and (inset) magnified image of surface; (g) TEM image of $\mathrm{Pd@ZnO-} \mathrm{WO}_{3} \mathrm{NFs}$, response characteristics of pristine $\mathrm{WO}_{3}, \mathrm{ZnO}^{-} \mathrm{WO}_{3}, \mathrm{Pd}-\mathrm{WO}_{3}, \mathrm{Pd}_{-} \mathrm{ZnO}$ $\mathrm{WO}_{3}$, and $\mathrm{Pd} @ \mathrm{ZnO}-\mathrm{WO}_{3} \mathrm{NFs}$ toward toluene in the concentration range of $1-5 \mathrm{ppm}$ at $350{ }^{\circ} \mathrm{C}$; (h) dynamic sensing transition; (i) response time evaluation; and (j) detection limit characteristics of the $\mathrm{Pd} @ \mathrm{ZnO}-\mathrm{WO}_{3} \mathrm{NFs}$ toward toluene down to $100 \mathrm{ppb}$ at $350{ }^{\circ} \mathrm{C}$; ( $\mathrm{k}$ ) selective toluene detection characteristics of the Pd@ZnO- $\mathrm{WO}_{3} \mathrm{NFs}$ with respect to the multiple interfering analytes at a concentration of $1 \mathrm{ppm}$ at $350{ }^{\circ} \mathrm{C}$. Reproduced with permission from [1], copyright 2016 ACS. 
[199], Pd [176] and In [200] and have been used to detect acetone, acetic acid, ethanol, $\mathrm{H}_{2} \mathrm{~S}$, and $\mathrm{CO}$.

ZnO hollow NFs functionalized by rare earth metals, such as Ce, show enhanced acetone sensing [193]. The Ce ion occurs either as $\mathrm{Ce}^{4+}$ and $\mathrm{Ce}^{3+}$ which is effective for improving the performance of chemical sensors. The surface morphology of Ce-doped $\mathrm{ZnO}$ HNFs is concave-convex and porous with an average diameter of $279 \mathrm{~nm}$. This diameter is smaller than pure $\mathrm{ZnO}$ hollow NFs $(316 \mathrm{~nm})$; whereas the aperture at $240 \mathrm{~nm}$ is larger than pure $\mathrm{ZnO}$ hollow fibers $(197 \mathrm{~nm})$. The small diameter and larger aperture of the doped $\mathrm{ZnO}$ hollow fibers provides a higher specific surface area for gas interaction and significantly improves sensing performance. The highest response of Ce-doped ZnO HNFs (75.04/100 ppm) and (71.2/500 ppm) toward acetone is measured at an optimal operating temperature of $260{ }^{\circ} \mathrm{C}$ and $230{ }^{\circ} \mathrm{C}$, respectively with a stability of over 40 days and retention of $96 \%$ of their initial performance. Furthermore, these sensors exhibit an excellent selectivity to acetone compared to other target gases, including ethanol, acetic acid, dimethylformamide (DMF) and ammonia [11,193].

Cho et al. [190] have synthesized Pt, Cu and La NPs (3-5 nm) to surface functionalize $\mathrm{ZnO}$ NFs using protein (apoferrtin (AF)) cage templates for enhanced acetone sensing. The as-spun $\mathrm{ZnO}$ NFs have an average diameter of $209 \mathrm{~nm}$ that decreases to $105 \mathrm{~nm}$ after calcination. The as-spun Pt, La, and $\mathrm{Cu}$ coated $\mathrm{ZnO}$ NFs have an average diameter of 100 , 87 and $145 \mathrm{~nm}$, respectively, after calcination. $\mathrm{Pt}$ and $\mathrm{Cu}$ NP-functionalized ZnO NFs exhibit approximately 6.4-fold $\left(R_{\mathrm{air}} / R_{\mathrm{gas}}=13.07\right)$ and 3.0 -fold $\left(R_{\mathrm{air}} / R_{\mathrm{gas}}=6.04\right)$ enhanced acetone response compared with the response $\left(R_{\text {air }} / R_{\text {gas }}=2.05\right)$ for pristine $\mathrm{ZnO} N F s$ at $450{ }^{\circ} \mathrm{C}$. Whereas for La NP-functionalized $\mathrm{ZnO} \mathrm{NFs}$, a 9.3-fold improvement in nitrogen monoxide response $\left(R_{\mathrm{air}} / R_{\mathrm{gas}}=10.06\right)$ is achieved compared with the response for pristine $\mathrm{ZnO}$ NFs. Functionalized ZnO NFs with $0.23 \mathrm{wt} \%$ Pt were shown to detect $29 \mathrm{ppb}$ of acetone with a response of 2 . The $0.23 \mathrm{wt} \% \mathrm{AF}-\mathrm{Pt}-\mathrm{NPs}$ to $\mathrm{ZnO}$ NFs show the fastest response and recovery times of $12 \mathrm{~s}$ and $108 \mathrm{~s}$, which are 8.3 -fold and 2.3-fold faster than that (100 s, and $252 \mathrm{~s})$ of pristine $\mathrm{ZnO}$ NFs to acetone at $5 \mathrm{ppm}$, respectively [190].

$\mathrm{ZnO}$ functionalized by rare earth metals (i.e., Er) exhibits improved ethanol sensing at an optimum temperature of $240{ }^{\circ} \mathrm{C}$ [194]. The diameter of the $\mathrm{ZnO}$ NFs decreased from $200 \mathrm{~nm}$ to $70 \mathrm{~nm}$ with an increase of Er content. The 0.5 atom \%, 1.0 atom $\%$ and 2.0 atom \% Er-doped $\mathrm{ZnO} \mathrm{NFs}$ have an average diameter $165 \pm 42 \mathrm{~nm}, 130 \pm 35 \mathrm{~nm}$ and $70 \pm 23 \mathrm{~nm}$, respectively, compared with pure $\mathrm{ZnO} \mathrm{NFs}$ which show average diameter of $200 \pm 50 \mathrm{~nm}$. The $1.0 \mathrm{wt} \%$ Er-doped ZnO NFs show the highest response of 37.3 toward $200 \mathrm{ppm}$ of ethanol at
$240{ }^{\circ} \mathrm{C}$ compared with that of pure ZnO NFs (10.1). The response/recovery time for pure $\mathrm{ZnO} N F$ s to $200 \mathrm{ppm}$ ethanol is only $5 / 2 \mathrm{~s}$, respectively, which is shorter than that of 1.0 atom \% Er-doped ZnO NFs (12 and 3 s) [194]. Similarly, Al-doped ZnO NFs exhibit a response of 8.6 toward $100 \mathrm{ppm}$ of ethanol at $250{ }^{\circ} \mathrm{C}$ with a response and recovery time of $5 \mathrm{~s}$ and 9 s, respectively [199]. Pd-doped ZnO NFs show a response of 5.5 toward $20 \mathrm{ppm}$ of $\mathrm{CO}$ at $220^{\circ} \mathrm{C}$ with response and recovery times in the range of 25-29 s and 12-17 s, respectively [176]. The 6 atom \% Cu-doped $\mathrm{ZnO}$ NFs exhibit a high response of 18.7 to $10 \mathrm{ppm} \mathrm{H}_{2} \mathrm{~S}$ compared with pure $\mathrm{ZnO}$ NFs with a response of 1.57 at $230{ }^{\circ} \mathrm{C}$ and response and recovery times of $18 \mathrm{~s}$ and $20 \mathrm{~s}$, respectively [196].

Doping with multivalent ions $\left(\mathrm{In}^{3+}, \mathrm{Al}^{3+}, \mathrm{Sn}^{4+}\right.$, etc.) may change the defect density and carrier concentration of a $\mathrm{ZnO}$ matrix [201-204]. A common type of $\mathrm{ZnO}$ doping is with indium, for which the product is called "IZO". When the amount of indium is greater than 0.05 , amorphous $\operatorname{In}_{2} \mathrm{O}_{3}$ forms and leads to a pronounced decrease in grain size. The optical band gap energy of IZO NTs also decreases with increased doping levels. Doped indium atoms may exist as trivalent cations that act as donor impurities at the substitutional sites of $\mathrm{Zn}^{2+}$, or may be present in amorphous $\mathrm{In}_{2} \mathrm{O}_{3}$. Both forms of $\mathrm{In}^{3+}$ may significantly influence gas sensing performance due to an increase in the number of free electrons. TEM images show the tubular structure of IZO with an average diameter in the range of $60-80 \mathrm{~nm}$. The compactness of these NTs increases with an increase in indium content. The response values for IZO nanotube-based sensors with different indium contents indicate that the gas response decreases with higher indium doping levels. The response sharply increases with increasing ethanol concentration below $100 \mathrm{ppm}$. While for the $\mathrm{ZnO}$ sensor, the increased rate of response slows down above 1000 ppm ethanol. The ethanol responds to the IZO with $10 \%$ dopant in the nanotube sensor. However, the undoped $\mathrm{ZnO}$ exhibits lower response to ethanol by about $50 \%$ [200].

$\alpha-\mathrm{Fe}_{2} \mathrm{O}_{3}$ nanostructured NFs/NTs have been functionalized by $\mathrm{Ca}$ [205], La [206], Pd [207], Sm [208], $\mathrm{Al}_{2} \mathrm{O}_{3}$ [209] and $\mathrm{Ce}$ [10] and applied to sensing of ethanol, acetone and formaldehyde. The sensing performance of $\alpha-\mathrm{Fe}_{2} \mathrm{O}_{3}$ is improved by increased doping with $\mathrm{Ca}$. Mismatch between the radii of $\mathrm{Ca}^{2+}$ and $\mathrm{Fe}^{3+}$ ions is apparently responsible for grain refinement. For example, the grain size of $\alpha-\mathrm{Fe}_{2} \mathrm{O}_{3}$ decreases from 28 to $7 \mathrm{~nm}$ with increase of $\mathrm{Ca}$ content in the range of $1-15 \mathrm{~mol} \% \mathrm{com}-$ pared with that of pure $\alpha-\mathrm{Fe}_{2} \mathrm{O}_{3}(31 \mathrm{~nm})$. Sensors with $7 \mathrm{~mol} \%$ Ca doping show the highest response to ethanol (26.8/100 ppm) and acetone $(24.9 / 100 \mathrm{ppm})$ at $200{ }^{\circ} \mathrm{C}$ compared with pure $\alpha-\mathrm{Fe}_{2} \mathrm{O}_{3}$ with response of 5.26 to $100 \mathrm{ppm}$ ethanol at $250{ }^{\circ} \mathrm{C}$. However, the sensor shows cross sensitivity to ethanol and ace- 
tone. In comparison to Ca-doped $\alpha-\mathrm{Fe}_{2} \mathrm{O}_{3}$, La-doped $\alpha-\mathrm{Fe}_{2} \mathrm{O}_{3}$ NTs show a similar response $(26 / 100 \mathrm{ppm})$ at $240{ }^{\circ} \mathrm{C}$ toward acetone with a much shorter recovery time of $10 \mathrm{~s}$ [206]. However, Nd-doped $\alpha-\mathrm{Fe}_{2} \mathrm{O}_{3}$ NTs exhibit almost double the response (44) of La-doped $\alpha-\mathrm{Fe}_{2} \mathrm{O}_{3} \mathrm{NTs}$ at $240{ }^{\circ} \mathrm{C}$ toward $50 \mathrm{ppm}$ of acetone with the response and recovery times of $19 \mathrm{~s}$ and $50 \mathrm{~s}$, respectively. These response parameters are significantly different to that of pure porous $\alpha-\mathrm{Fe}_{2} \mathrm{O}_{3}$ NTs (2.6). $\mathrm{Nd}$-doped porous $\alpha-\mathrm{Fe}_{2} \mathrm{O}_{3}$ nanotube sensors can detect $500 \mathrm{ppb}$ of acetone with a response of 2.4 [207].

$\mathrm{In}_{2} \mathrm{O}_{3}$ 1D nanostructures functionalized by $\mathrm{Co}$ [210], $\mathrm{Nd}$ [211], $\mathrm{Eu}$ [212], Yb [213,214], Pd [148], Mg [215], Ag [161], Er [216], V [217] and Sm [218] have shown promising results for gas sensing applications. For example, $\mathrm{In}_{2} \mathrm{O}_{3} \mathrm{NWs}$ functionalized by Co exhibited a response of 16.5 to $100 \mathrm{ppm}$ of ethanol at $300{ }^{\circ} \mathrm{C}$ with very short response and recovery times $(2 \mathrm{~s}$ and $3 \mathrm{~s}$ ), respectively [210]. However, Pd-doped $\mathrm{In}_{2} \mathrm{O}_{3} \mathrm{NFs}$ show a response of 26 toward $100 \mathrm{ppm}$ of ethanol at lower temperature $\left(240{ }^{\circ} \mathrm{C}\right)$ with shorter response and recovery times $(1 \mathrm{~s}$ and $10 \mathrm{~s})$, respectively. Rare earth metals and their oxides significantly improve gas sensing properties of semiconducting metal oxide materials by substitution in their lattice structure. For example, 3 wt $\% \mathrm{Eu}_{2} \mathrm{O}_{3}$-doped $\mathrm{In}_{2} \mathrm{O}_{3}$ NTs show excellent discrimination between acetone and ethanol with a response of 44 toward $50 \mathrm{ppm}$ ethanol as compared with acetone (11) at $260{ }^{\circ} \mathrm{C}$ with response and recovery time of $3 \mathrm{~s}$ and $21 \mathrm{~s}$, respectively [219]. Similarly, Yb-doped $\mathrm{In}_{2} \mathrm{O}_{3}$ NTs (average diameter $200 \mathrm{~nm}$ ) fabricated by single capillary electrospinning are used for formaldehyde sensing [213]. Yb-doped $\mathrm{In}_{2} \mathrm{O}_{3}$ NTs exhibit a response 3.8-fold higher (69.8) than pure $\mathrm{In}_{2} \mathrm{O}_{3}$ NTs (18.4) for $100 \mathrm{ppm}$ of formaldehyde at $230^{\circ} \mathrm{C}$. The response and recovery times of $\mathrm{Yb}$-doped $\mathrm{In}_{2} \mathrm{O}_{3}$ NTs to $100 \mathrm{ppm}$ formaldehyde are about $4 \mathrm{~s}$ and $84 \mathrm{~s}$, respectively. Yb-doped $\mathrm{In}_{2} \mathrm{O}_{3}$ NTs show a response of 2.4 toward $100 \mathrm{ppb}$ of formaldehyde [213].

Mg-doped $\operatorname{In}_{2} \mathrm{O}_{3}$ NTs exhibit a high response at low temperature $\left(150^{\circ} \mathrm{C}\right)$. Pure and $\mathrm{Mg}$-doped $\mathrm{In}_{2} \mathrm{O}_{3}$ NTs have an average diameter of $80 \mathrm{~nm}$. The smooth surface of $\mathrm{In}_{2} \mathrm{O}_{3}$ NTs becomes coarser with doping of $\mathrm{Mg}$. $\mathrm{Mg}$ doping introduces protrusions (mean size $\approx 29 \mathrm{~nm}$ ) on the outer surface of $\mathrm{Mg}-\mathrm{In}_{2} \mathrm{O}_{3} \mathrm{NTs}$. $\mathrm{Mg}$ doping leads to growth of some $\mathrm{In}_{2} \mathrm{O}_{3}$ grains on the outer walls of NTs to form protrusions. The response of Mg-doped $\operatorname{In}_{2} \mathrm{O}_{3}$ reduces with an increase in temperature and becomes stable after $300{ }^{\circ} \mathrm{C}$. The maximum response of 173.14 toward $10 \mathrm{ppm}$ of $\mathrm{H}_{2} \mathrm{~S}$ is obtained at a much lower temperature of $150{ }^{\circ} \mathrm{C}$. In comparison, pure $\mathrm{In}_{2} \mathrm{O}_{3}$ NTs exhibit a response of 12.31 at the same temperature. $\mathrm{Mg}$-doped $\mathrm{In}_{2} \mathrm{O}_{3}$ NTs are shown to detect $0.5 \mathrm{ppm}$ of $\mathrm{H}_{2} \mathrm{~S}$. The enhanced response is due to the substitution of $\mathrm{Mg}^{2+}$ ions as acceptors in the $\mathrm{In}^{3+}$ lattice resulting in high oxygen vacancies [215]. Similarly, Nd-doped $\mathrm{In}_{2} \mathrm{O}_{3}$ NTs showed enhanced formaldehyde sensing due to their porous and cracked morphology. Nd-doped $\mathrm{In}_{2} \mathrm{O}_{3}$ NTs have an average diameter of $200 \mathrm{~nm}$ as shown in Figure 10a-c. The optimum doping amount of $\mathrm{Nd}$ was $11 \mathrm{~mol} \%$. Nd-doped $\mathrm{In}_{2} \mathrm{O}_{3}$ porous NTs showed a high response of 46.8 to $100 \mathrm{ppm}$ of formaldehyde at optimum temperature $\left(240{ }^{\circ} \mathrm{C}\right)$ as shown in Figure $10 \mathrm{~d}$, whereas the response and recovery times are $8 \mathrm{~s}$ and $22 \mathrm{~s}$, respectively. The detection limit of the Nd-doped $\mathrm{In}_{2} \mathrm{O}_{3}$ NTs was $100 \mathrm{ppb}$ with a response of 2.4 [211].

W-doped NiO NTs (average outer diameter of $90 \mathrm{~nm}$ ) have been applied to xylene gas sensing [220]. W-doped NTs with the molar ratio $\mathrm{W}^{6+}: \mathrm{Ni}^{2+}$ of $2: 100$, show outstanding sensing properties toward xylene with enhanced response, selectivity and repeatability characteristics. Mole number ratios of $\mathrm{W}^{6+}$ to $\mathrm{Ni}^{2+}$ at $0,1,2$ and $4 \mathrm{~mol} \%$ can be synthesized by electrospinning. With increased doping content, the grain size of W-doped $\mathrm{NiO}$ reduces, and the NTs become less porous. The $2 \mathrm{~mol} \%$ W-doped NiO NTs show the highest response of 8.74 toward $200 \mathrm{ppm}$ xylene at $375^{\circ} \mathrm{C}$, which is about 3.3-times higher than sensors based on undoped NTs. The response and recovery time of $2 \mathrm{~mol} \% \mathrm{~W}$-doped NiO NTs is $178 \mathrm{~s}$ and $152 \mathrm{~s}$, respectively. Thus, W-doped NiO NTs can successfully detect low concentrations (15 ppm) of xylene with a response of 2.17 [220].

Pd-doped $\mathrm{TiO}_{2}$ NFs (average diameter $250 \mathrm{~nm}$ ) show high sensitivity to $\mathrm{NO}_{2}$ at a relatively low temperature of $180{ }^{\circ} \mathrm{C}$. The average diameter of pure $\mathrm{TiO}_{2}$ and Pd-doped $\mathrm{TiO}_{2} \mathrm{NFs}$ is 450 and $250 \mathrm{~nm}$ after calcination at $600{ }^{\circ} \mathrm{C}$. The rough surfaces of pure $\mathrm{TiO}_{2} \mathrm{NFs}$ convert into smooth surfaces with Pd doping. Pd-doped $\mathrm{TiO}_{2} \mathrm{NFs}$ are densely packed with nanocrystals of diameter $20-30 \mathrm{~nm}$. The $\mathrm{Pd}$-doped $\mathrm{TiO}_{2}$ and pure $\mathrm{TiO}_{2} \mathrm{NF}$-based sensors show the highest responses of 38 and 13 at temperatures of $180{ }^{\circ} \mathrm{C}$ and $200{ }^{\circ} \mathrm{C}$, respectively. Moreover, the Pd-doped $\mathrm{TiO}_{2} \mathrm{NF}$ sensor exhibits five times higher response than that of the $\mathrm{TiO}_{2} \mathrm{NF}$ sensor at $0.8 \mathrm{ppm}$, even at an operating temperature that is $20{ }^{\circ} \mathrm{C}$ lower [175].

Pure and 0.08 wt \% Pt-doped $\mathrm{SnO}_{2} \mathrm{NFs}$ have been used for $\mathrm{H}_{2} \mathrm{~S}$ gas sensing using a micro-machined (MEMS) platform [165]. The average diameter of pure $\mathrm{SnO}_{2}$ and $0.08 \mathrm{wt} \% \mathrm{Pt}-\mathrm{SnO}_{2}$ NFs are in the range of $200-300 \mathrm{~nm}$ and $\approx 120 \mathrm{~nm}$, respectively. The decrease in fiber diameter is because of retardation of grain growth of $\mathrm{SnO}_{2}$ particles due to the presence of secondary $\mathrm{Pt}$ nanoparticles. The $0.08 \mathrm{wt} \% \mathrm{Pt}$-doped $\mathrm{SnO}_{2} \mathrm{NF}$ sensors exhibit a response of 23-121 toward 4-20 ppm $\mathrm{H}_{2} \mathrm{~S}$ at $300{ }^{\circ} \mathrm{C}$, which is 25.9-40.6-fold higher than the response of pure $\mathrm{SnO}_{2} \mathrm{NFs}$. The introduction of the additive may increase the density of semiconductor surface adsorption sites, enhancing oxygen adsorption at the grain surface, leading to improvement in the sensing response. The Pt catalyst also may cause an increase in 


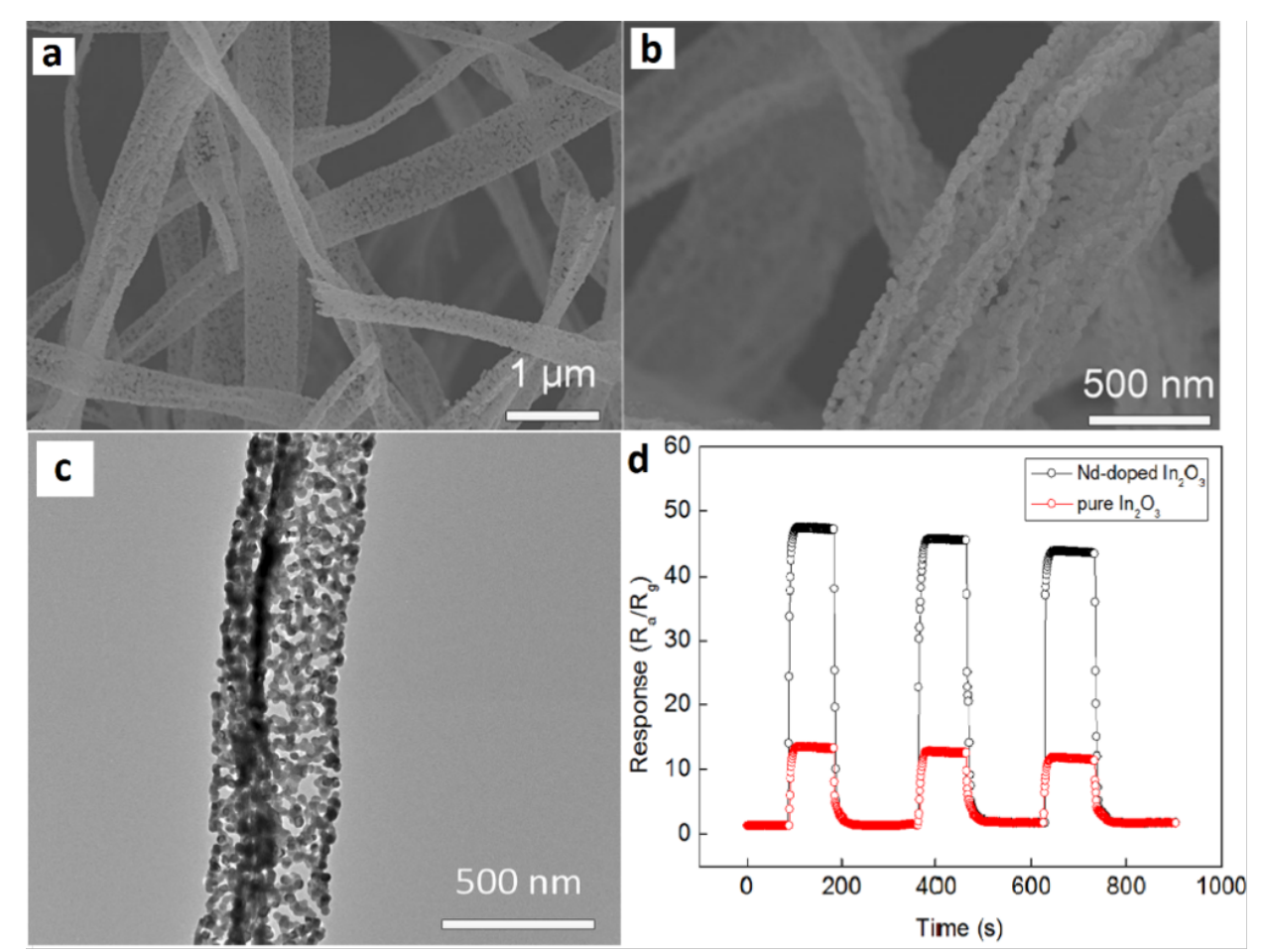

Figure 10: SEM images of (a) pure $\ln _{2} \mathrm{O}_{3}$ porous NTs; (b) Nd-doped $\ln _{2} \mathrm{O}_{3}$; (c) TEM image of Nd-doped $\ln _{2} \mathrm{O}_{3}$ porous NTs; (d) response and recovery curves of pure and $\mathrm{Nd}$-doped $\mathrm{In}_{2} \mathrm{O}_{3}$ porous nanotube sensors to $100 \mathrm{ppm}$ formaldehyde at $240{ }^{\circ} \mathrm{C}$. Reproduced with permission from [211], copyright 2016 Springer.

the response. As the temperature increases up to $500{ }^{\circ} \mathrm{C}$, the response decreases. A response time of $1 \mathrm{~s}$ for a $0.08 \mathrm{wt} \%$ Pt-doped $\mathrm{SnO}_{2} \mathrm{NF}$ sensor is significantly less than that for an undoped $\mathrm{SnO}_{2} \mathrm{NF}$ sensor (2-7 s). However, all these sensors show longer recovery times. Even at $400{ }^{\circ} \mathrm{C}$, the recovery values of an undoped $\mathrm{SnO}_{2} \mathrm{NFs}$ sensor ranges from 267 to $281 \mathrm{~s}$. These recovery values are much longer than the corresponding response time values ( $2-7 \mathrm{~s})$. The $0.08 \mathrm{wt} \% \mathrm{Pt}$-doped $\mathrm{SnO}_{2} \mathrm{NF}$ sensor shows recovery time values under similar conditions that range from $214 \mathrm{~s}$ to $267 \mathrm{~s}$ [165]. A detailed analysis of MOx sensors doped with different metals is shown in Table S3 in Supporting Information File 1.

4.1.3 Composite semiconducting metal oxides: The performance of semiconducting metal oxide gas sensors is improved by mixing two or more metal oxides to make composites. In many cases, these composites have advantageous properties of both metal oxides. Moreover, the porosity of the nanofibers can also be increased by mixing two or more metal oxides together having a mismatched crystal (lattice) size, resulting in enhanced gas diffusion (penetration) and subsequently fast response/recovery time. Furthermore, a hybrid structure (i.e. $\mathrm{p}-\mathrm{n}$ junction, $\mathrm{n}-\mathrm{n}$ junction or $\mathrm{p}-\mathrm{p}$ junction) facilitates low operating temperature gas sensing with high sensitivity by a high proportion of oxygen vacancies and efficient electron transfer
[221]. For example, $\mathrm{ZnO}-\mathrm{SnO}_{2}$ composite HFs exhibited excellent response (83) to $20 \mathrm{ppm}$ of ethanol at $260{ }^{\circ} \mathrm{C}$ with a response time of 4-7 s and recovery time of 4-5 s [222]. One of the problems with ethanol gas sensors is their similar sensitivity to acetone. $\mathrm{ZnO}-\mathrm{SnO}_{2}$ hollow NF based sensors show excellent selectivity to ethanol as compared with acetone, ammonia, glacial acetic acid, DMF, and formaldehyde [222]. A $\mathrm{ZnO}$ shell grown on $\mathrm{SnO}_{2}$ NFs by a hydrothermal method exhibits a response of 392.29 toward $100 \mathrm{ppm}$ of ethanol at $200{ }^{\circ} \mathrm{C}$ with response/recovery times of $75 \mathrm{~s} / 12 \mathrm{~s}$ [223]. Importantly, the operating temperature of $\mathrm{ZnO}-\mathrm{SnO}_{2}$ composite NTs decreases from $215{ }^{\circ} \mathrm{C}$ to $140{ }^{\circ} \mathrm{C}$ by decorating with $\mathrm{Ag}$ NPs using a seed-mediated growth method [158]. $\mathrm{CuO} / \mathrm{SnO}_{2}$ mixed NFs synthesized by a double needle electrospinning technique have been used for $\mathrm{H}_{2} \mathrm{~S}$ sensing. In this method, $\mathrm{CuO}$ NFs with an average diameter of $110 \mathrm{~nm}$ consist of larger nanograins than $\mathrm{SnO}_{2}$ nanofibers with an average grain size of $20 \mathrm{~nm}$. $\mathrm{CuO} / \mathrm{SnO}_{2}$ mixed NFs exhibit a very high response of 522 toward 10 ppm of $\mathrm{H}_{2} \mathrm{~S}$ at $300{ }^{\circ} \mathrm{C}$ compared with pure $\mathrm{SnO}_{2} \mathrm{NFs}$ (19). These $\mathrm{CuO} / \mathrm{SnO}_{2}$ mixed NFs show response time/recovery times of $1 / 305 \mathrm{~s}$ [224].

$\mathrm{In}_{2} \mathrm{O}_{3}-\mathrm{CeO}_{2}$ NTs synthesized by electrospinning exhibit an excellent response toward $\mathrm{H}_{2} \mathrm{~S}$ at low temperature $\left(25-110^{\circ} \mathrm{C}\right)$ and to acetone at relatively high temperature $\left(300^{\circ} \mathrm{C}\right)[225]$. 
The outer diameter and wall thickness are tuned in the range of 90-180 $\mathrm{nm}$ and 15-9 $\mathrm{nm}$, respectively, by changing the molar concentration of $\operatorname{In}_{2} \mathrm{O}_{3}$ and $\mathrm{CeO}_{2}$. The diameters and wall thickness of $\mathrm{In}_{75} \mathrm{Ce}_{25}, \mathrm{In}_{50} \mathrm{Ce}_{50}, \mathrm{In}_{25} \mathrm{Ce}_{75}$ and $\mathrm{CeO}_{2} \mathrm{NTs}$ are $\approx 100$, $120,140,180 \mathrm{~nm}$ and 12,10, 9, and $9 \mathrm{~nm}$, respectively. The diameter increases with an increase in Ce concentration in different samples whereas the wall thickness decreases [225]. The binary $\mathrm{In}_{2} \mathrm{O}_{3}-\mathrm{CeO}_{2}\left(\mathrm{In}_{75} \mathrm{Ce}_{25}\right)$ NTs exhibit a high response of 498 to $20 \mathrm{ppm}$ of $\mathrm{H}_{2} \mathrm{~S}$ at $80{ }^{\circ} \mathrm{C}$ and 30 toward $200 \mathrm{ppm}$ of acetone at $300{ }^{\circ} \mathrm{C}$, respectively. The response and recovery times for $\mathrm{H}_{2} \mathrm{~S}$ and acetone are 64/204 s and 9/80 s, respectively [225].

$\mathrm{Al}_{2} \mathrm{O}_{3}-\mathrm{In}_{2} \mathrm{O}_{3}$ composites with a heterostructure and mesoporous tubular structure have been applied to room temperature $\mathrm{NO}_{x}$ sensing [226]. These composite NTs can detect $291 \mathrm{ppb}$ of $\mathrm{NO}_{x}$ at room temperature with a response of 0.74 and a response time of $24 \mathrm{~s}$. The atomic ratios of $\mathrm{In}$ and $\mathrm{Al}$ were 100:0, 100:15, 100:20 and 100:25, and are labelled as pure $\mathrm{In}_{2} \mathrm{O}_{3}$ NTs, meso-15AI NTs, meso-20AI NTs and meso-25AI NRs, respectively. The average diameter of the NTs is around $200 \mathrm{~nm}$. The crystallite size of $\mathrm{In}_{2} \mathrm{O}_{3}$ reduces with increasing $\mathrm{Al}_{2} \mathrm{O}_{3}$ content. The grain size in pure $\mathrm{In}_{2} \mathrm{O}_{3}$ reduces from $30-50 \mathrm{~nm}$ to $8-13 \mathrm{~nm}$ in $\mathrm{Al}_{2} \mathrm{O}_{3}-\mathrm{In}_{2} \mathrm{O}_{3}$ composite NTs. The NTs containing $20 \% \mathrm{Al}_{2} \mathrm{O}_{3}$ (meso-20AI NTs) show a response of 100 toward $97 \mathrm{ppm}$ of $\mathrm{NO}_{x}$ at room temperature with a response time of $28 \mathrm{~s}$. This response time is 7.3-times higher than the pure $\mathrm{In}_{2} \mathrm{O}_{3}$ NTs. The response of the $\mathrm{Al}_{2} \mathrm{O}_{3}-\mathrm{In}_{2} \mathrm{O}_{3}$ composite NF sensor decreases in the order of meso-20AI NTs $>$ meso-25AI NRs $>$ meso-15AI NTs $>$ pure $\operatorname{In}_{2} \mathrm{O}_{3}$ NTs $>$ porous pure $\mathrm{Al}_{2} \mathrm{O}_{3}$ NRs. However, the response time increases in the order of pure $\mathrm{In}_{2} \mathrm{O}_{3} \mathrm{NTs}>$ meso-25AI NRs $>$ meso-15AI NTs $>$ meso-20AI NTs $>$ porous pure $\mathrm{Al}_{2} \mathrm{O}_{3}$ NRs [226].

$\mathrm{Xu}$ et al. [227] synthesized $\mathrm{In}_{2} \mathrm{O}_{3}$ composite $\mathrm{SnO}_{2}$ (ICTOs) NRs using electrospinning for room temperature $\mathrm{NO}_{x}$ sensing. Pristine $\mathrm{SnO}_{2}$ nanorods show an average diameter of $474 \mathrm{~nm}$, whereas the average diameter of 3ICNO (Sn:In atomic ratio 25:0.3) is $230 \mathrm{~nm}$. The TEM images (Figure 11a-d) show that NPs are connected through a neck between grains that improve electron conduction. The dynamic response of the 3ICTO sensor is shown in Figure 11e. The 3ICTO nanorods show the highest response of 8.98 toward $100 \mathrm{ppm}$ of $\mathrm{NO}_{x}$ at room temperature. The response time for 3ICTO is $4.67 \mathrm{~s}$, that is, 11-times higher than pristine $\mathrm{SnO}_{2}$ nanorods. The composite nanorods detect $0.1 \mathrm{ppm}$ of $\mathrm{NO}_{x}$ with a response of 0.92 and response time $20 \mathrm{~s}$ (Figure 11e,f). The response time of all these sensors are shown in Figure 11g. The slowest response of 3ICTOs at $0.5 \mathrm{ppm}$ is $35 \mathrm{~s}$. The 3ICTO sensor shows a very high selectivity toward $\mathrm{NO}_{x}$ in the presence of interfering gases as shown in Figure 11h.

P-type $\mathrm{TiO}_{2}-\mathrm{In}_{2} \mathrm{O}_{3}$ composite NFs have been synthesized by electrospinning for improved electrical conductivity and sensitivity to ppb levels of $\mathrm{NO}_{2}$ at room temperature [228]. Atomic ratios of Ti to In of $10: 0 ; 8: 1 ; 6: 1 ; 5: 1$, are labelled as pure $\mathrm{TiO}_{2}$, ITCN1, ITCN2, and ITCN3, respectively. The pore size at the optimum atomic ratio of $\mathrm{Ti}$ and In 14.3 atom \% (ITCN2) is $4-6 \mathrm{~nm}$, whereas the average nanoparticle size is about $9 \mathrm{~nm}$. The surface morphology of the $\mathrm{TiO}_{2}-\mathrm{In}_{2} \mathrm{O}_{3}$ composite NFs is shown in the Figure 12a-c. ITCN2 has an average diameter of
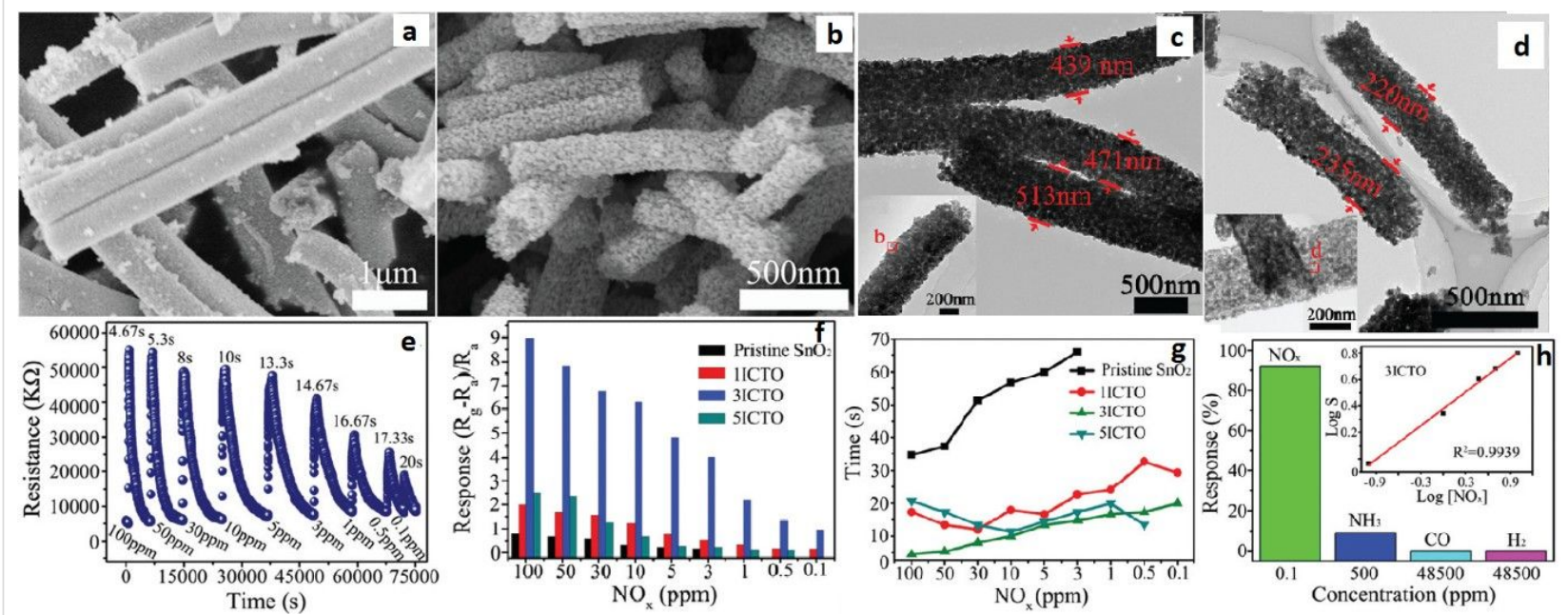

Figure 11: SEM images of (a) pristine $\mathrm{SnO}_{2}$ and (b) 3ICTO; TEM images of (c) pristine $\mathrm{SnO}_{2} \mathrm{NRs}$; (d) 3ICTO NRs; (e) dynamic response-recovery curves of the 3ICTO sensor for 100 ppm-0.1 ppm NO ${ }_{x}$ at RT; (f) gas response and (g) response time for the four samples; (h) response of the $3 I \mathrm{CTO}$ sensor to different gases, the inset shows a linear dependence relation between the logarithm of the response and concentration of $\mathrm{NO}_{x}$. Reproduced with permission from [227], copyright 2015 Royal Society of Chemistry. 

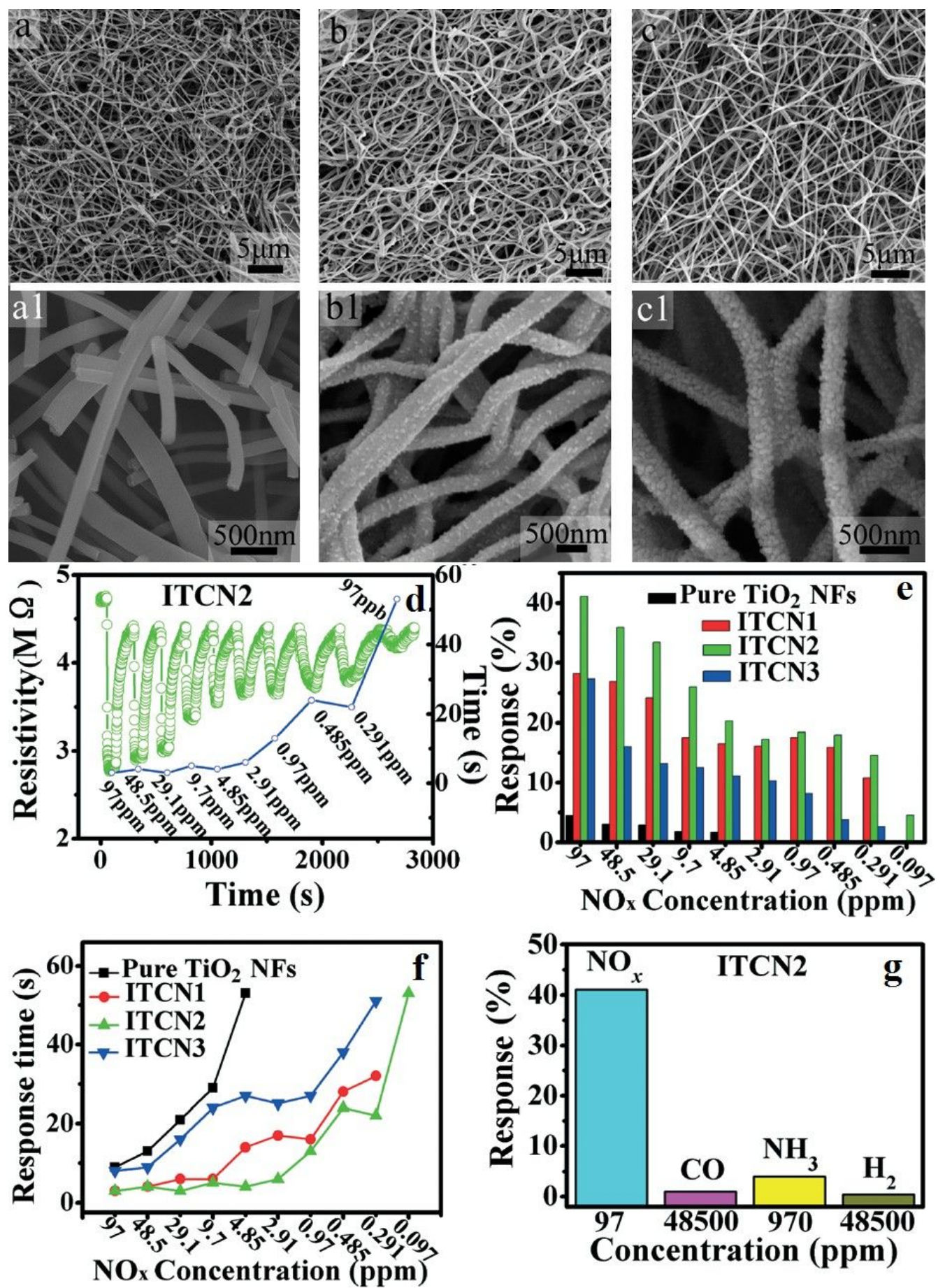

Figure 12: SEM images of (a), (a1) pure $\mathrm{TiO}_{2} \mathrm{NFs}$; (b), (b1) ITCN1; and (c), (c1) ITCN2. (d) The response-recovery cyclic curves vs the response time of ITCN2; (e) the bar graph represents the gas sensitivities of the samples; (f) the response time curves of the pure TiO 2 NFs, ITCN1, ITCN2 and ITCN3; and (g) a bar chart showing the response value of the ITCN2 sensor for four different gases. Reproduced with permission from [228], copyright 2014 Royal Society of Chemistry.

$200 \mathrm{~nm}$. The ITCN NFs show a loose mesoporous NF structure because nanoparticles are not closely bound in the centre of the fiber. The response time of ITCN2 is shown in Figure 12d. The highest response is $41.1 \%$ with a response time of $3 \mathrm{~s}$ for $97 \mathrm{ppm} \mathrm{NO}_{x}$. It is clear from the bar graph that the response of
ITCN is better than pure $\mathrm{TiO}_{2}$ sensors. The lowest detectable concentration for ITCN2 is $97 \mathrm{ppb}$. The ITCN2 sample also shows the fastest response time at the lowest detectable concentration ( $97 \mathrm{ppb}$ ). The response time of ITCN2 is $53 \mathrm{~s}$ for $97 \mathrm{ppb}$ at room temperature (Figure 12e,f). The responses of pure $\mathrm{TiO}_{2}$ 
NFs, and ITCN1, ITCN2 and ITCN3 for $97 \mathrm{ppb} \mathrm{NO}$ at room temperature are $4.48 \%, 28.2 \%, 41.1 \%, 27.4 \%$ with response/ recovery times of $9 \mathrm{~s}, 3 \mathrm{~s}, 3 \mathrm{~s}$, and $8 \mathrm{~s}$, respectively. The response of ITCN2 is 9.2-times higher than that of pure $\mathrm{TiO}_{2}$ NFs, whereas the response time of ITCN2 is 3-times faster than pure $\mathrm{TiO}_{2}$ NFs [228].

The $\mathrm{Fe}_{2} \mathrm{O}_{3}-\mathrm{In}_{2} \mathrm{O}_{3}$ composite NTs exhibit better formaldehyde sensing properties than other $\mathrm{In}_{2} \mathrm{O}_{3}$ composite NTs [229]. $\mathrm{Fe}_{2} \mathrm{O}_{3}-\mathrm{In}_{2} \mathrm{O}_{3}$ composite NTs have an average diameter of $200 \mathrm{~nm}$. The mixing of $\mathrm{Fe}_{2} \mathrm{O}_{3}$ shows no effect on the diameter of the $\mathrm{Fe}_{2} \mathrm{O}_{3}-\mathrm{In}_{2} \mathrm{O}_{3}$ composite NTs. The composite NTs show almost two times higher response (33) for $100 \mathrm{ppm}$ of formaldehyde at optimum temperature $\left(240{ }^{\circ} \mathrm{C}\right)$ than pure $\mathrm{In}_{2} \mathrm{O}_{3}$ fibers with response and recovery times of $5 \mathrm{~s}$ and $25 \mathrm{~s}$, respectively [229].

Similarly, $\mathrm{ZnO}-\mathrm{In}_{2} \mathrm{O}_{3}$ composite NFs have been evaluated for trimethylamine (TMA) sensing [230]. The surface morphology and grain size of calcined $\mathrm{ZnO}-\mathrm{In}_{2} \mathrm{O}_{3}$ composite NFs is dependent on composition of the NFs. For example, the grain size reduces with an increase in $\mathrm{In}_{2} \mathrm{O}_{3}$ content. The maximum response for $\mathrm{ZnO}-\mathrm{In}_{2} \mathrm{O}_{3}$ composite NFs with the composition of $\mathrm{Zn} / \mathrm{In} 67: 33,50: 50$, and 33:67 (atom \%) to 5 ppm TMA is 133.9 at $300{ }^{\circ} \mathrm{C}, 82.9$ at $350{ }^{\circ} \mathrm{C}$, and 119.4 at $375{ }^{\circ} \mathrm{C}$. The response of the $\mathrm{ZnO}-\mathrm{In}_{2} \mathrm{O}_{3}$ composite nanofibers to TMA are up to 4.8-times and 12.0-times higher than those of pure $\mathrm{ZnO}$ and $\operatorname{In}_{2} \mathrm{O}_{3}$ nanofibers, respectively. The sensor with $\mathrm{Zn} / \mathrm{In}$ 67:33 was found to be the best with respect to gas response, selectivity and sensing response speed [230].

Liu et al. [231] have synthesized $\mathrm{SnO}_{2} / \mathrm{In}_{2} \mathrm{O}_{3}$ hetero-NTs (SINs) using coaxial electrospinning for formaldehyde sensing. The samples with $0.1 \mathrm{~g}$ and $0.15 \mathrm{~g}$ of $\mathrm{SnCl}_{2} \cdot 2 \mathrm{H}_{2} \mathrm{O}$ are labelled as SINs 0.1 and SINs 0.15 , respectively. The $\mathrm{SnO}_{2} / \mathrm{In}_{2} \mathrm{O}_{3}$ hetero-NTs have an average diameter in the range of $80-120 \mathrm{~nm}$. The NTs are composed of nanoparticles with diameter in the range of $10-50 \mathrm{~nm}$. The hetero-NTs SINs 0.1 show very high response of 400 to $500 \mathrm{ppm}$ of formaldehyde at optimum temperature $\left(300^{\circ} \mathrm{C}\right)$ with response and recovery times of $60 \mathrm{~s}$ and $97 \mathrm{~s}$, respectively. The lowest possible concentration detectable by the sensors is $250 \mathrm{ppb}$ with a response of 1.44 [231].

Du et al. [232] have synthesized $\mathrm{SnO}_{2} / \mathrm{In}_{2} \mathrm{O}_{3}$ composite heteroNFs using modified bipolar electrospinning with a double jet modified by oxygen plasma. The morphology of the composite hetero-NFs changes significantly with this approach. The average diameter of the $\mathrm{SnO}_{2} \mathrm{NFs}$ is in the range of 200-250 nm with a crystallite size of $20 \mathrm{~nm}$. $\mathrm{In}_{2} \mathrm{O}_{3} \mathrm{NFs}$ have an average diameter of $100-150 \mathrm{~nm}$ with a crystallite size of $40-50 \mathrm{~nm}$. The surface of $\mathrm{SnO}_{2}, \mathrm{In}_{2} \mathrm{O}_{3}$, and $\mathrm{SnO}_{2} / \mathrm{In}_{2} \mathrm{O}_{3} \mathrm{NF}$ s become rough and their diameter increases to 450 and $500 \mathrm{~nm}$ after treatment with oxygen plasma. The optimum temperature also reduces from $375^{\circ} \mathrm{C}$ to $290{ }^{\circ} \mathrm{C}$ after plasma treatment. The oxygenplasma-treated composite NFs show a higher response of 35.69 toward $50 \mathrm{ppm}$ formaldehyde at optimum temperature and a low detection limit of $0.5 \mathrm{ppm}$ formaldehyde is measured. Moreover, treated composite fibers exhibit response and recovery times of about $20 \mathrm{~s}$ and $40 \mathrm{~s}$, respectively.

Electrospun $\mathrm{ZnO}-\mathrm{TiO}_{2} \mathrm{NFs}$ have been converted to 3D hierarchical heterojunctions composed of highly dispersed $\mathrm{ZnO}$ nanorods by a hydrothermal process and applied to ethanol sensing [233]. The $\mathrm{ZnO}-\mathrm{TiO}_{2}$ heterojunction NFs have a brushlike morphology. The average diameter of $\mathrm{TiO}_{2} \mathrm{NFs}$ and $\mathrm{ZnO}$ nanorods are about 100 and $300 \mathrm{~nm}$, respectively. The $\mathrm{ZnO}$ NRs of about $2 \mu \mathrm{m}$ length grow on the outer surface of $\mathrm{TiO}_{2}$ NFs. A ZnO-TiO 2 sensor shows a fast response with a maximum value of 50.6 at the operating temperature of $320{ }^{\circ} \mathrm{C}$, whereas the response and recovery times are 50.6 and 5-10 s to $500 \mathrm{ppm}$ of ethanol [233]. Similar branch-like nanostructures of $\alpha-\mathrm{Fe}_{2} \mathrm{O}_{3}$ nanorods $/ \mathrm{TiO}_{2}$ nanofibers have been fabricated using electrospinning technique and hydrothermal process [234] (Figure 13). The morphology of $\alpha-\mathrm{Fe}_{2} \mathrm{O}_{3} / \mathrm{TiO}_{2}$ hierarchical heterostructure nanofibers changes drastically when changing the molar ratio between $\alpha-\mathrm{Fe}_{2} \mathrm{O}_{3}$ and $\mathrm{TiO}_{2}$ precursors. The SEM images for the different molar ratios are shown in the Figure 13b-e. Furthermore, these hierarchical branch-like $\alpha-\mathrm{Fe}_{2} \mathrm{O}_{3} / \mathrm{TiO}_{2}$ structures have been applied to gas sensing applications because of their rough, loose, and well-aligned surface morphology, including a branch-like heterostructure. The morphology-operating temperature behaviour relation has also been studied and is shown in Figure 13f. The maximum response of four $\alpha-\mathrm{Fe}_{2} \mathrm{O}_{3} / \mathrm{TiO}_{2}$ sensors at optimum temperature $250{ }^{\circ} \mathrm{C}$ is (S-1) 6.5, (S-2) 8.0, (S-3) 13.9, and (S-4) 11.2, respectively. The developed hierarchical branch-like $\alpha-\mathrm{Fe}_{2} \mathrm{O}_{3} / \mathrm{TiO}_{2}$ materials also show rapid response/recovery times of $0.5 \mathrm{~s}$ and $1.5 \mathrm{~s}$ compared with their counterparts [234].

Lou et al. [235] report $\mathrm{TiO}_{2} / \mathrm{ZnO}$ composite nanostructures that show minimal response at a lower temperature of $280{ }^{\circ} \mathrm{C} \mathrm{com-}$ pared with the brush-like hierarchical heterojunctions. The $\mathrm{TiO}_{2} / \mathrm{ZnO}$ sensor shows a higher response of 15.7 to $100 \mathrm{ppm}$ of ethanol at $280{ }^{\circ} \mathrm{C}$ compared with that of pure $\mathrm{ZnO}$ (9.7) and $\mathrm{TiO}_{2}$ NFs (5.0). Lou et al. [235] have also proposed a heterostructure comprising $\mathrm{ZnO}$ nanosheets on $\mathrm{TiO}_{2} \mathrm{NFs}$ for this sensor. The morphology of the heterostructures is shown in Figure $14 \mathrm{a}-\mathrm{c}$. The diameter of the NFs is about $70-100 \mathrm{~nm}$ with nanosheets uniformly distributed over the surface of $\mathrm{TiO}_{2} \mathrm{NFs}$. The operating temperature has been significantly reduced with the $\mathrm{TiO}_{2} / \mathrm{ZnO}$ heterostructure when compared to pure $\mathrm{TiO}_{2} \mathrm{NFs}$ 
(a)

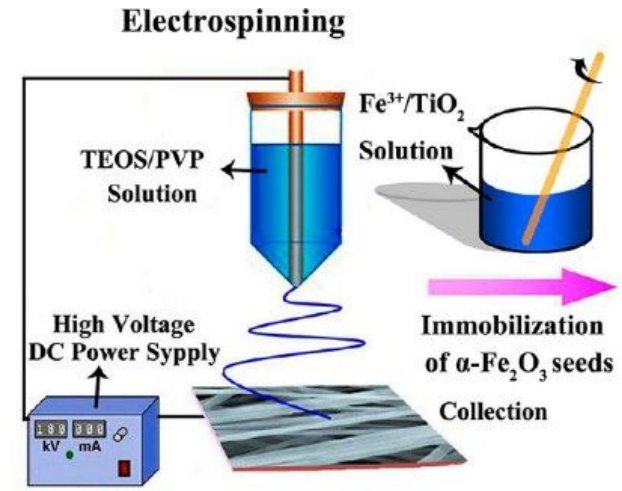

\section{Hydrothermal method}

$\mathrm{TiO}_{2}$

$\alpha-\mathrm{Fe}_{2} \mathrm{O}_{3}$ seeds/TiO

$\alpha-\mathrm{Fe}_{2} \mathrm{O}_{3}$ nanorods/TiO
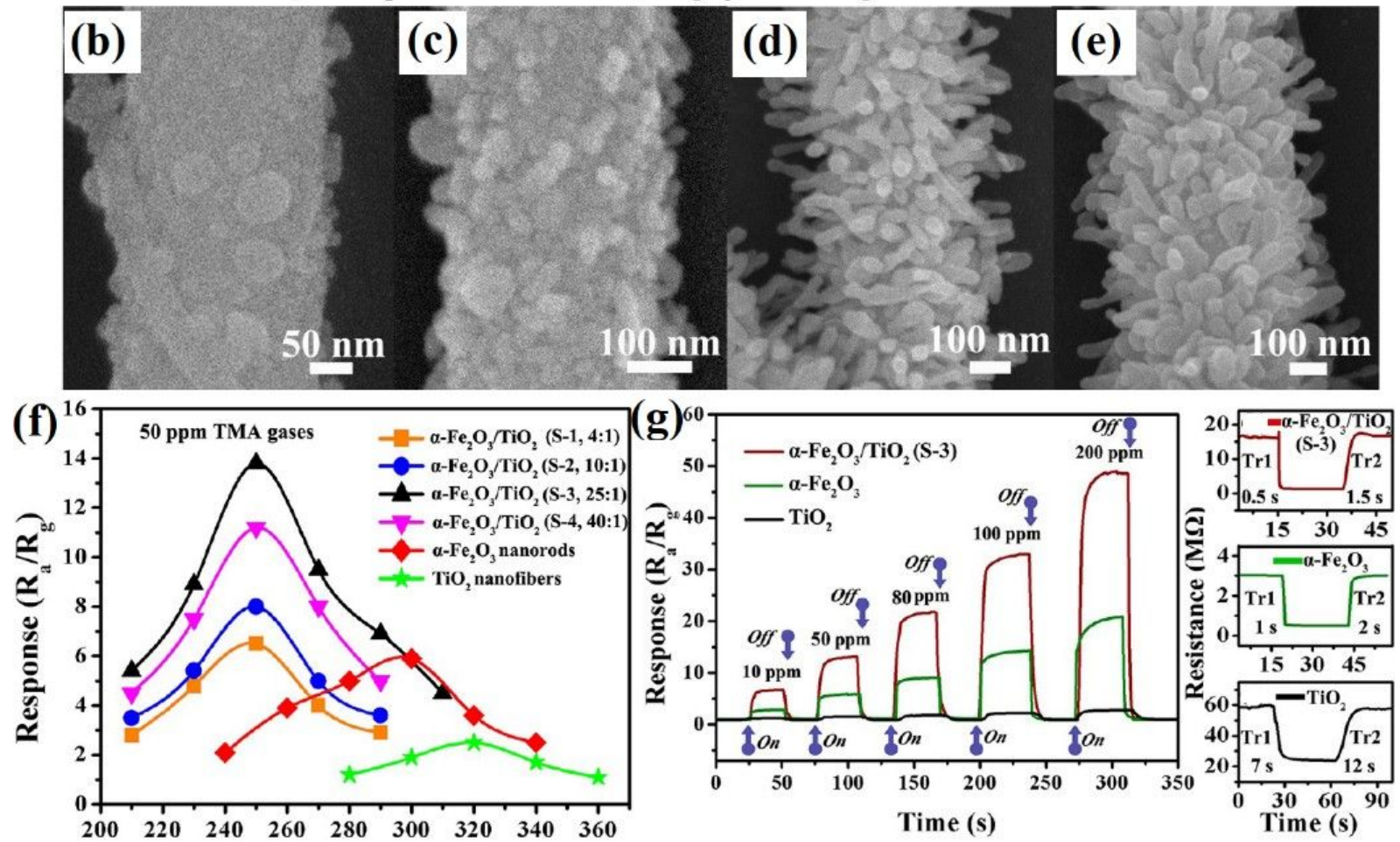

Temperature $\left({ }^{\circ} \mathrm{C}\right)$

Figure 13: (a) Synthesis strategy for branch-like $\alpha-\mathrm{Fe}_{2} \mathrm{O}_{3} / \mathrm{TiO}_{2}$ hierarchical heterostructures; $\mathrm{FESEM}$ images of hierarchical $\alpha-\mathrm{Fe}_{2} \mathrm{O}_{3} / \mathrm{TiO}_{2}$ heterostructures with different molar ratios: (b) S-1, 4:1, (c) S-2, 10:1, (d) S-3, 25:1; and (e) S-4, 40:1; (f) effect of operating temperature on different molar ratios as well as pristine $\alpha-\mathrm{Fe}_{2} \mathrm{O}_{3}$ nanorods, and $\mathrm{TiO}_{2}$ nanofibers, and (g) dynamic TMA-sensing response curves and response/recovery time of the pristine $\alpha-\mathrm{Fe}_{2} \mathrm{O}_{3}$ nanorods, $\mathrm{TiO}_{2}$ nanofibers, and $\alpha-\mathrm{Fe}_{2} \mathrm{O}_{3} / \mathrm{TiO}_{2}$ heterostructures. Reproduced with permission from [234], copyright $2013 \mathrm{ACS}$.

or $\mathrm{ZnO}$ NFs. The response of the $\mathrm{TiO}_{2} / \mathrm{ZnO}$ heterostructure is about $5.2,9.4,12.5,15.7$, and 19.6 to $10,20,50,100$ and $200 \mathrm{ppm}$ of ethanol, respectively (Figure 14h). The response and recovery times for $\mathrm{TiO}_{2} / \mathrm{ZnO}$ are about $5 / 3 \mathrm{~s}$, which compares with $7 / 13 \mathrm{~s}$ and $6 / 3 \mathrm{~s}$ for the pure $\mathrm{ZnO}$ and $\mathrm{TiO}_{2} \mathrm{NFs}$, respectively [235].

Feng et al. [103] report on $\mathrm{In}_{2} \mathrm{O}_{3}-\mathrm{WO}_{3}$ heterojunction NFs for acetone sensing. The molar percentage of $0,0.5,1.5$, and $3 \%$
$\mathrm{In}_{2} \mathrm{O}_{3}-\mathrm{WO}_{3}$ heterojunction NFs are labelled as $\mathrm{S} 1, \mathrm{~S} 2, \mathrm{~S} 3$, and S4. The average diameter of almost all samples is $170 \mathrm{~nm}$. The largest response is exhibited by a sensor with a molar ratio of $\mathrm{In}_{2} \mathrm{O}_{3} / \mathrm{WO}_{3}$ 1.5:100 for $50 \mathrm{ppm}$ of acetone at $275{ }^{\circ} \mathrm{C}$. The largest response is 12.9 for $50 \mathrm{ppm}$ of acetone which is 2.5 times higher than the pure $\mathrm{WO}_{3}$ NFs. The lowest possible detectable concentration is $0.4 \mathrm{ppm}$ of acetone with a response of 1.28. The response and recovery times are about $6 \mathrm{~s}$ and $64 \mathrm{~s}$ for the S3 sensor [103]. 

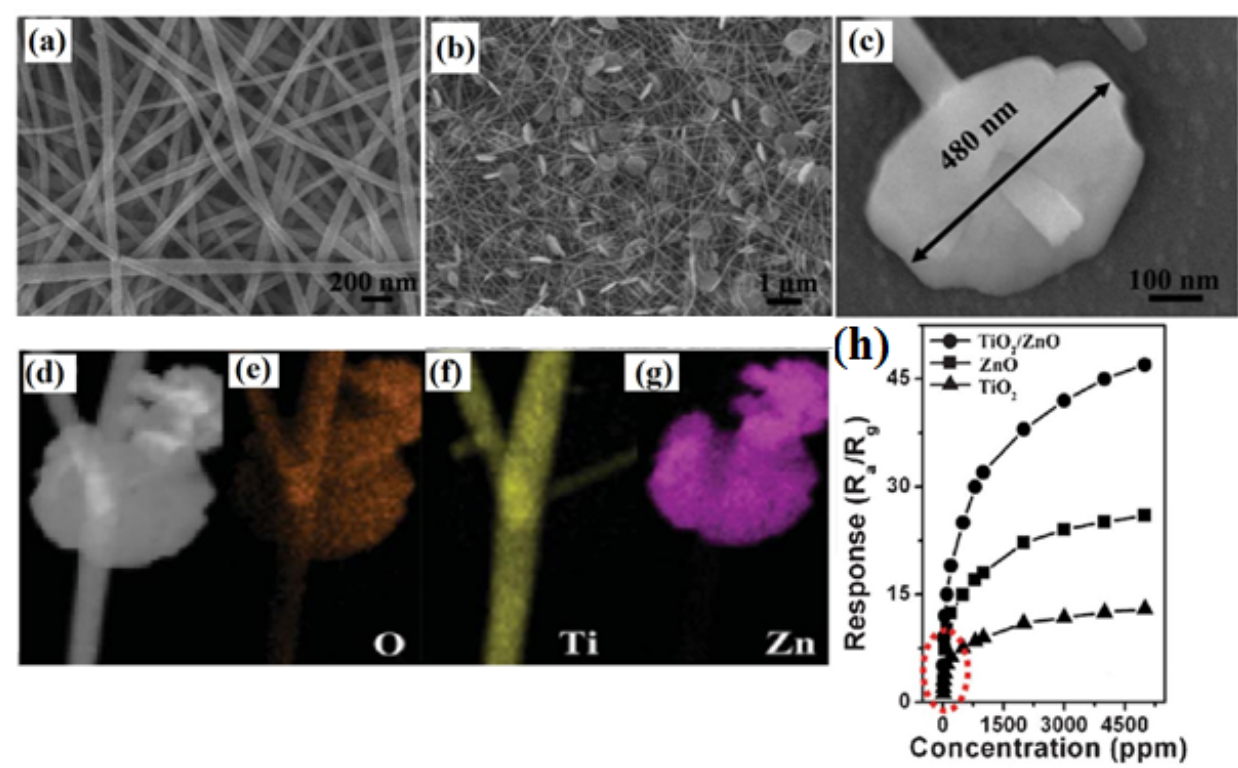

Figure 14: SEM images of (a) pure $\mathrm{TiO}_{2} \mathrm{NFs}$ and $(\mathrm{b}, \mathrm{c}) \mathrm{TiO}_{2} / \mathrm{ZnO}$ heterostructures. (d-g) STEM image of $\mathrm{TiO}_{2} / \mathrm{ZnO}$ heterostructures; ( $\mathrm{h}$ ) response of $\mathrm{TiO}_{2} / \mathrm{ZnO}$ heterostructure nanofibers at $280^{\circ} \mathrm{C}$, pure $\mathrm{ZnO}$ at $300{ }^{\circ} \mathrm{C}$ and pure $\mathrm{TiO}_{2}$ at $350^{\circ} \mathrm{C}$ versus ethanol concentration. Reproduced with permission from [235], copyright 2013 Royal Society of Chemistry.

$\mathrm{In}_{2} \mathrm{O}_{3}$ NFs coated with $\mathrm{SnO}_{2}$ nanoparticles have been synthesized by combining electrospinning and sol-gel processing in order to test for ammonia sensing [236]. The atomic percentage of $\mathrm{SnO}_{2}$ is about $0 \%, 7.5$ atom $\%, 16$ atom $\%$, and 21 atom $\%$ in $\mathrm{In}_{2} \mathrm{O}_{3}, \mathrm{SnO}_{2} / \mathrm{In}_{2} \mathrm{O}_{3}-1, \mathrm{SnO}_{2} / \mathrm{In}_{2} \mathrm{O}_{3}-2$ and $\mathrm{SnO}_{2} / \mathrm{In}_{2} \mathrm{O}_{3}-3$ NFs, respectively. The $\mathrm{SnO}_{2}$ NPs coated onto $\mathrm{In}_{2} \mathrm{O}_{3}$ NFs show an average diameter in the range of $30-80 \mathrm{~nm}$. The highest response of 21 is shown by $\mathrm{SnO}_{2} / \mathrm{In}_{2} \mathrm{O}_{3}-2$, toward 1 ppm of ammonia with response and recovery times as $7 \mathrm{~s}$ and $10 \mathrm{~s}$, respectively. The fabricated $\mathrm{SnO}_{2}$ NP-coated $\mathrm{In}_{2} \mathrm{O}_{3}$ NFs are able to detect $0.1 \mathrm{ppm}$ of ammonia [236].

Photoactivated $\mathrm{TiO}_{2} / \mathrm{Pd} / \mathrm{N} / \mathrm{Fe}_{2} \mathrm{O}_{3}$ composite fibers have been applied to $\mathrm{H}_{2}$ sensing [237]. The $\mathrm{TiO}_{2}$ nanofibers have an average diameter of $70 \pm 20 \mathrm{~nm}$ and their surface is smooth with few cracks. The operating temperature is lowered from $290{ }^{\circ} \mathrm{C}$ to $130{ }^{\circ} \mathrm{C}$ by using visible-light irradiation and additive materials. The response of the sensor increases from 11 (pure $\mathrm{TiO}_{2}$ $\mathrm{NFs})$ to $368\left(\mathrm{TiO}_{2} / \mathrm{Pd} / \mathrm{HNO}_{3} / \mathrm{Fe}_{2} \mathrm{O}_{3} / \mathrm{UV}_{2} \mathrm{NFs}\right.$ of $450-470 \mathrm{~nm}$ diameter) at an operating temperature of $150{ }^{\circ} \mathrm{C}$. The detection limit for hydrogen sensing is $25 \mathrm{ppm}$ for pure $\mathrm{TiO}_{2} \mathrm{NFs}$ but reduces to $0.5 \mathrm{ppm}$ for a $\mathrm{TiO}_{2} / \mathrm{Pd} / \mathrm{HNO}_{3} / \mathrm{Fe}_{2} \mathrm{O}_{3} / \mathrm{UV}_{2}$ sensor. The response time also reduces from $25 \mathrm{~s}$ to $0.9 \mathrm{~s}$ and recovery times are reduced from $40 \mathrm{~s}$ to $2 \mathrm{~s}$. The Pd concentration is optimized $\left(\mathrm{Pd} / \mathrm{TiO}_{2}=9 \%\right.$ molar ratio $)$ by observing the sensor response in dark and UV irradiation. At $150{ }^{\circ} \mathrm{C}$, the response time is $25,9,5$, and $0.9 \mathrm{~s}$ and recovery time is $40,22,10$, and $2 \mathrm{~s}$ for the pure $\mathrm{TiO}_{2}, \mathrm{Pd}-\mathrm{TiO}_{2}, \mathrm{TiO}_{2} / \mathrm{UV}_{1}(360-390 \mathrm{~nm})$, and $\mathrm{Pd}-\mathrm{TiO}_{2} / \mathrm{UV}_{2}(400-420 \mathrm{~nm})$ samples, respectively [237]. A detailed analysis of MOx sensors developed with different MOx materials is shown in Table S4 in Supporting Information File 1.

4.1.4 Conducting polymer-semiconducting metal oxide composites: Gas sensors based on conducting polymers have shown excellent electronic conductivity and electrochemical properties $[32,87,90]$. Conducting polymers are organic materials that show an enhanced resistivity toward external stimuli. These conducting polymers show chemical selectivity, which allows them to act as excellent materials for gas sensors. Gopalan et al. [88] used electrospinning to produce composite NFs by poly(diphenylamine) and poly(methyl methacrylate) (PMMA) for sensing applications. Sensors developed in this way can detect $10 \mathrm{ppm}$ of ammonia at room temperature with a linear response from 10 to $300 \mathrm{ppm}$.

Ji et al. [87] produced PMMA NFs and their composites with polyaniline (PANI) using electrospinning and in situ solution polymerization. The sensor displays a sensing magnitude of 77 toward triethylamine (TEA) vapour of $500 \mathrm{ppm}$ at room temperature. A linear, reversible and reproducible response to TEA vapours with different concentrations $(20-500 \mathrm{ppm})$ is observed. The doping acid concentration only changed the sensor resistance and did not have any influence on the sensing performance. For example, the sensor with toluene sulfonic acid as the doping acid exhibits the highest sensing magnitude (77) toward 500 ppm of TEA. Similarly, composites of PANI and metal oxides have been synthesized by electrospinning and 
applied to gas sensing. Wang et al. [238] synthesized polyaniline/polyamide 6 (PANI/PA6) composite NFs by in situ polymerization and electrospinning. Later, $\mathrm{TiO}_{2}-\mathrm{PANI} / \mathrm{PA} 6$ composite NFs were fabricated by RF magnetron sputtering. The SEM images of the resulting fibers are shown in Figure 15a-e. The PANI/PA6 and $\mathrm{TiO}_{2}-\mathrm{PANI} / \mathrm{PA} 6 \mathrm{NFs}$ have uniform diameter with a rough surface. The morphology of the PANI/PA6 fibers is distorted by the $\mathrm{TiO}_{2}$ deposition and this distortion becomes prominent at $90 \mathrm{~min}$ sputtering time. The effect of $\mathrm{TiO}_{2}$ nanoparticles on the dynamic response of the sensor is shown in Figure $15 \mathrm{f}-\mathrm{i}$. The sensors with 60 min sputtering time performed the best with the highest value of response as measured by resistance value (Figure 15h).

Polyaniline/titanium dioxide $\left(\mathrm{PANI} / \mathrm{TiO}_{2}\right)$ composite NFs have been prepared by electrospinning and used for $\mathrm{NH}_{3}$ sensing [239]. In this case, $\mathrm{Mn}_{3} \mathrm{O}_{4} / \mathrm{TiO}_{2}$ fibers are fabricated by electrospinning and, in a later stage, oxidatively polymerized aniline is prepared with $\mathrm{Mn}_{3} \mathrm{O}_{4}$. SEM images of the electrospun $\mathrm{Mn}_{3} \mathrm{O}_{4} / \mathrm{TiO}_{2}$ composite NFs and the as-obtained $\mathrm{PANI} / \mathrm{TiO}_{2}$ composite NFs show that the diameter of the $\mathrm{Mn}_{3} \mathrm{O}_{4} / \mathrm{TiO}_{2}$ fibers is greater than the $\mathrm{PANI} / \mathrm{TiO}_{2} \mathrm{NFs}$. This size difference might be due to the conversion of $\mathrm{Mn}_{3} \mathrm{O}_{4}$ to PANI. The highest sensitivity is for the sample which has an $\mathrm{Mn}$ to Ti ratio of 3:1. If the ratio of $\mathrm{Mn}$ to $\mathrm{Ti}$ is below this optimal value, the sensitivity increases with Ti content in the composite. However, if the ratio is above the optimal value, the sensitivity decreases with Ti content in the composite [239].

Core-shell titania-poly(3,4-ethylenedioxythiophene) $\left(\mathrm{TiO}_{2}\right.$ PEDOT) nanocables have been prepared by electrospinning of $\mathrm{TiO}_{2}$ combined with vapour phase polymerization of PEDOT [240]. $\mathrm{TiO}_{2}$ used as a template serves as a core with an average diameter of $78 \mathrm{~nm}$ and with a PEDOT sheath of about $6 \mathrm{~nm}$. The prepared nanocables are used for $\mathrm{NO}_{2}$ and $\mathrm{NH}_{3}$ sensing [240]. The detection limit for $\mathrm{NO}_{2}$ is $7 \mathrm{ppb}$, whereas for $\mathrm{NH}_{3}$ the limit is $675 \mathrm{ppb}$.

Li et al. [241] synthesized $\mathrm{SnO}_{2}$ nanofibrous sheets (NSs) coated with polypyrrole (PPy) for $\mathrm{NH}_{3}$ sensing at room temperature. The vertically aligned $\mathrm{SnO}_{2} \mathrm{NSs}$ are grown by hydrothermal treatment at $135{ }^{\circ} \mathrm{C}$ and then coated with PPy by vapour phase polymerization of pyrrole. The $\mathrm{SnO}_{2}$ nanofibers have an average diameter in the range $100-200 \mathrm{~nm}$. The NSs were further doped with compounds such as hydrochloric acid $(\mathrm{HCl})$ $( \pm)$-10-camphorsulfonic acid (CSA), $p$-toulenesulfonic acid (TSA) and poly(styrene sulfonic acid) (PSSA). The order of sensitivity of these dopant acids is PSSA $>\mathrm{HCl}>\mathrm{TSA}>\mathrm{CSA}$. The nanocomposite sensors exhibit sensitivity of $\approx 6.2 \% / \mathrm{ppm}$ in the range of 1-10.7 ppm of $\mathrm{NH}_{3}$ and successfully detect low concentrations of $\mathrm{NH}_{3}(257 \mathrm{ppb})$. The response and recovery times for $\mathrm{SnO}_{2} / \mathrm{PPy}$ nanocomposites toward $5 \mathrm{ppm}$ of $\mathrm{NH}_{3}$ are $259 \mathrm{~s}$ and $468 \mathrm{~s}$, respectively. Similarly, $\mathrm{SnO}_{2} \mathrm{NSs}$ have also been doped with PANI and tested for $\mathrm{NH}_{3}$. As with the nanocomposites, $\mathrm{SnO}_{2} \mathrm{NFs} / \mathrm{PANI}$ sensors show a high response (relative resistance change of $\approx 3700 \%$ toward $10.7 \mathrm{ppm}$ of $\mathrm{NH}_{3}$ ) and a detection limit of $46 \mathrm{ppb}$ at room temperature [242].

Wang et al. [243] synthesized hierarchical $\mathrm{p}-\mathrm{n}$ junction nanostructures made of n-type $\mathrm{SnO}_{2} \mathrm{NSs}$ standing on p-type carbon nanofibers by combining electrospinning and hydrothermal treatment. The morphology of the heterostructures is shown in Figure 16a-d. The average diameter of the $\mathrm{SnO}_{2} / \mathrm{PAN}$ NFs is in the range of $150-500 \mathrm{~nm}$. The size of $\mathrm{SnO}_{2} \mathrm{NSs}$ is controlled by the reaction time during hydrothermal treatment. The maximum response is obtained at $200{ }^{\circ} \mathrm{C}$ with the highest response from a sample with $24 \mathrm{~h}$ hydrothermal reaction time (Figure 16e). The $\mathrm{SnO}_{2} / \mathrm{PAN}$ NSs exhibit a maximum response of $\approx 16.3$ at $200{ }^{\circ} \mathrm{C}$ for $100 \mathrm{ppm}$ of hydrogen with response and recovery times of $4 \mathrm{~s}$ and $16 \mathrm{~s}$, respectively (Figure 16f) [243].

$\mathrm{Sn}-\mathrm{SnO}_{2} / \mathrm{PAN}$ heterostructure NFs have been synthesized for ethanol sensing by electrospinning followed by annealing [244]. The $\mathrm{Sn}-\mathrm{SnO}_{2} / \mathrm{PAN}$ NFs have an average diameter in the range of 350-400 nm after heat treatment. The $\mathrm{Sn}-\mathrm{SnO}_{2} / \mathrm{PAN} \mathrm{NFs}$ show a maximum response of 46.15 at $220{ }^{\circ} \mathrm{C}$ toward $1000 \mathrm{ppm}$ of ethanol compared with pure $\mathrm{SnO}_{2} \mathrm{NFs}$ with 15.16 at $280{ }^{\circ} \mathrm{C}$ [244].

\subsubsection{Graphene-semiconducting metal oxide composite:}

Reduced graphene oxide (rGO) nanosheets (NSs) can be incorporated into MOx NFs to improve their sensitivity and selectivity. Abideen et al. [89] have produced $\mathrm{rGO} / \mathrm{NS}-$ loaded $\mathrm{ZnO}$ NFs that comprise nanograins with an average diameter of $20 \mathrm{~nm}$. These $\mathrm{rGO} / \mathrm{NS}$-loaded $\mathrm{ZnO}$ NF-based gas sensors show an excellent sensitivity to $\mathrm{CO}, \mathrm{C}_{6} \mathrm{H}_{6}$, and $\mathrm{C}_{2} \mathrm{H}_{5} \mathrm{OH}$. The amount of rGO is optimized and the sensor containing $0.44 \mathrm{wt} \% \mathrm{rGO}$ NSs shows a higher response $\left(R_{\mathrm{a}} / R_{\mathrm{g}} \approx 119\right)$ toward $5 \mathrm{ppm}$ of $\mathrm{NO}_{2}$ than the other sensors. Moreover, the same sensor shows a response of 22.6, 19.1, and 19.1 toward 5 ppm of $\mathrm{CO}, \mathrm{C}_{6} \mathrm{H}_{6}$, and $\mathrm{C}_{2} \mathrm{H}_{5} \mathrm{OH}$, respectively. The response and recovery times for $1 \mathrm{ppm}$ of $\mathrm{NO}_{2}$ are $174 \mathrm{~s}$ and $107 \mathrm{~s}$, respectively [89].

Furthermore, Abideen et al. [245] have also synthesized graphene NS-loaded $\mathrm{SnO}_{2}$ NFs using electrospinning and optimized the amount of graphene in $\mathrm{SnO}_{2} \mathrm{NFs}$ for gas sensing. The average diameter of the NFs is in the range $200-300 \mathrm{~nm}$, whereas the grain size is significantly affected by the graphene content. The graphene NS-loaded $\mathrm{SnO}_{2}$ NFs achieve a maximum response of 3.13 at $300{ }^{\circ} \mathrm{C}$, whereas pristine $\mathrm{SnO}_{2} \mathrm{NFs}$ show a maximum response of 1.94 at $325^{\circ} \mathrm{C}$. The graphene NS-loaded 


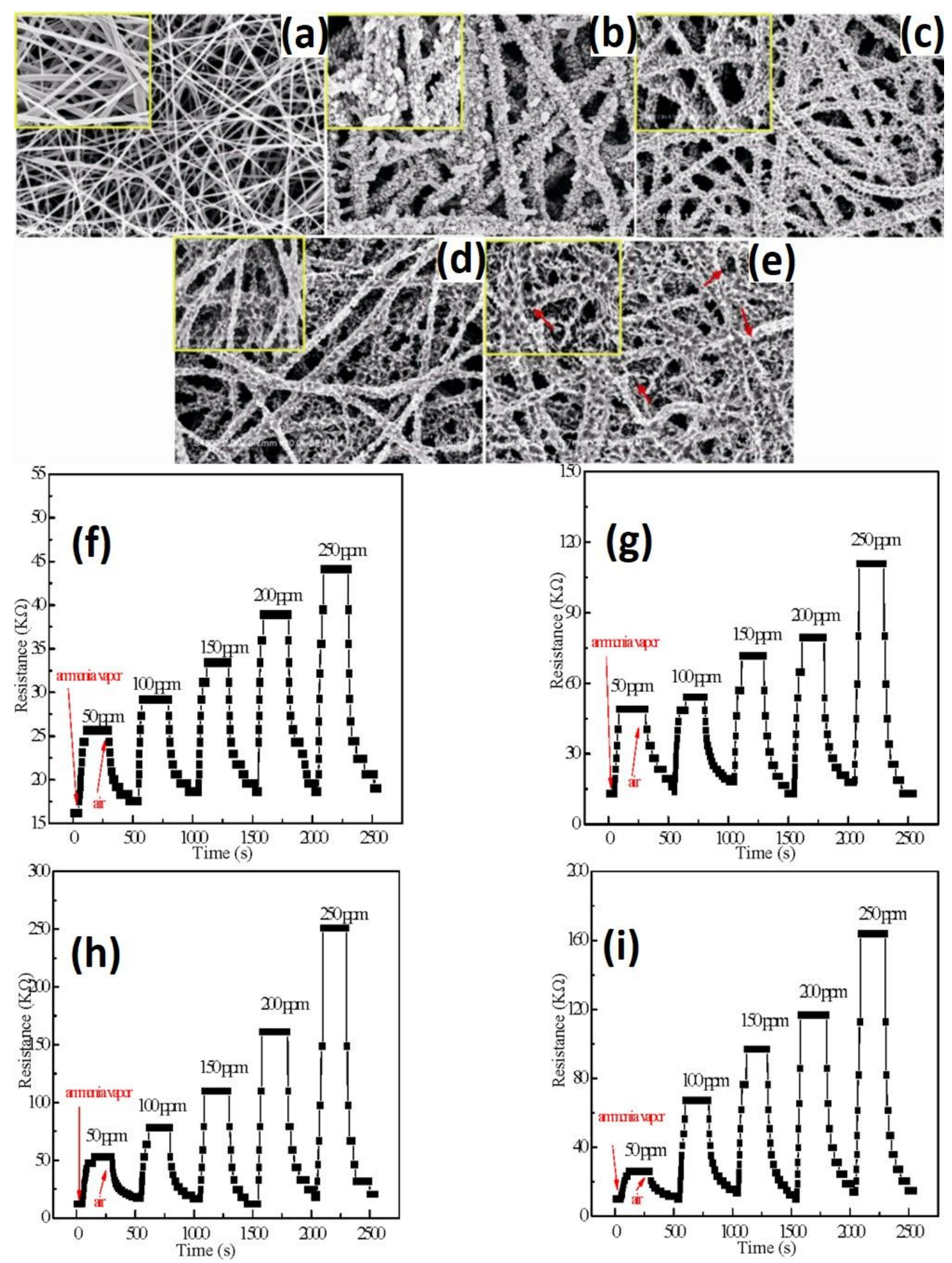

Figure 15: SEM image of (a) PA6 NFs; (b) PANI/PA6 NFs; (c) PANI/PA6 NFs sputtered for $30 \mathrm{~min}$; (d) TiO ${ }_{2}-\mathrm{PANI} / \mathrm{PA} 6 \mathrm{NFs}$ sputtered for 60 min;

(e) $\mathrm{TiO}_{2}-\mathrm{PANI} / \mathrm{PA6} \mathrm{NFs}$ sputtered for $90 \mathrm{~min}$; dynamic response and recovery of (f) PANI/PA6; (g) TiO ${ }_{2}-$ PANI/PA6 sputtered for 30 min;

(h) $\mathrm{TiO}_{2}-\mathrm{PANI} / \mathrm{PA} 6$ sputtered for $60 \mathrm{~min}$ and (i) $\mathrm{TiO}_{2}-\mathrm{PANI} / \mathrm{PA} 6$ sputtered for $90 \mathrm{~min}$ to ammonia vapour of different concentrations. Reproduced with permission from [238], copyright $2012 \mathrm{MDPI}$. 

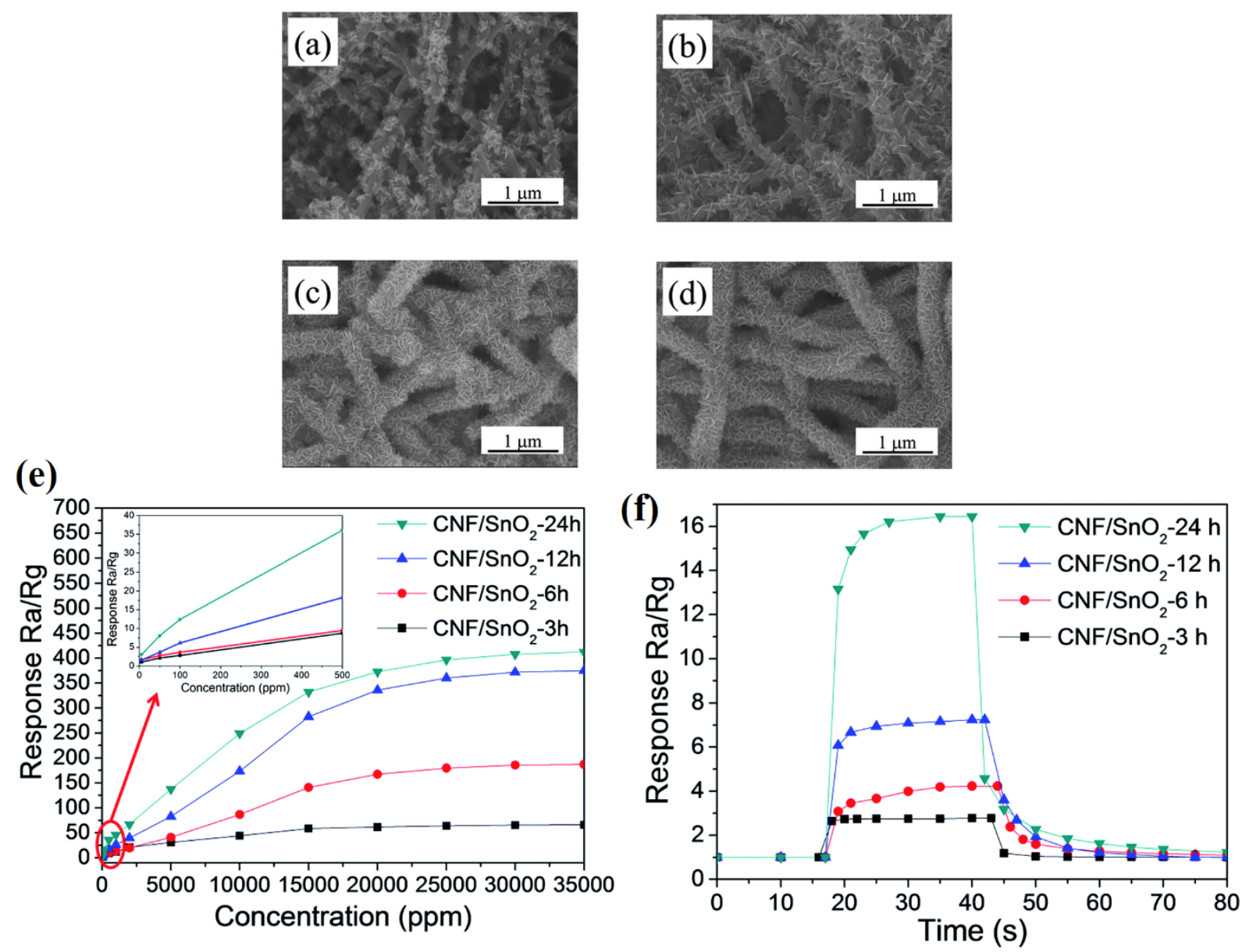

Figure 16: (a) SEM images of the hierarchical $\mathrm{SnO}_{2} / \mathrm{PAN} \mathrm{p}-\mathrm{n}$ junction nanostructures at different hydrothermal reaction times (a) $3 \mathrm{~h}$; (b) $6 \mathrm{~h}$; (c) $12 \mathrm{~h}$; and (d) $24 \mathrm{~h}$. (e) Linear plots of the response of the sensors based on the hierarchical p-n junction nanostructures with different hydrothermal reaction time against $\mathrm{H}_{2}$ in the range of $5 \mathrm{ppm}-3.5 \%$ at $200{ }^{\circ} \mathrm{C}$. (f) Response and recovery behaviour of the hierarchical $p-n$ junction nanostructures with different hydrothermal reaction times at $100 \mathrm{ppm} \mathrm{H_{2 }}$. Reproduced with permission from [243], copyright 2015 Royal Society of Chemistry.

$\mathrm{SnO}_{2} \mathrm{NFs}$ show a very short response time of $51.2 \mathrm{~s}$ at optimum graphene content $(0.5 \mathrm{wt} \%)$ [245].

Kim et al. [246] have synthesized (Pt or Pd) co-loaded $\mathrm{SnO}_{2}$ NFs containing rGO using electrospinning. They have also compared the gas sensing properties of ( $\mathrm{Pt}$ or $\mathrm{Pd}$ ) co-loaded $\mathrm{SnO}_{2} \mathrm{NFs}$ with rGO-loaded $\mathrm{SnO}_{2}$ to $1 \mathrm{ppm}$ and 5 ppm of $\mathrm{C}_{6} \mathrm{H}_{6}$, $\mathrm{C}_{7} \mathrm{H}_{8}$, and CO. The SEM images of the NFs and their gas sensing performance are shown in Figure 17. Pt or Pd nanoparticles with a diameter of 50-200 $\mathrm{nm}$ are dispersed on the surface of NFs as shown in the high-magnification SEM image (Figure 17b). The response of pristine $\mathrm{SnO}_{2} \mathrm{NFs}$, rGO-loaded $\mathrm{SnO}_{2} \mathrm{NFs}$, and $\mathrm{rGO} / \mathrm{Pd}$ co-loaded $\mathrm{SnO}_{2} \mathrm{NFs}$ is 1.6, 3.3, and 8.3 for $1 \mathrm{ppm}$ of $\mathrm{C}_{6} \mathrm{H}_{6}$, respectively at $200{ }^{\circ} \mathrm{C}$ [246].

\subsection{Surface acoustic wave gas sensors}

The surface acoustic wave (SAW) based sensor relies on detecting the change in the velocity of an acoustic wave on a piezoelectric substrate surface caused by the adsorption of analytes. Liu et al. [247] developed electrospun polyethylene (PEO) nanofibrous membrane based SAW gas sensors for detection of toluene, $\mathrm{H}_{2} \mathrm{O}_{2}$, isopropanol and nitrobenzene. PEO NFs were fabricated on an ST-cut quartz $\left(42^{\circ}\right.$ angle with $z$-axis $)$ SAW sensor. The PEO NFs have a diameter in the range of 100-300 nm with a sensing layer thickness of $8.1 \mu \mathrm{m}$. The normalized frequency shift of the developed sensor is -767 , $-343,-357$, and -537 toward $90 \%$ saturated concentration of isopropanol, $\mathrm{H}_{2} \mathrm{O}_{2}$, toluene, and nitrobenzene at room temperature. The response of the developed sensor is very fast with 1 min of adsorption, 2 min of diffusion, and 1 min of desorption time.

A humidity sensor has been fabricated with PANI/poly(vinyl butyral) (PVB) composite nanofibers deposited on a SAW resonator with a central frequency of $433 \mathrm{MHz}$ [248]. Nanofibers synthesized from several polymers with different 

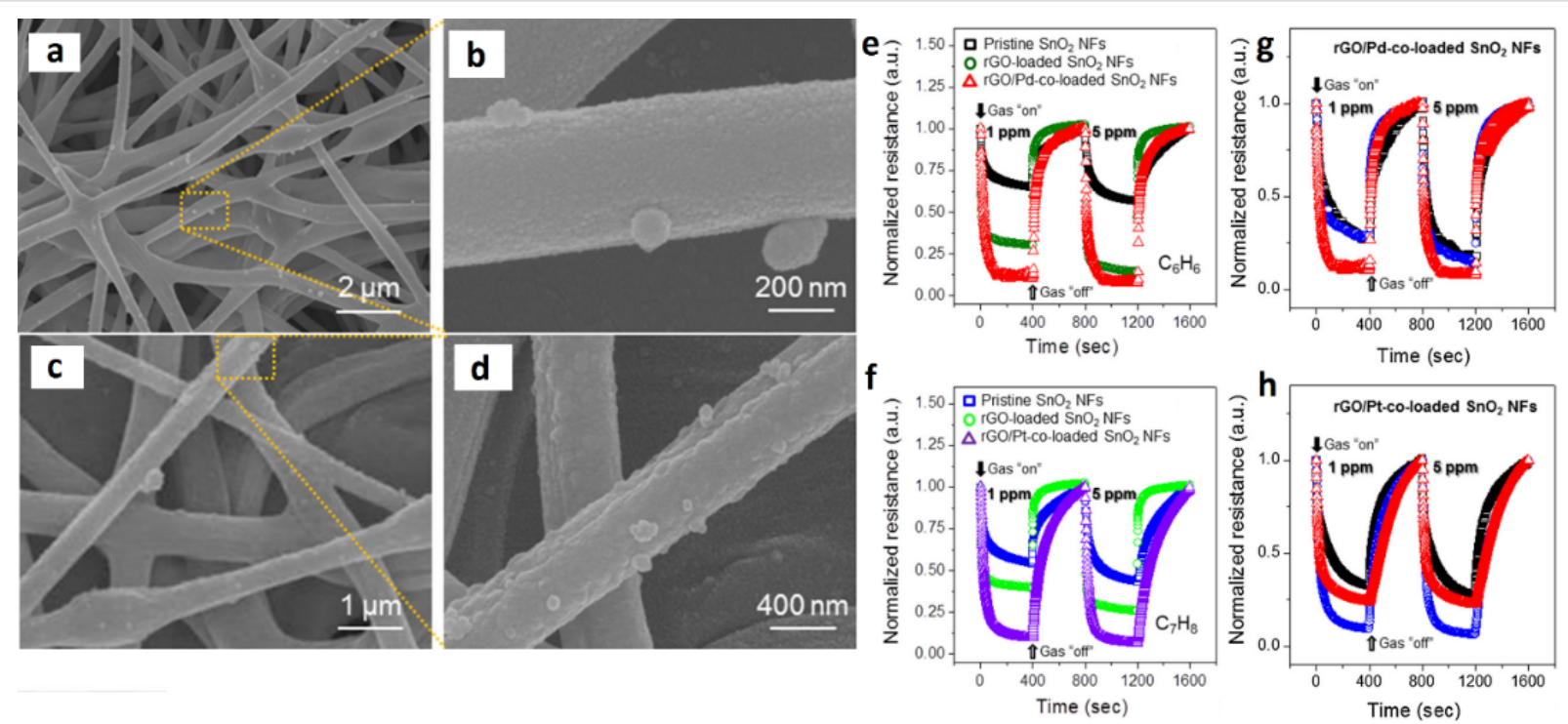

Figure 17: $\mathrm{rGO} / \mathrm{Pd}$ co-loaded $\mathrm{SnO}_{2} \mathrm{NFs}$ : $(a, c)$ low- and (b,d) high-magnification FE-SEM images. (e) Normalized dynamic resistance for pristine $\mathrm{SnO}_{2} \mathrm{NFs}$, rGO-loaded $\mathrm{SnO}_{2} \mathrm{NFs}$, and rGO/Pd co-loaded $\mathrm{SnO}_{2} \mathrm{NFs}$ in the presence of $1 \mathrm{ppm}$ and $5 \mathrm{ppm} \mathrm{C}_{6} \mathrm{H}_{6}$ at $200{ }^{\circ} \mathrm{C}$. (f) Normalized dynamic resistance for pristine $\mathrm{SnO}_{2} \mathrm{NFs}$, rGO-loaded $\mathrm{SnO}_{2} \mathrm{NFs}$, and rGO/Pt co-loaded $\mathrm{SnO}_{2} \mathrm{NFs}$ in the presence of $1 \mathrm{ppm}$ and $5 \mathrm{ppm} \mathrm{C}_{7} \mathrm{H}_{8}$ at $200{ }^{\circ} \mathrm{C}$. (g) Normalized dynamic resistance for rGO/Pd co-loaded $\mathrm{SnO}_{2} \mathrm{NFs}$ toward $1 \mathrm{ppm}$ and $5 \mathrm{ppm} \mathrm{CO}, \mathrm{C}_{6} \mathrm{H}_{6}$, and $\mathrm{C}_{7} \mathrm{H}_{8}$ gases at $200{ }^{\circ} \mathrm{C}$. (h) Normalized dynamic resistance for $\mathrm{rGO} / \mathrm{Pt}$ co-loaded $\mathrm{SnO}_{2} \mathrm{NFs}$ toward $1 \mathrm{ppm}$ and $5 \mathrm{ppm} \mathrm{CO}, \mathrm{C}_{6} \mathrm{H}_{6}$, and $\mathrm{C}_{7} \mathrm{H}_{8}$ gases at $200^{\circ} \mathrm{C}$. Reproduced with permission from [246], copyright 2017 Springer.

hydrophilicity, and viscoelasticity are tested as a template. PVB nanofibers with an average diameter of 100-200 $\mathrm{nm}$ show the maximum frequency shift. A frequency shift of $3.428 \mathrm{MHz}$ and 8.134 MHz, respectively, has been measured for PEO and PVP nanofibers. For the same humidity levels, a much lower sensitivity was obtained for PMMA, poly(vinylidene fluoride) (PVDF) and PVB with frequency shifts of $0.312 \mathrm{MHz}$, $0.334 \mathrm{MHz}$ and $0.425 \mathrm{MHz}$, respectively [248]. In SAW humidity sensors, the frequency shift response is predominantly due to changes in mass as well as electroacoustic and viscoelastic load of the sensing layer upon exposure to water molecules. A high humidity sensitivity $(\approx 0-75 \mathrm{kHz} / \% \mathrm{RH})$ and an ultrafast response ( $1 \mathrm{~s}$ and $2 \mathrm{~s}$ for humidification and desiccation, respectively) is reported for composite nanofibers [248]. Moreover, the sensor is able to detect humidity as low as $0.5 \%$ $\mathrm{RH}$ [248]. Electrospun PVP fibres on a $36^{\circ} \mathrm{LiTaO}_{3} \mathrm{SAW}$ sensor have been applied to hydrogen sensing [249]. The sensor shows a recovery time of $200 \mathrm{~s}$ upon exposure to hydrogen for $120 \mathrm{~s}$. A maximum frequency shift of $5.6 \mathrm{kHz}$ for $1 \%$ hydrogen is measured. Response of the electrospun fibers from $56 \%$ and 58\% PVP solutions was similar and higher than response for fibers with lower concentrations of PVP [249]. Similarly, electrospun PVP has been applied as a sensitive layer on SAW sensor for VOCs sensing (Figure 18a,b) [250]. The PVP fibers deposited on a SAW device is shown in Figure 18c. The PVP fibers have an average diameter of $120 \mathrm{~nm}$ with a film thickness in the range of $1.5-5 \mu \mathrm{m}$ at $18 \mathrm{KV}$ and $22 \mathrm{~cm}$. The developed sensor has been tested for different concentrations of toluene $(50,100,200$, and $273 \mathrm{ppm})$ as shown in Figure 18d,e. The minimum frequency shift that could be detected is $30 \mathrm{~Hz}$. The slope of the fit in Figure 18e shows the sensitivity of 3.25 $\mathrm{Hz} / \mathrm{ppm}$ that leads to a detection limit of $10 \mathrm{ppm}$ [250].

$\mathrm{CeO}_{2}$ NPs coated with PVP nanofibers based on low and high frequency SAW resonators operating at $879 \mathrm{MHz}(\mathrm{LF})$ and $1.56 \mathrm{GHz}(\mathrm{HF})$, respectively, have been fabricated for $\mathrm{RH}$ detection [251]. The samples of 0.1, 0.5, 1 and $2 \mathrm{mmol} \mathrm{CeO}_{2}$ with constant $300 \mathrm{mg}$ PVP are denoted as PC0.1, PC0.5, PC1 and PC2. SEM images of these $\mathrm{CeO}_{2} \mathrm{NPs}$ reveal a size range of 400-480 nm along with $\mathrm{CeO}_{2} / \mathrm{PVP}$ nanofibers (diameter $450 \mathrm{~nm}$ ). The sensor PC1-LF exhibits the maximum shift of $-300 \mathrm{kHz}$, while PC1-HF shows an enhanced frequency shift $(-2.5 \mathrm{MHz})$. The frequency shift of the SAW humidity sensor using the same sensitive material increases as the resonant frequency is raised with a maximum frequency shift of PVP-HF of -2.09 MHz. Moreover, PC1-HF does not exhibit any remarkable deterioration in frequency response and maintains its sensing characteristics (frequency shift of approximately $-2.3 \mathrm{MHz}$ from $11 \%$ to $95 \% \mathrm{RH}$ ) [251].

The humidity sensing performance of electrospun multiwalled carbon nanotube (MWCNTs)/nafion composites based on SAW devices was also investigated by Sheng et al. [252]. The MWCNTs had an average diameter in the range of 10-20 nm. Nafion appears as white-grey beads around MWCNTs in composite fibers. The resonance frequency of the sensor decreased 

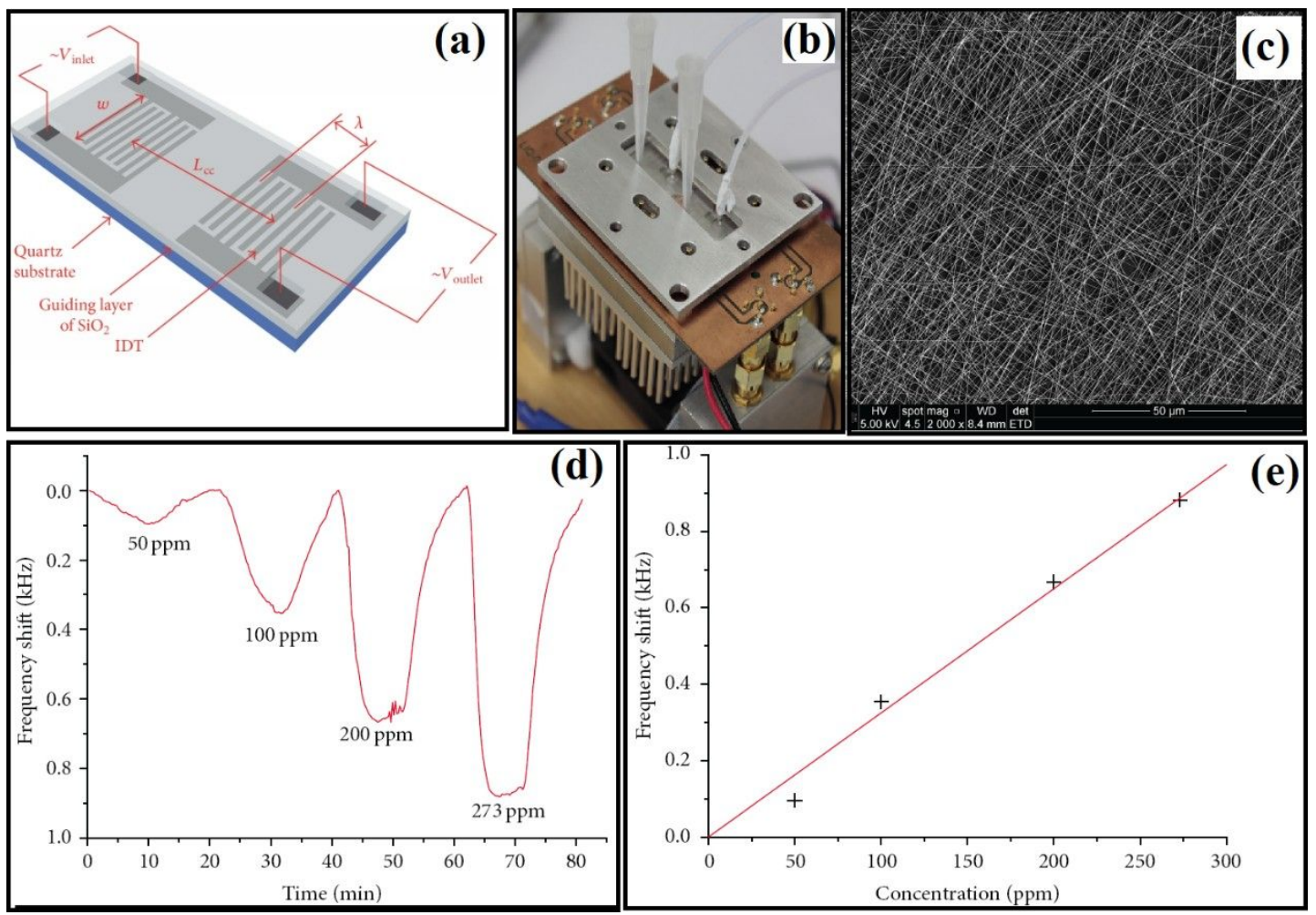

Figure 18: (a) 3D scheme representation; (b) real experimental setup of a Love-wave sensor with two RF ports, layer composition, and geometrical parameters; (c) SEM images of SAW resonators deposited with electrospun PVP nanofiber; (d) dynamic frequency shift of the SAW sensor with a sensitive layer of electrospun PVP nanofibers for different concentrations of toluene and (e) the linear relation between frequency shift and the concentration [250]. Images reproduced from [250], copyright 2017 Matatagui et al.

with an increase in humidity level. The sensor showed sensitivity up to $427.6 \mathrm{kHz} / \% \mathrm{RH}$ with excellent linearity $(\mathrm{R} 2>0.98)$ in the range from $10 \% \mathrm{RH}$ to $80 \% \mathrm{RH}$. The dynamic response of the sensor indicates a very short response time $<3$ s [252].

\subsection{Quartz crystal microbalance gas sensors}

Gas sensors based on a quartz crystal microbalance (QCM) offer superior sensitivity and resolution compared to other types of sensors because frequency is a quantity that can be measured with a very high degree of accuracy and precision [252,253]. QCMs are cost-effective and eliminate the need for timeconsuming sample preparation to suit a particular type of transducer. Other benefits of QCM sensors include room temperature operation and simple packaging requirements. QCMs are usually fabricated from thin disks of quartz, with circular electrodes patterned on both sides, onto which electrical signals are applied. The piezoelectric crystal transforms the electric signal applied on the metal pads to acoustic waves. In a simplified model from Sauerbrey [254], the wavelength of the oscillation is half the crystal thickness. The natural frequency of the resonant acoustic waves is determined by the crystal thickness.
When a mass is deposited on the crystal, it increases the thickness, increasing the wavelength of the acoustic waves, i.e., decreasing the frequency. The relationship between the change in the oscillation frequency, $\Delta f$, of a QCM to the change in mass added to the surface of the crystal, $\Delta m$, is given by the Sauerbrey equation $[12,253,254]$ :

$$
\Delta f=\frac{-2 \Delta m f_{0}^{2}}{A \sqrt{\rho u}}=\frac{-2 \Delta m f_{0}^{2}}{A \rho v},
$$

where $f_{0}$ is the resonant frequency of the crystal, $A$ is the area of the crystal, and $\rho, u$ and $v$ are the density, shear modulus and shear wave velocity of the substrate, respectively. As can be seen, any variations in mass changes the oscillating frequency, making the QCM suitable for sensing applications. The QCM response is measured as a change in the frequency per change in mass on the device unit area. As the operational frequency increases, or as the crystal thickness decreases, the QCM sensitivity increases. For example, the mass detection limit for a $10 \mathrm{MHz}$ QCM can be measured to about less than $1 \mathrm{ng} / \mathrm{cm}^{2}$ [255]. 
4.3.1 Non-conducting polymer: A PVP fibrous membrane based QCM device has been used for ethanol sensing [256]. The sensitivity of the sensor is improved by increasing the PVP concentration with a maximum response at $12 \% \mathrm{PVP}$ and then sensitivity decreases at higher concentrations. For low concentrations of PVP, the fibers show beads that reduce the overall surface area. On the other hand, higher PVP concentrations $(>12 \%)$ resulted in thicker fibers and the surface area reduces with a corresponding decrease in gas sensing response. As the vapour concentration increases, the sensitivity increases for two distinct patterns: a Langmuir pattern for a low concentration $(5-15 \mathrm{mg} / \mathrm{L})$ and convex for high concentrations $(>17.5 \mathrm{mg} / \mathrm{L})$ of the ethanol vapour. The surface area can be increased by increasing the thickness of fibrous membrane on the QCM, but diffusion of the gas takes more time with a thick porous layer and results in an increase in response time. The number of adsorption sites and sample porosity are enhanced by increasing the thickness of the fibrous layer [256].

Nanoporous polystyrene (PS) fibrous membrane functionalized by the polyethyleneimine (PEI) deposited on the QCM has been used for formaldehyde sensing [257]. The morphology and surface area of the fibrous PS membranes with fiber diameter of $110-870 \mathrm{~nm}$ are controllable by tuning the concentrations of PS solutions. PEI particles are found in clusters on the surface of a bead-on-string morphology after being functionalized by PEI. The fibers formed from $7 \mathrm{wt} \%, 10 \mathrm{wt} \%$ and $13 \mathrm{wt} \%$ PS solution have a bead-on-string morphology consisting of thin fibers (average diameter of $266 \mathrm{~nm}, 294 \mathrm{~nm}$ and $500 \mathrm{~nm}$, respectively) with numerous micrometre-sized beads along the fiber axis. This morphology may be due to the low viscosity of the solution used for electrospinning. On the other hand, beads are preferred in order to prevent separation between the fibrous membrane and the QCM electrode. The high-resolution images of the NFs show that fibers have well developed nano-textures with a rough surface morphology and the beads also show a porous structure. PS fibers that are formed from 10 and 13 wt \% PS solutions show surface area values of $37.23 \mathrm{~m}^{2} / \mathrm{g}$ and $47.25 \mathrm{~m}^{2} / \mathrm{g}$, respectively. The NFs from the $13 \mathrm{wt} \%$ PS solution have the largest fiber diameter but also have the highest surface area because of a porous structure. PEI particles with diameter of $50 \mathrm{~nm}$ to $1.2 \mu \mathrm{m}$ are randomly distributed over the surface of fibrous PS membranes [257].

The maximum frequency shifts of the QCM-based PEI-PS (7 wt \%) sensor exposed to $10,30,70$, and $140 \mathrm{ppm}$ of formaldehyde are 7, 8, 14, and $19 \mathrm{~Hz}$, respectively. The sensor based on PEI-PS with 10 and $13 \mathrm{wt} \%$ NFs shows a maximum frequency shift of 7 and $15 \mathrm{~Hz}$, respectively. On the other hand, the maximum frequency shifts of the QCM-based PEI-PS (7, 10 , and $13 \mathrm{wt} \%$ ) sensors are 19,43 , and $75 \mathrm{~Hz}$, respectively for
$140 \mathrm{ppm}$ of formaldehyde. When exposed to $140 \mathrm{ppm}$ of formaldehyde, the maximum frequency shifts of the QCMbased PEI-PS sensors with various PEI coating loadings (1000, 2000, and $6000 \mathrm{~Hz}$ ) are 5, 33, and $75 \mathrm{~Hz}$, respectively. The developed sensor also shows excellent selectivity for formaldehyde [257].

A polyethyleneimine (PEI) functionalized polyamide 6 (PA 6) nanofibrous net (NFN) (PEI-PA 6 NFN) has been evaluated for formaldehyde sensing using a QCM platform [258]. The NFN structure contains a nanofibrous web as shown in Figure 19b (inset). This NFN membrane shows advantages of large specific surface area, high porosity, large stacking density and strongly tight adhesive force to the devices. These advantages result in ready facilitation of analyte diffusion and oscillation transmission into the membranes. Figure 19a-f shows SEM images of a 2D spider-web like nano-net comprising interlinked ultathin nanowires with a diameter of $26 \mathrm{~nm}$. These 1D nanowires are supported by conventional electrospun PA 6 fibers [258]. A response of $1.4 \mathrm{~Hz}$ toward $1 \mathrm{ppm}$ formaldehyde has been measured for PEI flat film based QCM sensors. These sensors show maximum frequency shifts of 3.8, 5.7, 9.7, 13.9 and $19.0 \mathrm{~Hz}$ upon exposure to 5, 15, 35, 70 and $100 \mathrm{ppm}$ fomaldehyde, respectively. However, in comparison a maximum frequency shift of 2.4 and $4 \mathrm{~Hz}$ has been measured for the PEI-PZ 6 NFN (20 and $30 \mathrm{kV}$ ), respectively under the same conditions. As shown in Figure 19g, maximum responses of 19.0, 25.6 and $52.8 \mathrm{~Hz}$ toward $100 \mathrm{ppm}$ formaldehyde for QCM sensors coated with PEI flat film, PEI-PA 6 NFN $(20 \mathrm{kV})$ and PEI-PA $6 \mathrm{NFN}$ $(30 \mathrm{kV})$ have been measured [258]. Similarly, PANI functionalized PA6 nanofibers were used for $\mathrm{HCl}$ gas detection using QCM with a detection limit of $7 \mathrm{ppb}$ at RT [259].

4.3.2 Conducting polymer: Polyacrylic acid (PAA) has proven to be one of the best polyelectrolyte sensing materials for ammonia and trimethyleamine (TMA) because of the interaction between analyte molecules and the carboxyl groups of PAA [260,261]. The PAA fibrous membrane (FM) morphologies for different ratios of water/ethanol (100/0, 50/50, and $0 / 100)$ result in an average diameter of $1.1 \mu \mathrm{m}, 6.7 \mu \mathrm{m}$, and $2 \mu \mathrm{m}$, respectively. A PAA fibrous membrane formed with water as the solvent shows the highest response (232) to $1 \mathrm{ppm}$ of ammonia compared with those obtained from the mixed solvent and pure ethanol [260]. A low detection limit up to $130 \mathrm{ppb}$ for ammonia at a relative humidity of $40 \%$ is measured. The maximum frequency shift of PAA-QCM sensors is 113,60 , and $94 \mathrm{~Hz}$ when formed from $\mathrm{H}_{2} \mathrm{O}$ /ethanol with weight ratios of $100 / 0,50 / 50$, and $0 / 100$, respectively. The maximum frequency shift of the PAA-QCM sensors exposed to $130 \mathrm{ppb}, 450 \mathrm{ppb}, 1 \mathrm{ppm}, 2 \mathrm{ppm}$, and $5 \mathrm{ppm}$ of ammonia is 12 , $37,60,111$, and $232 \mathrm{~Hz}$, respectively. The maximum frequen- 

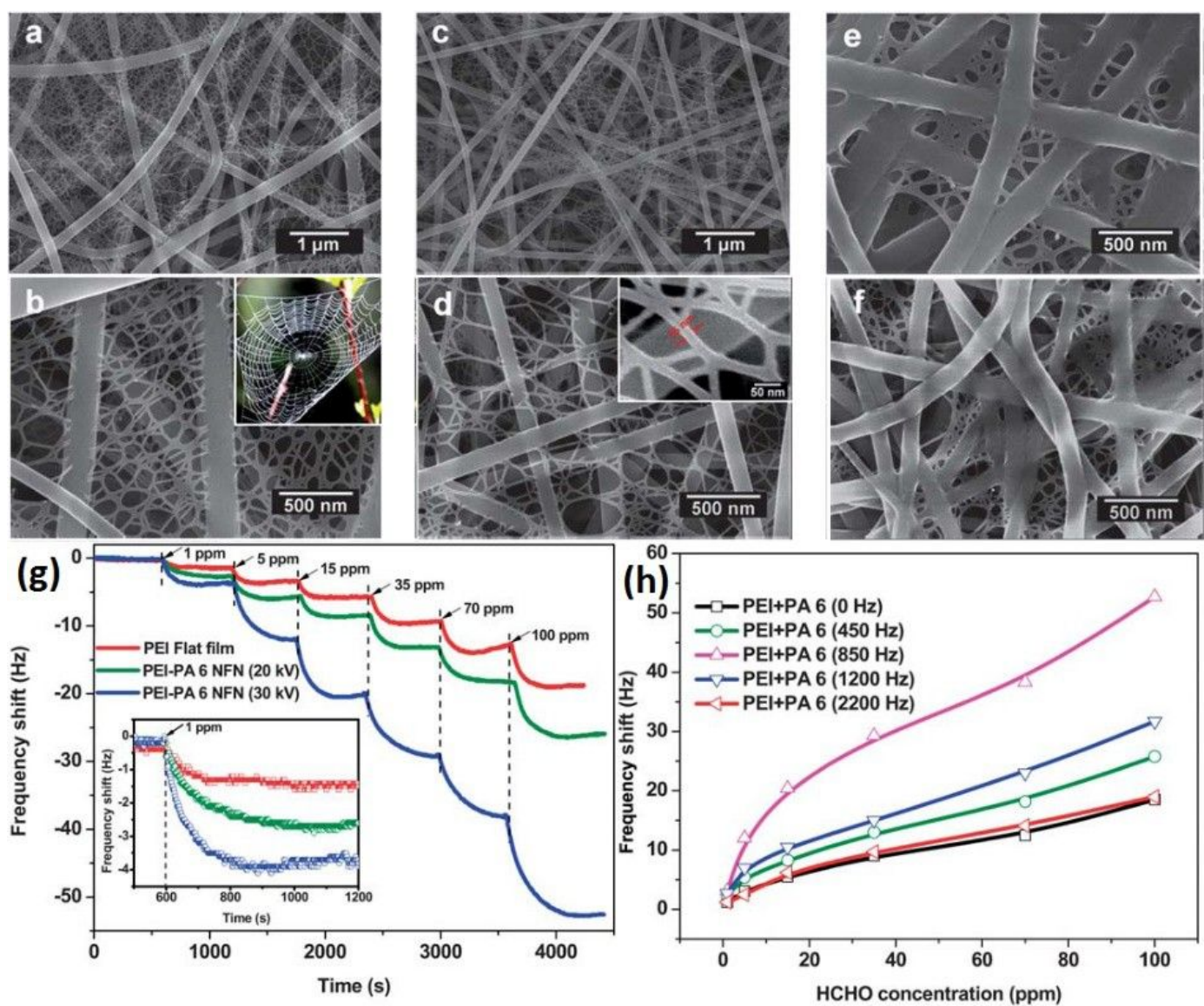

Figure 19: FE-SEM images of PA 6 NFN membranes formed with different voltages: (a, b) $20 \mathrm{kV}$ and (c, d) $30 \mathrm{kV}$; and their corresponding samples modified with PEI: (e) PEI-PA 6 (20 kV) and (f) PEI-PA 6 (30 kV). Inset of (b) shows the optical image of the spider-web morphology. (g) Dynamic response of QCM sensors coated with three different sensing structures upon exposure to increased formaldehyde concentrations. The inset is the amplified image for $1 \mathrm{ppm}$ formaldehyde detection; (h) dependence of frequency shift for QCM-based PEI-PA 6 NFN (30 kV) sensors with various PA 6 coating loadings on formaldehyde concentration (1-100 ppm). Reproduced with permission from [258], copyright 2011 Royal Society of Chemistry.

cy shift of the PAA-QCM sensors increases with increase in the coating load. Sensors with higher coating loadings show a higher response for the same concentration of ammonia. The effect of humidity is linear for the PAA-QCM sensors. The frequency shifts increase from 32 to $225 \mathrm{~Hz}$ with increased relative humidity from $25 \%$ to $45 \%$, because $\mathrm{H}_{2} \mathrm{O}$ molecules are pre-sorbed by the high proportion of hydrophilic carboxyl groups of PAA in the fibrous membranes [260]. The morphology of the PAA nanofibrous membrane has been changed to nanonet (nanofibers interconnected with a web like nanosheet) by adding a certain amount of $\mathrm{NaCl}$ into PAA, which further increases the surface area as well as the sensing properties [261].

Poly(styrene-block-maleic acid) (PS- $b$-PMA) NFs have been used as a novel sensing layer for QCM-based ammonia sensors [262]. PS- $b$-PMA, a block copolymer, is an ideal sensing material due to the interaction between ammonia molecules and carboxyl groups of PS- $b$-PMA. Different specific surface areas of PS- $b$-PMA are synthesized and named as samples A-F with respect to the mixture weight ratio of acetone/DMF at $0 / 10,1 / 9$, $1 / 4,1 / 3,3 / 7$ and $5 / 5$, respectively. The fiber diameters are broadly distributed in the range of 261-744 nm, although the majority are distributed in the $364-485 \mathrm{~nm}$ range. The specific surface area is varied by controlling the acetone concentration in a mixture of acetone and DMF. The specific surface areas for samples A-F are 1.9, 2.7, 3.7, 4.6, 3.6 and $0.9 \mathrm{~m}^{2} / \mathrm{g}$, respectively [262]. The frequency shifts of the PS- $b$-PMA nanofibrous films exposed to $1.5,2.5,5,10,25$ and $50 \mathrm{ppm}$ of ammonia are $0.1,0.6,1.2,1.5,6.5$ and $28.2 \mathrm{~Hz}$, respectively. The frequency shifts of all sensors show good linear change with increased ammonia concentration. The developed sensors also show good reversibility by drying with nitrogen. In addition, the sensor shows similar frequency shifts with repeated injection of the same ammonia concentration in three experiments [262].

Jia et al. [263] report on the use of phenyl acetic acid (PA)modified polystyrene (PS) nanofibrous membranes as the sensing material for the detection of ammonia in a QCM-based 
gas sensor. The sensing layer is prepared by PS NFs and later PA was dispersed on the surface of the NFs. The average diameter of the PS and PA modified nanofibers are $474 \mathrm{~nm}$ and $488 \mathrm{~nm}$, respectively. The frequency shifts in the PS/PA-coated QCM sensors exposed to 1.5, 5, 10, 25 and $50 \mathrm{ppm}$ of ammonia are $0.5,1.1,1.2,2.1$ and $0.4 \mathrm{~Hz}$, respectively. The developed sensor detects concentrations as low as $1.5 \mathrm{ppm}$ of $\mathrm{NH}_{3}$. The response shows a decline for increased ammonia concentrations [263].

4.3.3 Conducting/Non-Conducting Polymer Blend: A poly(acrylic acid) (PAA) and poly(vinyl alcohol) (PVA) blend has been used as a sensing layer with a QCM sensing platform for $\mathrm{NH}_{3}$ detection [264]. In this blend, PVA - which is water soluble - is used as a template, thus a strong bond between the PAA and water facilitates fiber formation and water evaporation. The viscosity of solutions increases with an increase in the weight percentage of PAA to PVA due to hydrogen bonding between carboxyl groups of PAA and hydroxyl groups of PVA. The conductivity of blend solutions is also increased from 74.9 to $102.2 \mathrm{mS} / \mathrm{m}$ with increased weight percentage of PAA to PVA from 11 to $33 \mathrm{wt} \%$ [264]. The average NF diameter increase from 200 to $330 \mathrm{~nm}$ with increased weight percentage of PAA to PVA from 0 to 33 wt \%. The PVA nanofibrous membrane remains insensitive to $\mathrm{NH}_{3}$ whereas $11,18,25$, and $33 \mathrm{wt} \%$ of PAA to PVA blended nanofibrous membranes show average resonance frequency shifts of 40,150,240, and $380 \mathrm{~Hz}$, respectively. The frequency shift increases with an increase in PAA concentration into the blend. The average frequency shift for 50,100 and $200 \mathrm{ppm}$ is 150,410 , and $730 \mathrm{~Hz}$, respectively. The frequency shift increases from 12 to $46 \mathrm{~Hz}$ with increased relative humidity from 50 to $60 \%$. The frequency shift of $18 \mathrm{wt} \%$ PAA to PVA at the relative humidity of 50,55 , and $60 \%$ is 65,150 , and $330 \mathrm{~Hz}$ when exposed to $50 \mathrm{ppm}$ of $\mathrm{NH}_{3}$ [264,265]. Electrospun nanofibers synthesised by blending polyvinylamine (PVAm) and polyacrylonitrile (PAN) has been deposited on QCM and utilized for formaldehyde sensing [266]. The developed sensor showed an extremely low detection limit of $500 \mathrm{ppb}$ with rapid response time of $120 \mathrm{~s}$. The developed sensor showed maximum a frequency shift of 0.2, 0.4, 0.7, 2.5, $4.2 \mathrm{~Hz}$ upon exposure to $0.5,1,5,15,35 \mathrm{ppm}$ of formaldehyde, respectively [266].

4.3.4 Semiconducting metal oxide: A nanostructured complex of polyethyleneimine (PEI)-functionalized $\mathrm{TiO}_{2} \mathrm{NFs}$ $\left(\mathrm{PEI}-\mathrm{TiO}_{2}\right)$ has been used as a sensing layer on a QCM for formaldehyde detection [21]. The developed sensor shows a high sensitivity of 13.7 toward $100 \mathrm{ppm}$ of formaldehyde and a low detection limit of $1 \mathrm{ppm}$ of formaldehyde at room temperature. The NFs have a porous structure with an average diameter of $625 \mathrm{~nm}$. The highly porous structure of the fibers may be due to rapid phase separation during the calcination process. $\mathrm{TiO}_{2}$ fibre morphologies change after dispersion with ethylene glycol (EG). $\mathrm{TiO}_{2}$ nanoparticles are transferred to the surface of fibers, perhaps during the magnetic stirring, thus leading to the hollow structure of these fibres. The QCM sensor, coated with only $\mathrm{TiO}_{2}$ fibers, exhibits a frequency shift of only $0.2 \mathrm{~Hz}$ upon exposure to $1 \mathrm{ppm}$ formaldehyde vapour. The frequency shift of the $\mathrm{TiO}_{2}$ fiber-coated QCM sensors exposed to 5, 15, 35, 70 and $100 \mathrm{ppm}$ of formaldehyde is $0.3,0.5,0.9,1.2$ and $1.6 \mathrm{~Hz}$, respectively. On the other hand, frequency shifts of 0.4 and $0.8 \mathrm{~Hz}$ toward $1 \mathrm{ppm}$ formaldehyde vapour were observed for a PEI coating at loadings of 2700 and $6600 \mathrm{~Hz}$. The PEI coating load of $6600 \mathrm{~Hz}$ shows a maximum response of $13.7 \mathrm{~Hz}$ to $100 \mathrm{ppm}$ formaldehyde, which is eight times more than the response for the sensor based on $\mathrm{TiO}_{2}$ fibers [21]. Similarly, electrospun $\mathrm{ZnO}$ and $\mathrm{CeO}_{2} / \mathrm{ZnO} \mathrm{NF}$ has been deposited directly on the QCM electrodes and been annealed in air at $500{ }^{\circ} \mathrm{C}$ for 5 hours. The developed QCM sensors were applied for volatile organic compound (VOC) sensing (such as benzene, propanol, ethanol and dichloromethane) [267]. The average diameter before annealing was $315 \pm 95$ and $270 \pm 70 \mathrm{~nm}$, which reduced to $160 \pm 55 \mathrm{~nm}$ for $\mathrm{ZnO}$ and $110 \pm 30 \mathrm{~nm}$ for $\mathrm{CeO}_{2} / \mathrm{ZnO}$ fibers, respectively (Figure 20a,b). The dynamic response of the sensors is shown in Figure 20c, where the maximum frequency shift is $116 \mathrm{~Hz}$ and $147 \mathrm{~Hz}$ toward $456 \mathrm{ppm}$ of benzene vapors for $\mathrm{CeO}_{2} / \mathrm{ZnO}$ and $\mathrm{ZnO}$ fibers, respectively (Figure 20d). On the other hand, the sensor shows a poor selectivity toward benzene in an interfering environment of propanol, dichloromethane and ethanol (Figure 20e) [267].

\subsubsection{Graphene-conducting/non-conducting polymer com-} posite: Nanostructured complexes based on carboxyl graphene oxide (G-COOH) and polystyrene (PS) NFs have been utilized for ammonia detection based on a QCM platform [268]. The G-COOH/PS NFs (average diameter of $569 \mathrm{~nm}$ ) consist of nanowires of diameter $37 \mathrm{~nm}$. SEM images of the G-COOH/PS composite NFs indicate a mesoporous structure and that G-COOH sheets are randomly distributed within NFs (Figure 21a,b). The G-COOH shows a selective interaction between ammonia and the carboxyl group. The pure PS fibers show a beads-on-string morphology with an average diameter of $1 \mu \mathrm{m}$, whereas G-COOH/PS composite NFs show a random fiber morphology with an average diameter of $569 \mathrm{~nm}$. Both types of NFs show nanowires with an average diameter of $37 \mathrm{~nm}$. The diameter of the G-COOH/PS composite NFs is less than that of the pure PS NFs, which may be due to an increase in electrical conductance of the composite solution after addition of G-COOH [268].

The pure PS nanofibrous membrane shows an insignificant response for all concentrations less than $30 \mathrm{ppm} \mathrm{NH}_{3}$ with a 


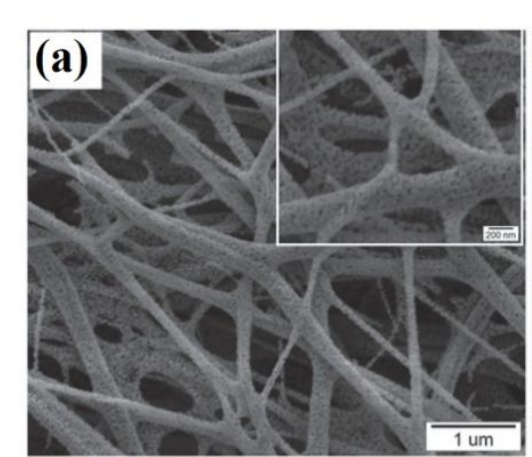

(c)

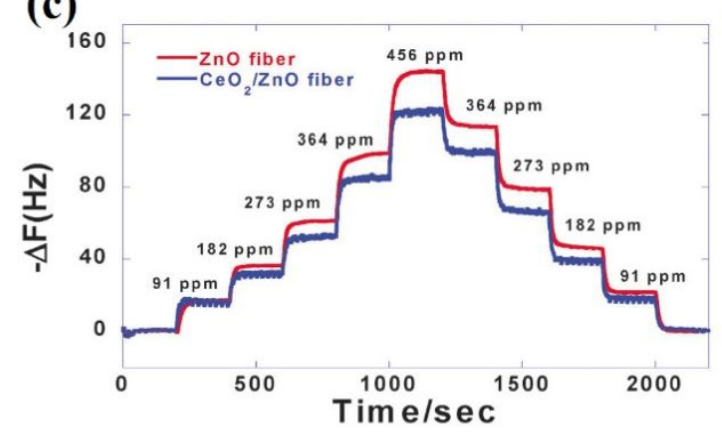

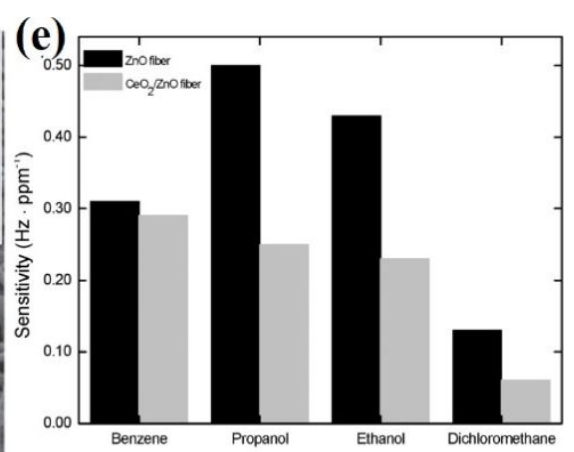

(d)

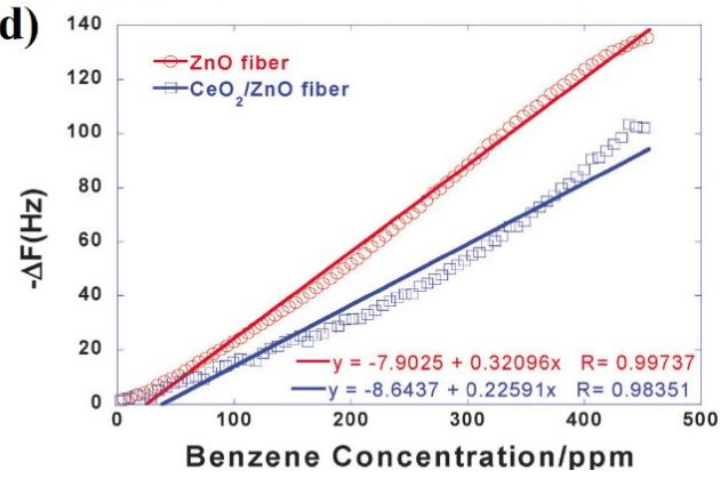

Figure 20: SEM images of (a) $\mathrm{ZnO}$ and (b) $\mathrm{CeO}_{2} / \mathrm{ZnO}$ nanofibers; (c) The step response for adsorption and desorption of benzene with $\mathrm{ZnO}$ and $\mathrm{CeO}_{2} / \mathrm{ZnO}$ fiber coated QCMs. (d) The linear adsorption response of $\mathrm{ZnO}$ and $\mathrm{CeO}_{2} / \mathrm{ZnO}$ fibers as a function of benzene concentration. (e) Sensitivity of the $\mathrm{ZnO}$ fiber and $\mathrm{CeO}_{2} / \mathrm{ZnO}$-coated sensor to benzene, propanol, ethanol and dichloromethane vapours. Reproduced with permission from[267], copyright 2014 Royal Society of Chemistry.

maximum frequency shift of 0.5 and $0.3 \mathrm{~Hz}$ at 30 and $40 \mathrm{ppm}$, respectively. The frequency shift of the G-COOH/PS nanofibrous membrane coated QCM sensor exposed to 1, 3, 10, 20, 30 and $40 \mathrm{ppm}$ of ammonia is $0.3,0.5,1.8,4.8,4$ and $3.5 \mathrm{~Hz}$, respectively (Figure 21c). A reversibility test was performed using $\mathrm{N}_{2}$ gas inserted after the sensor attained saturated. By exposing the sensor to repeated adsorption-desorption cycles, good reversibility of the as-prepared sensor was observed (Figure 21d) [268].

\subsection{Optical gas sensors}

Recently, optical sensors have attracted a great deal of interest due to their exceptional physical property and mechanical advantages. An optical transducer is a new type of platform for sensing which is known to have better gas selectivity compared to other types of sensors [269]. Furthermore, optical sensors show immunity to electromagnetic interference (EMI) which allows for a wide range of applications not possible with other sensors. In addition, optical sensors are resistant to corrosive, reactive and flammable environments [270]. These sensors are able to integrate with existing fiber networks for remote and distributed sensing capabilities. Different spectrophotometric techniques have been developed, the most common being absorbance/transmittance/reflectance, Raman, Fourier-transform infrared spectroscopy (FTIR) spectroscopy and surface plasmon resonance (SPR).

PAN/ZnO composite nanofibers have been synthesized by combining atomic layer deposition (ALD) with electrospinning and applied to optical gas sensing of VOCs [271]. The $\mathrm{ZnO}$ layer is deposited on PAN nanofibers using ALD. The gas sensing characteristics are measured by photoluminescence (PL) spectroscopy at room temperature using a solid-state laser with wavelength $355 \mathrm{~nm}$. The ZnO NFs are obtained with 5 min deposition time for electrospinning and coated with 50 cycles of ALD $\mathrm{ZnO}$ at $100{ }^{\circ} \mathrm{C}$. The thickness of the $\mathrm{ZnO}$ coating at $20 \mathrm{~nm}$ was confirmed by TEM. The ZnO/PAN NFs show two emission bands, i.e., near-band emission (NBE) and deep-level emission (DLE). ZnO/PAN NFs exhibit a change in PL in an ethanol environment. The introduction of ethanol increases the NBE and decreases the DLE. The ratio of the NBE peak intensity and DLE before and after ethanol exposure is $0.83 \pm 0.04$ and $1.31 \pm 0.03$ toward $150 \mathrm{ppm}$ of ethanol at room temperature, respectively [271].

Electrospun composite NFs of PAN containing metal oxide nanoparticles $\left(\mathrm{Fe}_{2} \mathrm{O}_{3}, \mathrm{ZnO}\right)\left(10 \% \mathrm{Sb}_{3} \mathrm{O}_{4}, 90 \% \mathrm{SnO}_{2}\right)$ have been synthesized and applied to $\mathrm{CO}_{2}$ sensing using FTIR spectrosco- 

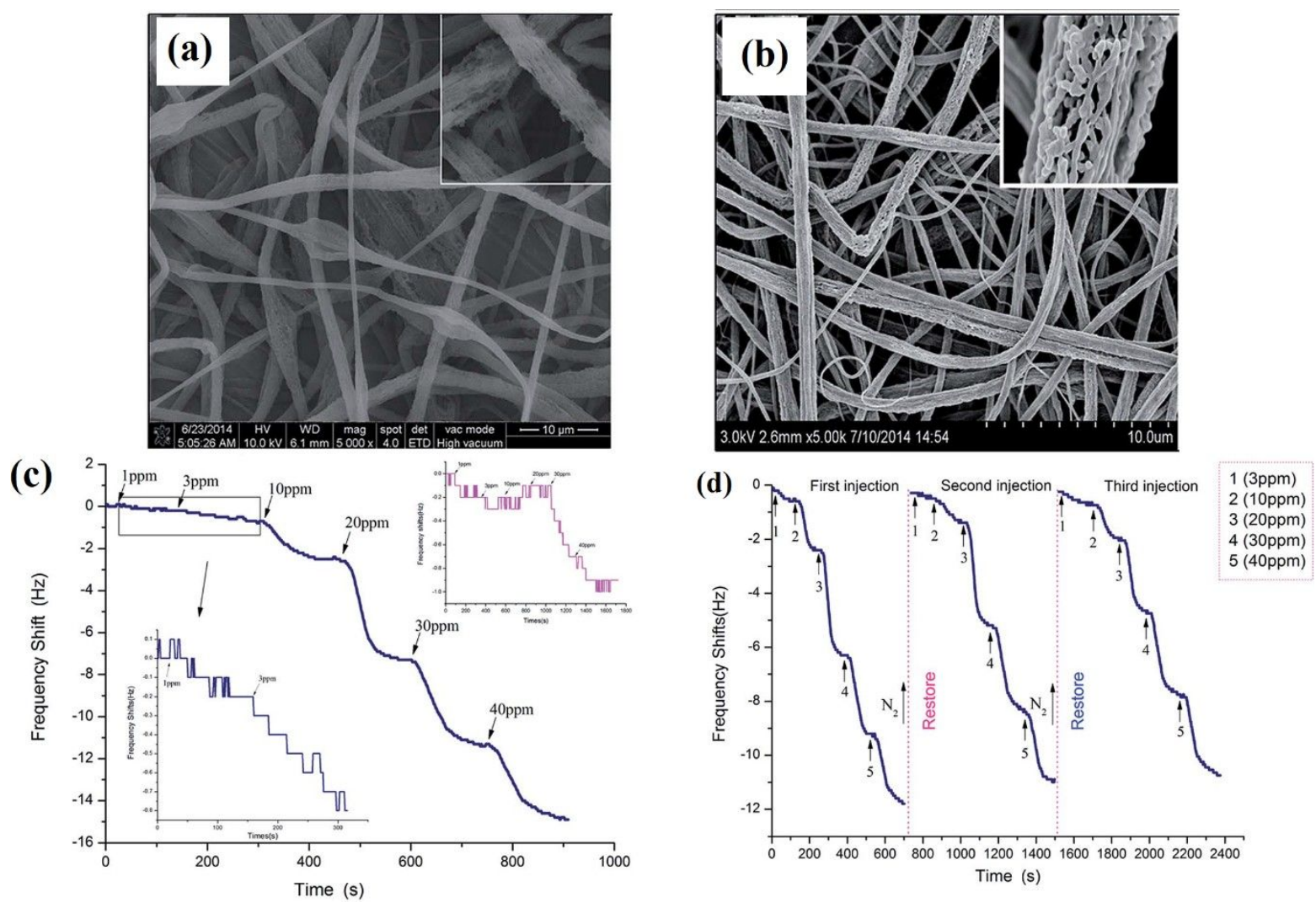

Figure 21: FE-SEM images of electrospun (a) pure porous PS NFs and (b) G-COOH/PS composite NFs. (c) Dynamic response of G-COOH/PS NFs to $\mathrm{NH}_{3}$; inset shows the response of PS NFs. (d) Reversibility testing for QCM sensors coated with G-COOH/PS membranes upon exposure to increased ammonia concentrations. Reproduced with permission from [268], copyright 2015 Royal Society of Chemistry.

py [272]. The average diameter of pure PAN NFs reduced from $200 \mathrm{~nm}$ to $50-150 \mathrm{~nm}$ for composite NFs while the porosity increased from $70 \%$ for pure PAN NFs to $86 \%$ for composite counterparts. The absorption spectrum in air without composite NFs was lower than spectra for composite NFs. The PAN/ $\mathrm{Fe}_{2} \mathrm{O}_{3}$ shows the highest absorption peak to $2000 \mathrm{ppm} \mathrm{CO}_{2}$ $\left(\mathrm{C}=\mathrm{H}\right.$ at $\left.2356 \mathrm{~cm}^{-1}\right)$ compared with the $\mathrm{PAN} / \mathrm{Sb}-\mathrm{SnO}_{2}$ $[26,272]$.

A fluorescence sensor has been developed for $\mathrm{CO}_{2}$ detection by using ion pair form of 8-hydroxypyrene-1,3,6-trisulfonic acid (HPTS) as a sensing material. Poly(methyl methacrylate) (PMMA) and ethyl cellulose (EC) are used as polymeric material whereas EC and PMMA have an average diameter in the range 370-527 nm (Figure 22a,b). The change in fluorescence spectra of electrospun materials as a function of different concentrations of $\mathrm{CO}_{2}$ is shown in Figure 22c,d. The fluorescence intensity decays with increasing $\mathrm{CO}_{2}$ concentration. The gaseous carbon dioxide converts into carbonic acid by reacting with water in nanofibers that interacts with the HPTS (fluorescent dye). The dynamic sensing results of both matrix materials are shown in Figure 22e, f for various concentrations of $\mathrm{CO}_{2}$.
The response and recovery time varies between $1-5 \mathrm{~min}$ for both matrix materials [273].

Electrospun fibers of a fluorescent conjugated polymer (P) (benzothiophene-based conjugated polymer with sulfur-containing fused rings as the backbone) has been applied as a sensing layer for detection of explosives, including picric acid (PA), trinitrotoluene (TNT), 2,4-dinitrotoluene (DNT), and nitrobenzene (NB) [2,3]. Polystyrene is applied as a supporting material and is doped with conjugate polymer $\mathbf{P}$ during electrospinning. The nanofibers have an average diameter in the range of 800-1000 nm. Fluorescence microscopy images of electrospun nanofibers before and after exposing nanofibers to TNT vapours show the fluorescence is dramatically quenched. The conjugate polymer $\mathbf{P}$ exhibits maximum florescence intensity at $4.1 \times 10^{-7} \mathrm{M}$ concentration of TNT. The fluorescence intensity decreases with an increase in explosive concentration. The order of fluorescence quenching efficiency is PA $>$ TNT $>$ DNT $>$ NB with values of $85 \%, 65 \%, 25 \%$ and $12 \%$. The order of efficiency follows the same sequence as the electron deficiency of these explosives. The electrospun nanofibers exhibit different sensing efficiencies for different explosives that is related to 

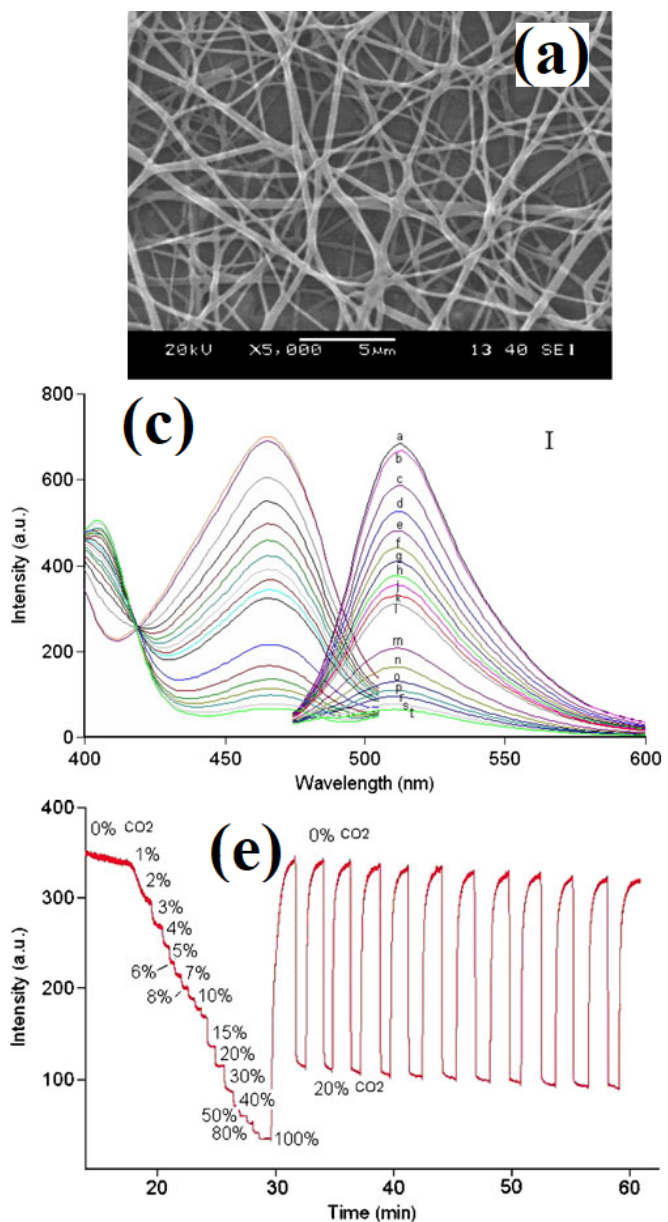
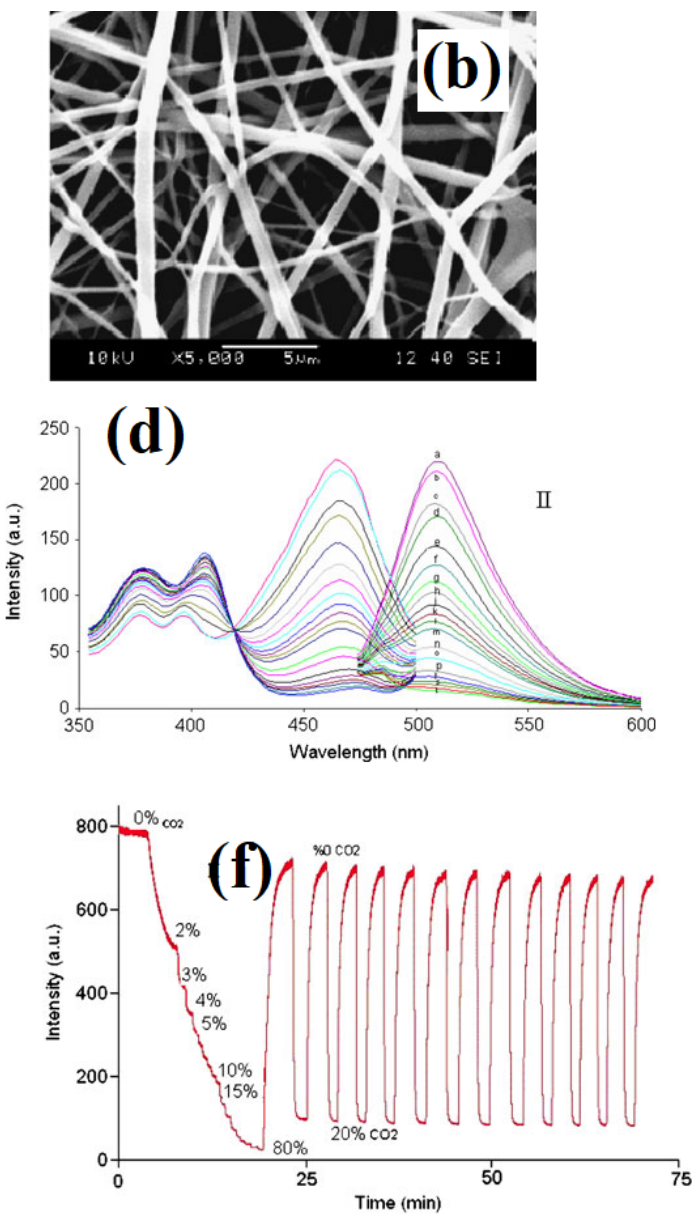

Figure 22: SEM images of electrospun nanofibrous membranes of (a) PMMA and (b) ethyl cellulose (EC). Excitation and emission spectra of electrospun fiber ion pair form of HPTS in (c) EC (d) PMMA after exposure to certain concentrations of $\mathrm{CO}_{2}\left(\lambda_{\max }(\mathrm{ex})=465 \mathrm{~nm}, \lambda_{\max }(\mathrm{em})=513 \mathrm{~nm}\right)-$ a: initial, b: $1 \% \mathrm{CO}_{2}$, c: $2 \%$, d: $3 \%$, e: $4 \%$, f: $5 \%$, g: $6 \%$, h: $7 \%$, i: $8 \%$, j: $8 \%$, k: $9 \%$, l: $10 \%$, m: $20 \%$, n: $30 \%$, o: $40 \%$, p: $50 \%$, r: $60 \%$, s: $80 \%$, and $\mathrm{t}: 100 \% \mathrm{CO}_{2}$. Emission-based kinetic response of ion pair form of HPTS in (e) EC and (f) PMMA to gaseous $\mathrm{CO}_{2}$. Reproduced with permission from [273], copyright 2010 Springer.

their vapour pressure and electron deficiency. The conjugate polymer $\mathbf{P}$ nanofibers show the highest quenching efficiency to $\mathrm{NB}$ at around 4 times that of DNT [2,3].

Fluorescent polymer nanofibers are used for the chemical sensing of explosives by electrospinning fluorescent polymer or by doping low cost polymers with fluorophores [274]. Xue et al. [274] has synthesized composite nanofibers based on $\mathrm{PEO} / \mathrm{MePyCz}$ (polyethylene oxide/4-(2-(2-(2-methoxyethoxy)ethoxy)ethoxy)-9-(pyren-1-yl)-9H-carbazole) for nitrocompound colorimetric sensing. The $\mathrm{PEO} / \mathrm{MePyCz} \mathrm{NFs}$ have an average diameter in the range of $0.8 \mu \mathrm{m}$ to $1.6 \mu \mathrm{m}$. Moreover, fluorescence microscopy images (FLM) of the fiber show evenly distributed blue-emitting sensing molecules of $\mathrm{MePyCz}$ in PEO nanofibers. The $\mathrm{PEO} / \mathrm{MePyCz}$ composite nanofibers are further functionalized by ThFO (2-(thiophen-2-yl)-fluoren-9one) to prepare $\mathrm{PEO} / \mathrm{MePyCz} / \mathrm{ThFO}$ composite colorimetric sensors, which change the emission from blue to cyan to green
(Figure 23a-c). The fluorescence spectra of PEO/MePyCz composite nanofibers toward DNT vapour is shown in Figure $23 \mathrm{~d}-\mathrm{g}$. The quenching efficiency of the $\mathrm{PEO} / \mathrm{MePyCz}$ composite nanofibers reached to $89 \%$ with the $0.5 \mathrm{wt} \%$ doping of $\mathrm{MePyCz}$ with no decay in ambient environment. The spincoated film of PEO/MePyCz shows an efficiency of $73 \%$. The selectivity of $\mathrm{PEO} / \mathrm{MePyCz}$ has also been tested against various nitro-compounds as shown in Figure $23 \mathrm{~h}$. The $\mathrm{PEO} / \mathrm{MePyCz}$ composite nanofibers do not show any quenching toward urea, ethanol and naphthalene [274].

Evanescent optical fiber humidity sensors have been fabricated using PAA nanofibers and tested for $30 \%$ to $95 \% \mathrm{RH}$ [275]. The PAA nanofibers are deposited on the optical core of the fiber optic cord. The samples synthesized with PAA solution with viscosity 47 and 49 cps are named as A and B. Samples made with different deposition times (which corresponds to different densities) are labelled as sample 1 (5 min), sample 2 

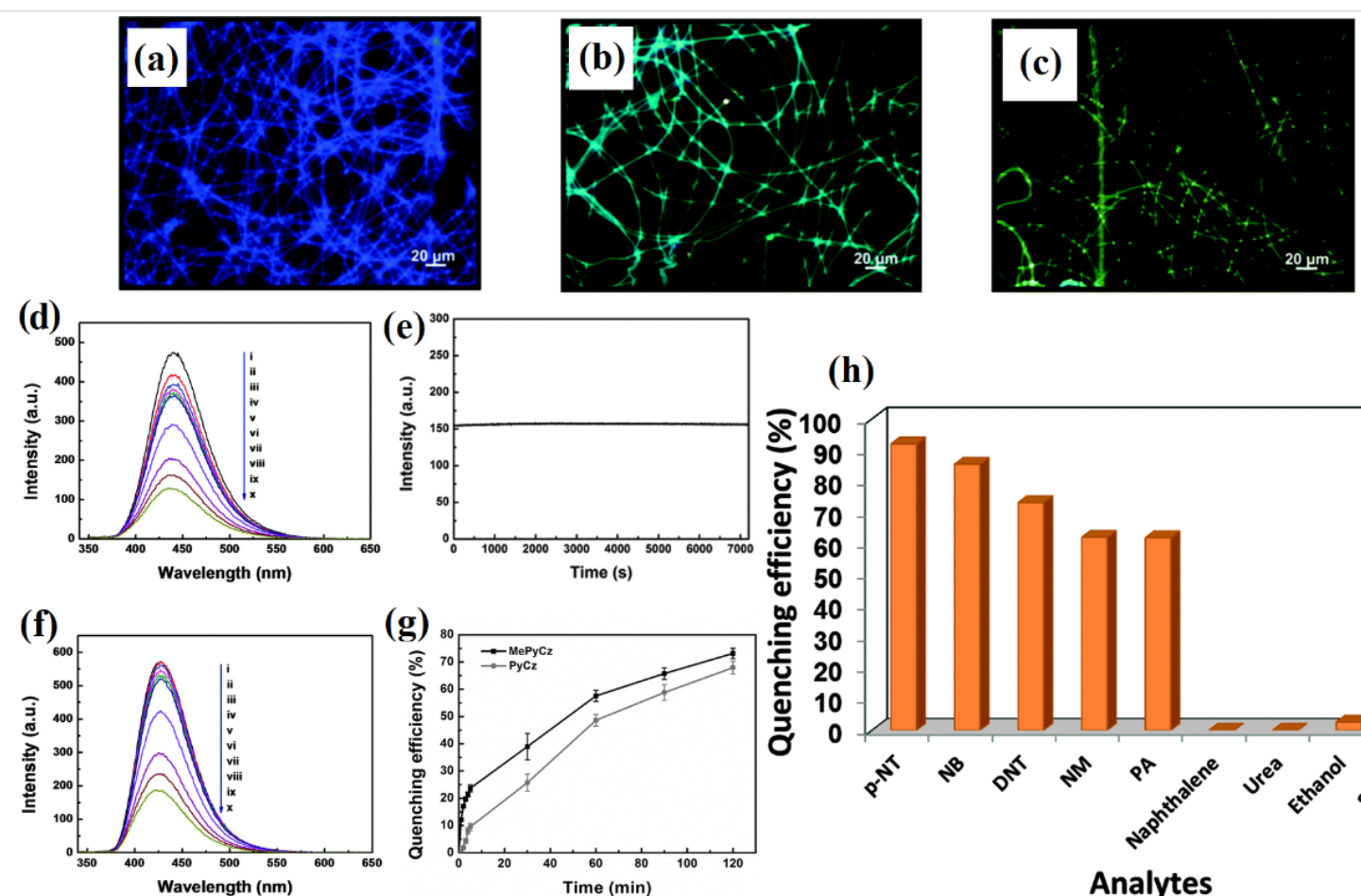

(g)

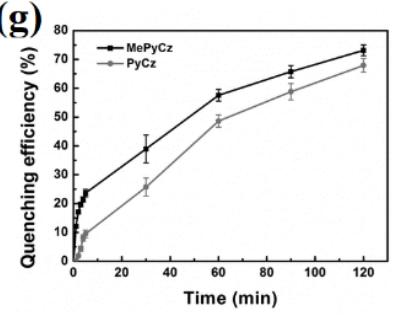

(h)

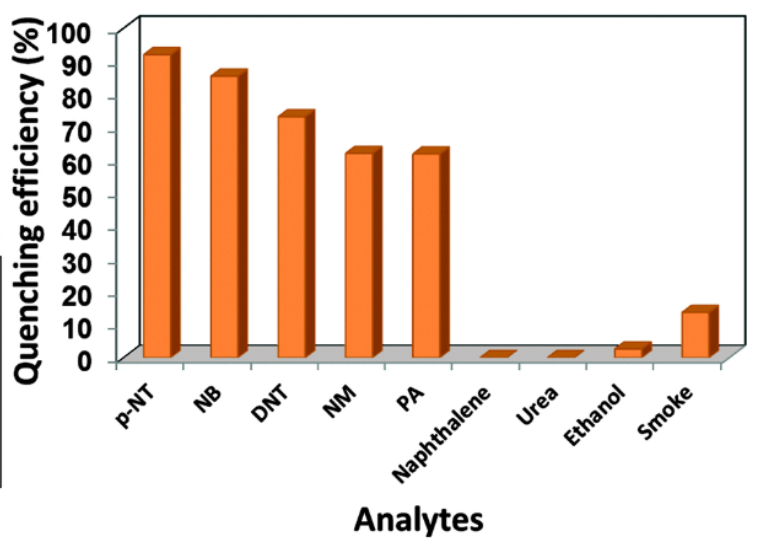

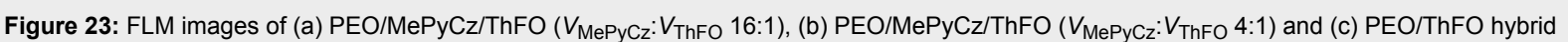
nanofibers. (d) Time-dependent fluorescence quenching process of PEO/MePyCz fibrous film toward DNT vapour (from i to x: 0, 1, 2, 3, 4, 5, 30, 60, 90, $120 \mathrm{~min} ; \lambda_{\mathrm{ex}}=330 \mathrm{~nm}$ ). (e) Time course curve of PEO/MePyCz hybrid fibrous film in ambient air without DNT. (f) Time-dependent fluorescence quenching process of PEO/PyCz fibrous film toward DNT in vapour (from i to x: 0, 1, 2, 3, 4, 5, 30,60, 90, $120 \mathrm{~min} ; \lambda_{\mathrm{ex}}=330 \mathrm{~nm}$ ). (g) The quenching efficiency curves versus exposure time with standard deviation error bars of three batches prepared at different times. (h) Fluorescence quenching efficiencies of PEO/MePyCz electrospun nanofibrous films toward various analytes. Reproduced from [274], copyright 2015 Royal Society of Chemistry.

(15 $\mathrm{min}$ ), and sample 3 (30 $\mathrm{min})$. The average fiber diameter for samples $1 \mathrm{~A}, 2 \mathrm{~A}$ and $3 \mathrm{~A}$ is $1.61 \pm 0.28 \mu \mathrm{m}, 1.54 \pm 0.32 \mu \mathrm{m}$, and $1.51 \pm 0.43 \mu \mathrm{m}$, respectively. In contrast, the average fiber diameter for samples $1 \mathrm{~B}, 2 \mathrm{~B}$ and $3 \mathrm{~B}$ is $0.59 \pm 0.15 \mu \mathrm{m}$, $0.48 \pm 0.09 \mu \mathrm{m}$ and $0.53 \pm 0.18 \mu \mathrm{m}$, respectively. The sensing characteristics of these optical fiber sensors depend dramatically on the electrospun nanofiber diameter and density of the electrospun nanofiber mat. The relative absorption spectrum of the sensor 1B shows that the absorption decreases with an increase in RH. The effect means that higher power is transmitted with higher relative humidity, resulting in lower absorption values. On the other hand, the 1A sensor with a lower density of nanofibers shows the opposite response to that of sample 1B. Losses from these electrospun nanofibers results in a decrease in optical transmittance. Highly dense nanofibers (3A and $3 \mathrm{~B}$ ) show slow response and high levels of hysteresis. The best results are obtained from the $1 \mathrm{~B}$ samples that have a thinner diameter and high fiber density. The response time for these samples is $340 \mathrm{~ms}$, with a recovery time of $210 \mathrm{~ms}$ [275].

Davis et al. [276] have developed a dual-mode optical sensor with electrospun nanofibers embedded with various polydiacetylene (PDAs). The four most common solvents have been identified using solvent-dependent fluorescent transition of nanofibers. Moreover, biomolecules has also been detected by biotinylated-PCDA monomers embedded into silica reinforced nanofiber mats. The nanofibrous mats are produced with a uniform fiber distribution of 400-600 nm for fluorescence experiments. PDA nanofibers show excellent fluorescence detection with a distinct fluorescence transition from blue to red against various organic solvents (hexane, methanol, chloroform, and THF). The optical and SEM images of nanofibers encapsulated with PCDA-biotin are shown in Figure 24a-c. The fibrous mat converts into blue phase under UV irradiation. The TEM images of the PEO/TEOS electrospun nanofibers mats encapsulated with PCDA-biotin, before and after UV-irradiation, shows no morphological change (Figure 24d,e). Volatile amine groups are identified using three-component PDA nanofibers with an exposure time of $30 \mathrm{~min}$ and results are shown in Figure $24 \mathrm{f}$ [276].

Polydimethylsiloxane (PDMS) containing polycaprolactone (PCL) core-shell nanofibers have been synthesized by electrospinning and used as an optical oxygen sensor [277]. The nanofibers consist of two parts PDMS containing $0.1 \%$ ruthenium(II) dichloride $(\mathrm{Ru}(\mathrm{dpp})(\mathrm{Cl}))$, moisture-cured PDMS con- 

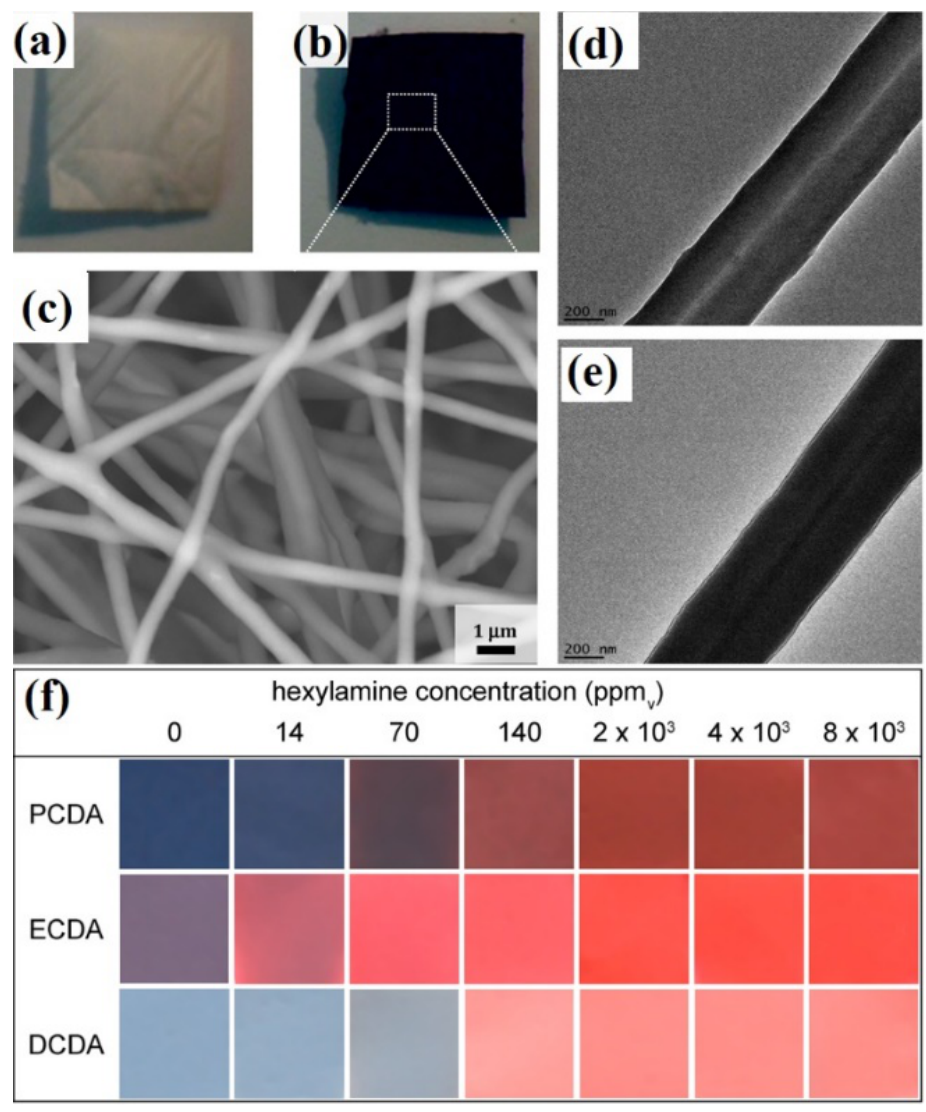

Figure 24: Photographs of electrospun fiber mat embedded with PCDA-biotin before (a) and after (b) UV-irradiation (1 $\mathrm{mW}^{\mathrm{cm}}{ }^{-1}$ ) for $5 \mathrm{~min}$. (c) SEM image of the nanofibers containing polymerized PCDA-biotin. (d, e) TEM images of PCDA-biotin nanofibers before and after UV-irradiation.

(f) Flatbed scanner images illustrating the colorimetric response of a polydiacetylene-embedded nanofiber sensor array to various concentrations of hexylamine vapour. Reproduced from [276], copyright 2014 ACS.

taining $0.5 \%$ weight doping ratio of ruthenium(II) tetraphenylboron $(\mathrm{Ru}(\mathrm{dpp})(\mathrm{PB}))$, and moisture-cured PDMS containing $0.5 \%$ weight doping ratio platinum (II) octaethylporphyrin (PtOEP), labelled as S1, S2, and S3. The core-shell nanofibers of S1, S2, and S3 have average diameters of $512 \pm 195$, $401 \pm 131$, and $570 \pm 192 \mathrm{~nm}$, respectively. The S1, S2, and S3 core-shell fibers absorb visible light at $455 \mathrm{~nm}$ and emit red luminescence at 618,622 , and $645 \mathrm{~nm}$, respectively. The intensity of the emission is quenched with an increase in oxygen concentration without any peak shift. The sensitivity of the sensors is represented by the ratio of the intensity of an oxygen-free environment to the intensity of pure oxygen $\left(I_{0} / I_{100}\right)$. The $I_{0} / I_{100}$ ratios for S1-S3 are 2.97, 4.1, and 24, respectively. The response times of samples $\mathrm{S} 1-\mathrm{S} 3$ are $0.36 \pm 0.05 \mathrm{~s}$, $0.28 \pm 0.08 \mathrm{~s}$, and $0.49 \pm 0.13 \mathrm{~s}$, respectively. In addition, the recovery times are $0.72 \pm 0.27 \mathrm{~s}, 0.51 \pm 0.15 \mathrm{~s}$, and $0.70 \pm 0.15 \mathrm{~s}$, respectively [277].

Electrospun nanofibers based on analyte-sensitive dyes immobilized in polymer have been used as a sensing material in optochemical (luminescence) sensors for oxygen detection
$[278,279]$. Luminescence lifetime was measured by phase-shift fluorometry with a bluish-green light as an excitation source. Electrospun nanofibers are synthesized by mixing an oxygensensitive dye, platinum tetra(pentafluorophenyl) porphyrine (PtTFPP), with polystyrene. The fibers have a band-like morphology with a width of $620 \mathrm{~nm}$ and thickness of $100 \mathrm{~nm}$ at the thinnest part of the fiber. Moreover, the fibers are nanoporous on the surface which increases the diffusion of the analyte gas. The nanofibers are excited with a wavelength of $505 \mathrm{~nm}$. The electrospun film shows slightly enhanced sensitivity compared with a thick film. The electrospun film shows almost a two times faster response time $(2.2 \mathrm{~s})$ compared with that of the thick film (4 s). One drawback with electrospun films is the degradation of a polymer dye due to enhanced accessibility of oxygen; this is commonly known as photo bleaching. With this approach, photo bleaching may be controlled by increasing the thickness of the electrospun film to a moderate range [278,279].

\section{Future Perspectives and Conclusion}

In summary, we have reviewed recent progress and achievements in the rapidly emerging field of gas sensing using electro- 
spun 1D nanostructures. The dominant 1D nanostructures used to date in this field include nanofibers, nanowires, hollow nanofibers and nanotubes although other forms are known. The chemical, electrical, optical and gravimetric response to different target gases are compiled for many materials, including pure semiconducting metal oxides (MOx), MOx functionalized by noble/rare-earth/transition metals, MOx-MOx composites, conjugate polymer-MOx and graphene-MOx composites. In addition, these responses are, to a large degree, dependent on many different fibrous assemblies that are possible, including mixed nanocomposites, double-layer and core-shell structures and hollow forms. A wide range of analytes such as $\mathrm{NO}_{2}, \mathrm{NH}_{3}$, $\mathrm{CO}, \mathrm{CO}_{2}, \mathrm{H}_{2}, \mathrm{H}_{2} \mathrm{~S}$ and volatile organic compounds (e.g., ethanol, toluene, acetone and formaldehyde) can be detected using electrospun 1D nanostructures, with a detection limit as low as $7 \mathrm{ppb}$ and response/recovery times as quick as milliseconds.

Recent advances in the technology, as well as the volume and diversity of outcomes, clearly demonstrate that the electrospinning method offers unique opportunities for development of highly sensitive and selective 1D nanostructures with remarkable specific surface area and high porositity. Electrospun fibers show versatility of function via appropriate integration with specific sensing architectures for particular target outcomes. For example, the design of a particular sensor may be guided by the advantages and disadvantages listed in Table 1 that refers to fiber structure. Table 1 highlights the generic trade-offs between sensitivity, response time and detection limit using 1D nanostructures.

For 1D materials, we find that gas sensing performance can be improved in two ways:

(i) By enhancing the specific surface area of nanofibers via the synthesis of different morphologies such as micro- or mesoporous fibers, nanobelts, hierarchical nanofibers, and core-shell nanofibers. Such structures can be obtained by using electrospinning alone or in combination with sputtering or chemical vapour deposition $[37,69-76,78,80]$. The surface reactivity of a chemisorbed oxygen and target gas is increased by introducing hollow nanofibers or nanotubes because a target gas can react with both the inner and the outer walls of the hollow nanofiber or nanotube. On the other hand, with hollow fibers the recovery time increases because a target gas takes more time to desorb completely from the inner walls. Thus, there is a trade-off between sensitivity and recovery time of hollow nanofiber based gas sensors. Moreover, the surface area cannot be increased indefinitely to improve the sensitivity of nanofibers because there is an optimum surface area for which a nanofibrous gas sensor shows maximum sensitivity, regardless of morphology $[79,83,132,133,139,141]$.

(ii) By functionalizing nanofibers with different catalytic materials such as noble metals, rare-earth metals, transition metals and graphene and/or by making composites of two or more materials. Functionalization of electrospun fibers with other materials such as noble metals, metal oxides and carbon materials remarkably improves the sensing performance in terms of sensitivity, selectivity, response and recovery rate by improving charge transport properties and by enabling more surface active sites. In some cases, the effect of crystal facets with high surface reactivity $[12,13]$ significantly influences the sensing performance. Table 2 summarizes the specific characteristics of nanofibrous gas sensors using a range of different materials.

Recently, a great deal of attention and research effort has been devoted to the development of electrospun fibers incorporated with functional nanoparticles (NPs) [39,40]. This approach shows good potential for applications involving the selfassembly of anisotropic NPs to generate new functional devices [63]. These materials could be beneficial for gas sensing applications utilizing the properties of both nanostructures and polymers. These hybrid materials need to be explored for all types of gas sensing platforms [57].

We have also outlined the differences between sensing technologies used with electrospun fibers. Table 3 summarizes the four predominant platforms used with gas sensors.

Many existing gas sensors based on electrospun 1D nanostructures are conductometric, due to their reduced cost, simple operation and potential for device miniaturization. Conductometric sensors are able to detect many different gases with high and

\begin{tabular}{|c|c|c|c|}
\hline Structure & Advantage & Disadvantage & References \\
\hline nanofibers & short recovery time & $\begin{array}{l}\text { minimal response, long } \\
\text { response time }\end{array}$ & {$[95,110,115,144,280,281]$} \\
\hline hollow nanofibers/nanotubes & high sensitivity, short response time & long recovery time & {$[78,102,119,129,133,282]$} \\
\hline nanowires & high sensitivity, low detection limit & long response/recovery time & {$[135]$} \\
\hline
\end{tabular}


Table 2: Advantages and disadvantages of functionalized materials. Note that the response of pure metal oxide nanofibers (Table S2 in Supporting Information File 1) is taken as the reference point.

\begin{tabular}{|c|c|c|c|}
\hline Material & Advantages & Disadvantages & References \\
\hline pure MOx & minimal response/recovery time & $\begin{array}{l}\text { minimal sensitivity, high } \\
\text { operating temperature, low } \\
\text { detection limit }\end{array}$ & $\begin{array}{l}{[100,105,115,118]} \\
{[119,144,282-284]}\end{array}$ \\
\hline functionalized MOx & $\begin{array}{l}\text { high sensitivity, lower detection } \\
\text { limit, short response/recovery time }\end{array}$ & $\begin{array}{l}\text { slightly lower operating } \\
\text { temperature }\end{array}$ & $\begin{array}{l}{[10,11,104,175,178,179]} \\
{[188,200,209,215,220]}\end{array}$ \\
\hline MOx-MOx composites & $\begin{array}{l}\text { enhanced selectivity, short } \\
\text { response/recovery time, improved } \\
\text { operating temperature }\end{array}$ & $\begin{array}{l}\text { slightly improved response, } \\
\text { slightly improved detection } \\
\text { limit }\end{array}$ & $\begin{array}{l}{[222,224-228,230]} \\
{[235,285-287]}\end{array}$ \\
\hline $\begin{array}{l}\text { conjugated polymer-conjugated } \\
\text { polymer composites or conjugated } \\
\text { polymer/non-conjugated } \\
\text { polymer-MOx composites }\end{array}$ & $\begin{array}{l}\text { low operating temperature, high } \\
\text { selectivity, minimal detection limit, } \\
\text { minimal response/recovery time }\end{array}$ & minimal response & $\begin{array}{l}{[87,238,241,248,258]} \\
{[278,279,288-294]}\end{array}$ \\
\hline graphene-MOx, CNTs-MOx & $\begin{array}{l}\text { lower operating temperature, } \\
\text { minimal response/recovery time, } \\
\text { minimal detection limit, }\end{array}$ & minimal response & $\begin{array}{l}{[89,243,244,246,252]} \\
{[268,295,296]}\end{array}$ \\
\hline
\end{tabular}

fast response. However, for many of these sensors, an operating temperature above $100{ }^{\circ} \mathrm{C}$ is a requisite for efficient operation. This requirement, usually related to the effective recovery rate, may limit their extended use under ambient or mobile circumstances. Conductometric gas sensors developed in MEMS operate with much lower power consumption due to their miniaturized size $[165,298]$. For environmental sensing, as well as for some biomedical applications, it is desirable to deploy gas sensors that operate at room temperature or at least below $100{ }^{\circ} \mathrm{C}$. Operation of gas sensors at these temperatures will result in lower power consumption with potential for associated reductions in weight and/or size. These two feature improvements may pave the way for mobile, multi-locale, selective gas sensors to provide statistically viable data on a wide range of environments. In addition, there is a much lower (or no) risk of ignition if the sensor is deployed to detect flammable or explosive analytes.

Gas sensing platforms other than conductometric, such as resonating or optical platforms offer room temperature opera- tion with enhanced sensing performance. However, optical technology is relatively expensive to fabricate and to operate. Surface acoustic wave sensors operate at room temperature but have limited response and modest detection limits. The solution to this cost/performance problem may come from further development of QCM technology. QCM technology is simple, robust, low cost, and has been shown to produce excellent results even at room temperature [253,254]. For example, QCM technology has been demonstrated to show lower detection limits of $50 \mathrm{ppb}$ and $130 \mathrm{ppb}$ for detection of formaldehyde and $\mathrm{NH}_{3}$ gases, respectively $[257,258,260]$.

QCM devices can detect changes in the mass of an adsorbed target gas in picogram quantities and are highly sensitive. However, QCM devices are also sensitive to a humid environments, and thus to date their applications are limited. Nevertheless, these devices have a very short response and recovery time (e.g., $3 \mathrm{~s}$ ). The incorporation of electrospun 1D nanostructures in QCM devices that operate at room temperature and in combination with several sensors in a single platform is a promising

Table 3: Advantages and disadvantages of current gas sensing platforms.

\begin{tabular}{|c|c|c|}
\hline Platform & Advantages & Disadvantages \\
\hline $\begin{array}{l}\text { conductometric } \\
\& \text { MEMS }\end{array}$ & high sensitivity, easily miniaturized & $\begin{array}{l}\text { high power requirement, high operating } \\
\text { temperature, high response/recovery } \\
\text { time }\end{array}$ \\
\hline $\begin{array}{l}\text { surface acoustic } \\
\text { wave (SAW) }\end{array}$ & $\begin{array}{l}\text { low power requirement, room temperature } \\
\text { operation }\end{array}$ & $\begin{array}{l}\text { low sensitivity, high response/recovery } \\
\text { time }\end{array}$ \\
\hline $\begin{array}{l}\text { quartz crystal } \\
\text { microbalance } \\
(\mathrm{QCM})\end{array}$ & $\begin{array}{l}\text { low power requirement, room temperature } \\
\text { operation, low detection limit }\end{array}$ & $\begin{array}{l}\text { low selectivity, sensitive to humidity, } \\
\text { high response/recovery time }\end{array}$ \\
\hline optical & $\begin{array}{l}\text { fast response time, low power requirement, } \\
\text { high selectivity, room temperature operation }\end{array}$ & low sensitivity, higher detection limit \\
\hline
\end{tabular}

\section{References}

$[75,79,89,93,188,215$

$280,283,285,292,295]$

[247-249,251,252]

$[21,256,258,262,263]$

[2,3,271,275,297] 
avenue for research which has not yet been sufficiently explored. The potential for QCM devices to combine reproducibility, reliability and stability is an open field of investigation which may lead to excellent sensing systems in the near future. Furthermore, few metal oxides and their composites with other metal oxides, conjugate polymers and/or carbon compounds (e.g., graphene) on QCM sensing platforms have been explored. There is also a need to develop new materials for QCM gas sensors, which are insensitive to humidity, for real world applications.

It is evident from this review that there is a bright future for high-performance chemical sensors thanks to the unique properties of electrospun 1D nanostructures. Furthermore, there is a great opportunity for further development of materials, their functionality and their integration with an array of platforms to provide highly selective and sensitive data on a target gas in a multi-gas environment. The diversity of material compositions now available, in conjunction with novel additives and sophisticated nanostructures, provides a plethora of choices for the aspiring surface or gas phase scientist. The future challenge will be to align these choices with tractable problems that highlight the versatility and value of electrospun 1D nanostructures.

\section{Supporting Information}

Different types of electrospun material based gas sensors. Sensing performance of electrospun pure MOx nanofibers categorized based on the analyte gas. Sensing performance of electrospun metal-doped MOx nanofibers categorized based on the analyte gas. Sensing performance of electrospun MOx-MOx nanofibers categorized based on the analyte gas.

\section{Supporting Information File 1}

Summary of electrospun materials and their gas sensing performance.

[https://www.beilstein-journals.org/bjnano/content/ supplementary/2190-4286-9-202-S1.pdf]

\section{Acknowledgements}

The authors would like to acknowledge Prof Ian Mackinnon for his careful review of the manuscript and constructive feedback, and A/Prof Prashant Sonar for scientific discussions. N.M. acknowledges support from the Queensland Government through the 2016 Queensland - Chinese Academy of Science grant. M.S. acknowledges funding from Australian Research Council - Discovery Project, ARC DP150101939. M.I. would like to acknowledge QUT Postgraduate Research Award.
This work was performed in part at the Queensland node of the Australian National Fabrication Facility, a company established under the National Collaborative Research Infrastructure Strategy to provide nano and micro-fabrication facilities for Australia's researchers.

\section{ORCID ${ }^{\circledR}$ iDs}

Muhammad Imran - https://orcid.org/0000-0002-3321-2427

Nunzio Motta - https://orcid.org/0000-0002-3857-1031

Mahnaz Shafiei - https://orcid.org/0000-0002-3520-1553

\section{References}

1. Koo, W.-T.; Choi, S.-J.; Kim, S.-J.; Jang, J.-S.; Tuller, H. L.; Kim, I.-D. J. Am. Chem. Soc. 2016, 138, 13431-13437.

doi:10.1021/jacs.6b09167

2. Long, Y.; Chen, H.; Wang, H.; Peng, Z.; Yang, Y.; Zhang, G.; Li, N.; Liu, F.; Pei, J. Anal. Chim. Acta 2012, 744, 82-91. doi:10.1016/j.aca.2012.07.028

3. Long, Y.; Chen, H.; Yang, Y.; Wang, H.; Yang, Y.; Li, N.; Li, K.; Pei, J.; Liu, F. Macromolecules 2009, 42, 6501-6509. doi:10.1021/ma900756w

4. Wang, T.; Ma, S.; Cheng, L.; Luo, J.; Jiang, X.; Jin, W. Sens. Actuators, B 2015, 216, 212-220. doi:10.1016/j.snb.2015.04.040

5. Cheng, L.; Ma, S.; Li, X.; Luo, J.; Li, W.; Li, F.; Mao, Y.; Wang, T.; Li, Y. Sens. Actuators, B 2014, 200, 181-190. doi:10.1016/j.snb.2014.04.063

6. Wang, C.; Ma, S.; Sun, A.; Qin, R.; Yang, F.; Li, X.; Li, F.; Yang, X. Sens. Actuators, B 2014, 193, 326-333. doi:10.1016/j.snb.2013.11.058

7. Li, W.; Ma, S.; Li, Y.; Li, X.; Wang, C.; Yang, X.; Cheng, L.; Mao, Y.; Luo, J.; Gengzang, D.; Wan, G.; Xu, X. J. Alloys Compd. 2014, 605, 80-88. doi:10.1016/j.jallcom.2014.03.182

8. Mohanapriya, P.; Segawa, H.; Watanabe, K.; Watanabe, K.; Samitsu, S.; Natarajan, T.; Jaya, N. V.; Ohashi, N. Sens. Actuators, B 2013, 188, 872-878. doi:10.1016/j.snb.2013.07.016

9. Liu, D.; Liu, T.; Zhang, H.; Lv, C.; Zeng, W.; Zhang, J. Mater. Sci. Semicond. Process. 2012, 15, 438-444. doi:10.1016/j.mssp.2012.02.015

10. Liu, C.; Shan, H.; Liu, L.; Li, S.; Li, H. Ceram. Int. 2014, 40, 2395-2399. doi:10.1016/j.ceramint.2013.08.011

11. Wan, G.; Ma, S.; Li, X.; Li, F.; Bian, H.; Zhang, L.; Li, W. Mater. Lett. 2014, 114, 103-106. doi:10.1016/j.matlet.2013.09.094

12. Kalantar-zadeh, K.; Fry, B. Nanotechnology-Enabled Sensors; Springer US: Boston, MA, U.S.A., 2008. doi:10.1007/978-0-387-68023-1

13. Comini, E.; Faglia, G.; Sberveglieri, G. Solid state gas sensing; Springer: Berlin, Germany, 2009; Vol. 20. doi:10.1007/978-0-387-09665-0

14. Gründler, P. Chemical sensors: an introduction for scientists and engineers; Springer: Berlin, Germany, 2007.

15. Bahreyni, B.; Shafai, C. Sens. Actuators, A 2007, 137, 74-80. doi:10.1016/j.sna.2007.02.003

16. Khoshaman, A. H.; Bahreyni, B. Sens. Actuators, B 2012, 162, 114-119. doi:10.1016/j.snb.2011.12.046

17. Zheng, J.; Li, G.; Ma, X.; Wang, Y.; Wu, G.; Cheng, Y. Sens. Actuators, B 2008, 133, 374-380. doi:10.1016/j.snb.2008.02.037 
18. Xie, J.; Wang, H.; Duan, M. Sens. Actuators, B 2014, 203, 239-244. doi:10.1016/j.snb.2014.06.119

19. Minh, V. A.; Tuan, L. A.; Huy, T. Q.; Hung, V. N.; Quy, N. V. Appl. Surf. Sci. 2013, 265, 458-464. doi:10.1016/j.apsusc.2012.11.028

20. Khoshaman, A. H.; Li, P. C.; Merbouh, N.; Bahreyni, B. Sens. Actuators, B 2012, 161, 954-960. doi:10.1016/j.snb.2011.11.071

21. Wang, X.; Cui, F.; Lin, J.; Ding, B.; Yu, J.; Al-Deyab, S. S. Sens. Actuators, B 2012, 171-172, 658-665. doi:10.1016/j.snb.2012.05.050

22. Shafiei, M.; Hoshyargar, F.; Lipton-Duffin, J.; Piloto, C.; Motta, N.; O'Mullane, A. P. J. Phys. Chem. C 2015, 119, 22208-22216. doi:10.1021/acs.jpcc.5b06894

23. Shafiei, M.; Sadek, A.; Yu, J.; Latham, K.; Breedon, M.; McCulloch, D.; Kalantar-zadeh, K.; Wlodarski, W. Sens. Lett. 2011, 9, 11-15. doi:10.1166/sl.2011.1409

24. Shafiei, M.; Spizzirri, P. G.; Arsat, R.; Yu, J.; du Plessis, J.; Dubin, S.; Kaner, R. B.; Kalantar-zadeh, K.; Wlodarski, W. J. Phys. Chem. C 2010, 114, 13796-13801. doi:10.1021/jp104459s

25. Yu, J.; Chen, G.; Li, C. X.; Shafiei, M.; Ou, J. Z.; Plessis, J. d.; Kalantar-zadeh, K.; Lai, P. T.; Wlodarski, W. Sens. Actuators, A 2011, 172, 9-14. doi:10.1016/j.sna.2011.02.021

26. Yaacob, M. H.; Ahmad, M. Z.; Sadek, A. Z.; Ou, J. Z.; Campbell, J.; Kalantar-zadeh, K.; Wlodarski, W. Sens. Actuators, B 2013, 177, 981-988. doi:10.1016/j.snb.2012.11.098

27. Jane, H.; Ralph, P. T. Meas. Sci. Technol. 2013, 24, 012004. doi:10.1088/0957-0233/24/1/012004

28. Arsat, R.; Breedon, M.; Shafiei, M.; Spizziri, P. G.; Gilje, S.; Kaner, R. B.; Kalantar-zadeh, K.; Wlodarski, W. Chem. Phys. Lett. 2009, 467, 344-347. doi:10.1016/j.cplett.2008.11.039

29. Shafiei, M.; Yu, J.; Chen, G.; Lai, P. T.; Motta, N.; Wlodarski, W.; Kalantar-zadeh, K. Sens. Actuators, B 2013, 187, 267-273. doi:10.1016/j.snb.2012.11.019

30. Shafiei, M.; Hoshyargar, F.; Motta, N.; O'Mullane, A. P. Mater. Des. 2017, 122, 288-295. doi:10.1016/j.matdes.2017.03.017

31. Hoshyargar, F.; Shafiei, M.; Piloto, C.; Motta, N.; O'Mullane, A. P. J. Mater. Chem. C 2016, 4, 11173-11179. doi:10.1039/C6TC03548E

32. Ding, B.; Wang, M.; Yu, J.; Sun, G. Sensors 2009, 9, 1609-1624. doi:10.3390/s90301609

33. Shafiei, M.; Yu, J.; Arsat, R.; Kalantar-zadeh, K.; Comini, E.; Ferroni, M.; Sberveglieri, G.; Wlodarski, W. Sens. Actuators, B 2010, 146, 507-512. doi:10.1016/j.snb.2009.12.028

34. Comini, E. Mater. Today 2016, 19, 559-567. doi:10.1016/j.mattod.2016.05.016

35. Liang, H.-W.; Liu, S.; Yu, S.-H. Adv. Mater. 2010, 22, 3925-3937. doi:10.1002/adma.200904391

36. Liu, J.-W.; Liang, H.-W.; Yu, S.-H. Chem. Rev. 2012, 112, 4770-4799. doi:10.1021/cr200347w

37. Teo, W. E.; Ramakrishna, S. Nanotechnology 2006, 17, R89-R106. doi:10.1088/0957-4484/17/14/R01

38. Ramakrishna, S.; Fujihara, K.; Teo, W.-E.; Yong, T.; Ma, Z.; Ramaseshan, R. Mater. Today 2006, 9, 40-50. doi:10.1016/S1369-7021(06)71389-X

39. Crespy, D.; Friedemann, K.; Popa, A.-M. Macromol. Rapid Commun. 2012, 33, 1978-1995. doi:10.1002/marc.201200549

40. Zhang, C.-L.; Yu, S.-H. Chem. Soc. Rev. 2014, 43, 4423-4448. doi:10.1039/c3cs60426h

41. Haghi, A.; Zaikov, G. E. Electrospinning process and nanofiber research; Nova Science Publishing, 2011.
42. Ding, B.; Wang, M.; Wang, X.; Yu, J.; Sun, G. Mater. Today 2010, 13, 16-27. doi:10.1016/S1369-7021(10)70200-5

43. Choi, S.-J.; Persano, L.; Camposeo, A.; Jang, J.-S.; Koo, W.-T.; Kim, S.-J.; Cho, H.-J.; Kim, I.-D.; Pisignano, D. Macromol. Mater. Eng 2017, 302, 1600569. doi:10.1002/mame.201600569

44. Gilbert, W.; Thompson, S. P. On the Magnet, Magnetick Bodies Also, and on the Great Magnet the Earth: A New Physiology, Demonstrated by Many Arguments \& Experiments; Chiswick Press, 1900.

45. Tucker, N.; Stanger, J. J.; Staiger, M. P.; Razzaq, H.; Hofman, K. J. Eng. fibres Fabr. 2012, 7, 63-73.

46. Chronakis, I. S. J. Mater. Process. Technol. 2005, 167, 283-293. doi:10.1016/j.jmatprotec.2005.06.053

47. Li, D.; Xia, Y. Adv. Mater. 2004, 16, 1151-1170. doi:10.1002/adma.200400719

48. Taylor, G. Proc. R. Soc. London, Ser. A 1964, 280, 383-397. doi:10.1098/rspa.1964.0151

49. Reneker, D. H.; Yarin, A. L.; Fong, H.; Koombhongse, S. J. Appl. Phys. 2000, 87, 4531-4547. doi:10.1063/1.373532

50. Doshi, J.; Reneker, D. H. J. Electrost. 1995, 35, 151-160. doi:10.1016/0304-3886(95)00041-8

51. Tomer, V.; Teye-Mensah, R.; Tokash, J. C.; Stojilovic, N.; Kataphinan, W.; Evans, E. A.; Chase, G. G.; Ramsier, R. D.; Smith, D. J.; Reneker, D. H. Sol. Energy Mater. Sol. Cells 2005, 85 , 477-488. doi:10.1016/j.solmat.2004.04.019

52. Zhang, G.; Kataphinan, W.; Teye-Mensah, R.; Katta, P.; Khatri, L.; Evans, E.; Chase, G. G.; Ramsier, R.; Reneker, D. Mater. Sci. Eng., B 2005, 116, 353-358. doi:10.1016/j.mseb.2004.05.050

53. Shin, C.; Chase, G. G.; Reneker, D. H. Colloids Surf., A 2005, 262, 211-215. doi:10.1016/j.colsurfa.2005.04.034

54. Putthanarat, S.; Eby, R.; Kataphinan, W.; Jones, S.; Naik, R.; Reneker, D.; Farmer, B. Polymer 2006, 47, 5630-5632. doi:10.1016/j.polymer.2005.06.130

55. Lannutti, J.; Reneker, D.; Ma, T.; Tomasko, D.; Farson, D. Mater. Sci. Eng., C 2007, 27, 504-509. doi:10.1016/j.msec.2006.05.019

56. Deitzel, J.; Kleinmeyer, J.; Hirvonen, J.; Tan, N. B. Polymer 2001, 42, 8163-8170. doi:10.1016/s0032-3861(01)00336-6

57. Shafiei, M.; El-chami, I.; Rintoul, L.; Bahreyni, B. Mater. Des. 2017, 113, 76-83. doi:10.1016/j.matdes.2016.10.011

58. Bhardwaj, N.; Kundu, S. C. Biotechnol. Adv. 2010, 28, 325-347. doi:10.1016/j.biotechadv.2010.01.004

59. Jacobs, V.; Anandjiwala, R. D.; Maaza, M. J. Appl. Polym. Sci. 2010, 115, 3130-3136. doi:10.1002/app.31396

60. Deitzel, J.; Kleinmeyer, J.; Harris, D.; Beck Tan, N. Polymer 2001, 42, 261-272. doi:10.1016/s0032-3861(00)00250-0

61. Son, W. K.; Youk, J. H.; Lee, T. S.; Park, W. H. Polymer 2004, 45 2959-2966. doi:10.1016/j.polymer.2004.03.006

62. Righi, T. M.; Almeida, R. S.; d'Ávila, M. A. Electrospinning of gelatin/PEO blends: Influence of process parameters in the nanofiber properties. In Proceedings of Macromolecular Symposia, 2012; pp 230-234.

63. Chen, H.; Di, J.; Wang, N.; Dong, H.; Wu, J.; Zhao, Y.; Yu, J.; Jiang, L. Small 2011, 7, 1779-1783. doi:10.1002/smll.201002376

64. Nirmala, R.; Jeon, K. S.; Lim, B. H.; Navamathavan, R.; Kim, H. Y. Ceram. Int. 2013, 39, 9651-9658. doi:10.1016/j.ceramint.2013.05.087

65. Verdejo, R.; Bernal, M. M.; Romasanta, L. J.; Lopez-Manchado, M. A. J. Mater. Chem. 2011, 21, 3301-3310. doi:10.1039/C0JM02708A

66. Wang, Q.; Du, Y.; Feng, Q.; Huang, F.; Lu, K.; Liu, J.; Wei, Q. J. Appl. Polym. Sci. 2013, 128, 1152-1157. doi:10.1002/app.38273 
67. Das, S.; Wajid, A. S.; Bhattacharia, S. K.; Wilting, M. D.; Rivero, I. V.; Green, M. J. J. Appl. Polym. Sci. 2013, 128, 4040-4046. doi:10.1002/app.38694

68. Bao, Q.; Zhang, H.; Yang, J.-x.; Wang, S.; Tang, D. Y.; Jose, R.; Ramakrishna, S.; Lim, C. T.; Loh, K. P. Adv. Funct. Mater. 2010, 20 , 782-791. doi:10.1002/adfm.200901658

69. Lin, T.; Wang, H.; Wang, X. Adv. Mater. 2005, 17, 2699-2703. doi:10.1002/adma.200500901

70. Viswanathamurthi, P.; Bhattarai, N.; Kim, H.; Lee, D.; Kim, S.; Morris, M. Chem. Phys. Lett. 2003, 374, 79-84. doi:10.1016/S0009-2614(03)00702-4

71. Shao, C.; Yang, X.; Guan, H.; Liu, Y.; Gong, J. Inorg. Chem. Commun. 2004, 7, 625-627. doi:10.1016/j.inoche.2004.03.006

72. Liu, Z.; Sun, D. D.; Guo, P.; Leckie, J. O. Nano Lett. 2007, 7, 1081-1085. doi:10.1021/nl061898e

73. Li, D.; McCann, J. T.; Xia, Y. Small 2005, 1, 83-86. doi:10.1002/smll.200400056

74. Li, D.; Xia, Y. Nano Lett. 2004, 4, 933-938. doi:10.1021/nI049590f

75. Choi, S.-J.; Chattopadhyay, S.; Kim, J. J.; Kim, S.-J.; Tuller, H. L.; Rutledge, G. C.; Kim, I.-D. Nanoscale 2016, 8, 9159-9166. doi:10.1039/c5nr06611e

76. Fan, X.-X.; He, X.-L.; Li, J.-P.; Gao, X.-G.; Jia, J. Vacuum 2016, 128, 112-117. doi:10.1016/j.vacuum.2016.03.016

77. Jun, J.; Lee, J. S.; Shin, D. H.; Oh, J.; Kim, W.; Na, W.; Jang, J. J. Mater. Chem. A 2017, 5, 17335-17340. doi:10.1039/C7TA02725G

78. Liang, X.; Jin, G.; Liu, F.; Zhang, X.; An, S.; Ma, J.; Lu, G. Ceram. Int. 2015, 41, 13780-13787. doi:10.1016/j.ceramint.2015.08.060

79. Liu, L.; Li, S.; Guo, X.; Wang, L.; Liu, L.; Wang, X. J. Mater. Sci.: Mater. Electron. 2016, 27, 5153-5157. doi:10.1007/s10854-016-4407-7

80. Li, Z.; Fan, Y.; Zhan, J. Eur. J. Inorg. Chem. 2010, 3348-3353. doi:10.1002/ejic.201000313

81. Luzio, A.; Canesi, E.; Bertarelli, C.; Caironi, M. Materials 2014, 7, 906-947. doi:10.3390/ma7020906

82. Nair, V.; Regius, F.; Ragavendar, A.; Suman, S. Role of electrospun ZnO-NiO metaloxide nanocomposite fibres for sensor applications. In 2015 International Conference on Proceedings of Industrial Engineering and Operations Management (IEOM), 2015; pp 1-8. doi:10.1109/IEOM.2015.7228112

83. Khalil, A.; Kim, J. J.; Tuller, H. L.; Rutledge, G. C.; Hashaikeh, R. Sens. Actuators, B 2016, 227, 54-64. doi:10.1016/j.snb.2015.12.012

84. Macías, M.; Chacko, A.; Ferraris, J. P.; Balkus, K. J., Jr. Microporous Mesoporous Mater. 2005, 86, 1-13. doi:10.1016/j.micromeso.2005.05.053

85. Tian, W.; Zhai, T.; Zhang, C.; Li, S.-L.; Wang, X.; Liu, F.; Liu, D.; Cai, X.; Tsukagoshi, K.; Golberg, D.; Bando, Y. Adv. Mater. 2013, 25 , 4625-4630. doi:10.1002/adma.201301828

86. Xu, S.; Kan, K.; Yang, Y.; Jiang, C.; Gao, J.; Jing, L.; Shen, P.; Li, L.; Shi, K. J. Alloys Compd. 2015, 618, 240-247. doi:10.1016/j.jallcom.2014.08.153

87. Ji, S.; Li, Y.; Yang, M. Sens. Actuators, B 2008, 133, 644-649. doi:10.1016/j.snb.2008.03.040

88. Gopalan, A.; Lee, K.-P.; Manian, K.; Santhosh, P.; Song, K.-D.; Lee, D.-D. Fabrication of functional nanofibrous ammonia sensor. In Proceedings of 2006 Sixth IEEE Conference on Nanotechnology, 2006; pp 783-786.

89. Abideen, Z. U.; Katoch, A.; Kim, J.-H.; Kwon, Y. J.; Kim, H. W.; Kim, S. S. Sens. Actuators, B 2015, 221, 1499-1507. doi:10.1016/j.snb.2015.07.120
90. Fratoddi, I.; Venditti, I.; Cametti, C.; Russo, M. V. Sens. Actuators, B 2015, 220, 534-548. doi:10.1016/j.snb.2015.05.107

91. Comini, E.; Faglia, G.; Sberveglieri, G. Electrical-Based Gas Sensing. Solid State Gas Sensing; Springer US: Boston, MA, U.S.A., 2009; pp 1-61. doi:10.1007/978-0-387-09665-0_2

92. Zhang, J.; Liu, X.; Neri, G.; Pinna, N. Adv. Mater. 2016, 28, 795-831. doi:10.1002/adma.201503825

93. Bian, H.; Ma, S.; Sun, A.; Xu, X.; Yang, G.; Gao, J.; Zhang, Z.; Zhu, H. Superlattices Microstruct. 2015, 81, 107-113. doi:10.1016/j.spmi.2015.01.022

94. Park, J.-A.; Moon, J.; Lee, S.-J.; Kim, S. H.; Zyung, T.; Chu, H. Y. Mater. Lett. 2010, 64, 255-257. doi:10.1016/j.matlet.2009.10.052

95. Park, J.-A.; Moon, J.; Lee, S.-J.; Kim, S. H.; Zyung, T.; Chu, H. Y. Thin Solid Films 2010, 518, 6642-6645. doi:10.1016/j.tsf.2010.02.074

96. Leng, J.-y.; Xu, X.-j.; Lv, N.; Fan, H.-t.; Zhang, T. J. Colloid Interface Sci. 2011, 356, 54-57. doi:10.1016/j.jcis.2010.11.079

97. Lu, X.; Liu, X.; Zhang, W.; Wang, C.; Wei, Y. J. Colloid Interface Sci. 2006, 298, 996-999. doi:10.1016/j.jcis.2006.01.032

98. Nguyen, T.-A.; Jun, T.-S.; Rashid, M.; Kim, Y. S. Mater. Lett. 2011, 65, 2823-2825. doi:10.1016/j.matlet.2011.05.103

99. Sungpanich, J.; Thongtem, T.; Thongtem, S. Mater. Lett. 2011, 65, 3000-3004. doi:10.1016/j.matlet.2011.06.004

100.Giancaterini, L.; Emamjomeh, S. M.; De Marcellis, A.; Palange, E.; Cantalini, C. Procedia Eng. 2015, 120, 791-794. doi:10.1016/j.proeng.2015.08.824

101.Bai, X.; Ji, H.; Gao, P.; Zhang, Y.; Sun, X. Sens. Actuators, B 2014, 193, 100-106. doi:10.1016/j.snb.2013.11.059

102.Chi, X.; Liu, C.; Liu, L.; Li, Y.; Wang, Z.; Bo, X.; Liu, L.; Su, C. Sens. Actuators, B 2014, 194, 33-37. doi:10.1016/j.snb.2013.12.078

103.Feng, C.; Li, X.; Ma, J.; Sun, Y.; Wang, C.; Sun, P.; Zheng, J.; Lu, G. Sens. Actuators, B 2015, 209, 622-629. doi:10.1016/j.snb.2014.12.019

104.Feng, C.; Wang, C.; Cheng, P.; Li, X.; Wang, B.; Guan, Y.; Ma, J.; Zhang, H.; Sun, Y.; Sun, P.; Zheng, J.; Lu, G. Sens. Actuators, B 2015, 221, 434-442. doi:10.1016/j.snb.2015.06.114

105. Giancaterini, L.; Emamjomeh, S. M.; De Marcellis, A.; Palange, E.; Resmini, A.; Anselmi-Tamburini, U.; Cantalini, C. Sens. Actuators, B 2016, 229, 387-395. doi:10.1016/j.snb.2016.02.007

106.Kim, N.-H.; Choi, S.-J.; Kim, S.-J.; Cho, H.-J.; Jang, J.-S.; Koo, W.-T.; Kim, M.; Kim, I.-D. Sens. Actuators, B 2016, 224, 185-192. doi:10.1016/j.snb.2015.10.021

107.Kim, N.-H.; Choi, S.-J.; Yang, D.-J.; Bae, J.; Park, J.; Kim, I.-D. Sens. Actuators, B 2014, 193, 574-581. doi:10.1016/j.snb.2013.12.011

108. Nguyen, T.-A.; Park, S.; Kim, J. B.; Kim, T. K.; Seong, G. H.; Choo, J.; Kim, Y. S. Sens. Actuators, B 2011, 160, 549-554. doi:10.1016/j.snb.2011.08.028

109. Yang, X.; Salles, V.; Kaneti, Y. V.; Liu, M.; Maillard, M.; Journet, C.; Jiang, X.; Brioude, A. Sens. Actuators, B 2015, 220, 1112-1119. doi:10.1016/j.snb.2015.05.121

110.Wei, S.; Zhao, G.; Du, W.; Tian, Q. Vacuum 2016, 124, 32-39. doi:10.1016/j.vacuum.2015.11.010

111.Choi, S.-W.; Park, J. Y.; Kim, S. S. Chem. Eng. J. 2011, 172, 550-556. doi:10.1016/j.cej.2011.05.100

112.Choi, J.-M.; Byun, J.-H.; Kim, S. S. Sens. Actuators, B 2016, 227 , 149-156. doi:10.1016/j.snb.2015.12.014

113.Yoon, J.-W.; Kim, H.-J.; Jeong, H.-M.; Lee, J.-H. Sens. Actuators, $B$ 2014, 202, 263-271. doi:10.1016/j.snb.2014.05.081 
114.Yoon, J.-W.; Choi, J.-K.; Lee, J.-H. Sens. Actuators, B 2012, 161, 570-577. doi:10.1016/j.snb.2011.11.002

115.Zheng, W.; Li, Z.; Zhang, H.; Wang, W.; Wang, Y.; Wang, C. Mater. Res. Bull. 2009, 44, 1432-1436. doi:10.1016/j.materresbull.2008.12.013

116. Fan, H.; Zhang, T.; Xu, X.; Lv, N. Sens. Actuators, B 2011, 153, 83-88. doi:10.1016/j.snb.2010.10.014

117.Zhou, H.; Li, Z.; Niu, X.; Xia, X.; Wei, Q. Ceram. Int. 2016, 42, 1817-1826. doi:10.1016/j.ceramint.2015.09.145

118.Kim, I.-D.; Jeon, E.-K.; Choi, S.-H.; Choi, D.-K.; Tuller, H. L. J. Electroceram. 2010, 25, 159-167. doi:10.1007/s10832-010-9607-6

119.Ab Kadir, R.; Li, Z.; Sadek, A. Z.; Abdul Rani, R.; Zoolfakar, A. S.; Field, M. R.; Ou, J. Z.; Chrimes, A. F.; Kalantar-zadeh, K. J. Phys. Chem. C 2014, 118, 3129-3139. doi:10.1021/jp411552z

120.Cheng, L.; Ma, S. Y.; Wang, T. T.; Li, X. B.; Luo, J.; Li, W. Q.; Mao, Y. Z.; GZ, D. J. Mater. Lett. 2014, 131, 23-26. doi:10.1016/j.matlet.2014.05.151

121.Li, T.; Zeng, W.; Zhao, W. Mater. Lett. 2016, 167, 230-233. doi:10.1016/j.matlet.2016.01.013

122.Li, W. Q.; Ma, S. Y.; Luo, J.; Mao, Y. Z.; Cheng, L.; Gengzang, D. J.; Xu, X. L.; Yan, S. H. Mater. Lett. 2014, 132, 338-341. doi:10.1016/j.matlet.2014.06.112

123.Cho, N. G.; Yang, D. J.; Jin, M.-J.; Kim, H.-G.; Tuller, H. L.; Kim, I.-D. Sens. Actuators, B 2011, 160, 1468-1472. doi:10.1016/j.snb.2011.07.035

124.Wei, S.; Wang, S.; Zhang, Y.; Zhou, M. Sens. Actuators, B 2014, 192, 480-487. doi:10.1016/j.snb.2013.11.034

125.Katoch, A.; Sun, G.-J.; Choi, S.-W.; Byun, J.-H.; Kim, S. S. Sens. Actuators, B 2013, 185, 411-416. doi:10.1016/j.snb.2013.05.030

126. Katoch, A.; Abideen, Z. U.; Kim, J.-H.; Kim, S. S. Sens. Actuators, B 2016, 232, 698-704. doi:10.1016/j.snb.2016.04.013

127.Cho, S.; Kim, D.-H.; Lee, B.-S.; Jung, J.; Yu, W.-R.; Hong, S.-H.; Lee, S. Sens. Actuators, B 2012, 162, 300-306. doi:10.1016/j.snb.2011.12.081

128. Yu, X.; Song, F.; Zhai, B.; Zheng, C.; Wang, Y. Phys. E (Amsterdam, Neth.) 2013, 52, 92-96. doi:10.1016/j.physe.2013.03.030

129.Katoch, A.; Choi, S.-W.; Kim, H. W.; Kim, S. S. J. Hazard. Mater. 2015, 286, 229-235. doi:10.1016/j.jhazmat.2014.12.007

130.Senthil, T.; Anandhan, S. J. Colloid Interface Sci. 2014, 432, 285-296. doi:10.1016/j.jcis.2014.06.029

131.Trocino, S.; Frontera, P.; Donato, A.; Busacca, C.; Scarpino, L. A.; Antonucci, P.; Neri, G. Mater. Chem. Phys. 2014, 147, 35-41. doi:10.1016/j.matchemphys.2014.03.057

132.Wang, L.; Cao, J.; Qian, X.; Zhang, H. Mater. Lett. 2016, 171, 30-33. doi:10.1016/j.matlet.2016.02.053

133.Cao, J.; Dou, H.; Zhang, H.; Mei, H.; Liu, S.; Fei, T.; Wang, R.; Wang, L.; Zhang, T. Sens. Actuators, B 2014, 198, 180-187. doi:10.1016/j.snb.2014.03.015

134.Lim, S. K.; Hwang, S.-H.; Chang, D.; Kim, S. Sens. Actuators, B 2010, 149, 28-33. doi:10.1016/j.snb.2010.06.039

135.Xu, L.; Dong, B.; Wang, Y.; Bai, X.; Liu, Q.; Song, H. Sens. Actuators, B 2010, 147, 531-538. doi:10.1016/j.snb.2010.04.003

136.Zheng, W.; Lu, X.; Wang, W.; Li, Z.; Zhang, H.; Wang, Y.; Wang, Z.; Wang, C. Sens. Actuators, B 2009, 142, 61-65. doi:10.1016/j.snb.2009.07.031

137.Chi, X.; Liu, C.; Zhang, J.; Liu, L.; Li, H.; He, Y.; Bo, X.; Liu, L. J. Semicond. 2014, 35, 064005. doi:10.1088/1674-4926/35/6/064005
138.Lu, Q.; Wang, C.; Liu, S.; Ren, M. Mater. Trans. 2011, 52, 1206-1210. doi:10.2320/matertrans.M2010436

139.Park, J. Y.; Asokan, K.; Choi, S.-W.; Kim, S. S. Sens. Actuators, B 2011, 152, 254-260. doi:10.1016/j.snb.2010.12.017

140.Kim, I.-D.; Rothschild, A. Polym. Adv. Technol. 2011, 22, 318-325. doi:10.1002/pat.1797

141.Jiang, C.; Zhang, G.; Wu, Y.; Li, L.; Shi, K. CrystEngComm 2012, 14, 2739-2747. doi:10.1039/c2ce06405g

142.Landau, O.; Rothschild, A. J. Electroceram. 2015, 35, 148-159. doi:10.1007/s10832-015-0007-9

143.Zhang, J.; Choi, S.-W.; Kim, S. S. J. Solid State Chem. 2011, 184, 3008-3013. doi:10.1016/j.jssc.2011.09.014

144.Cui, J.; Shi, L.; Xie, T.; Wang, D.; Lin, Y. Sens. Actuators, B 2016, 227, 220-226. doi:10.1016/j.snb.2015.12.010

145. Nikfarjam, A.; Salehifar, N. Sens. Actuators, B 2015, 211, 146-156. doi:10.1016/j.snb.2015.01.078

146. Jiang, Z.; Yin, M.; Wang, C. Mater. Lett. 2017, 194, 209-212. doi:10.1016/j.matlet.2017.02.031

147.Lee, D. Y.; Cho, J.-E.; Cho, N.-I.; Lee, M.-H.; Lee, S.-J.; Kim, B.-Y. Thin Solid Films 2008, 517, 1262-1267. doi:10.1016/j.tsf.2008.05.027

148.Liu, L.; Zhang, T.; Li, S.; Wang, L.; Tian, Y. Mater. Lett. 2009, 63, 1975-1977. doi:10.1016/j.matlet.2009.05.060

149.Lotus, A. F.; Kang, Y. C.; Walker, J. I.; Ramsier, R. D.; Chase, G. G. Mater. Sci. Eng., B 2010, 166, 61-66. doi:10.1016/j.mseb.2009.10.001

150. Cacciotti, I.; Bianco, A.; Pezzotti, G.; Gusmano, G. Chem. Eng. J. 2011, 166, 751-764. doi:10.1016/j.cej.2010.07.008

151. Yamazoe, N.; Sakai, G.; Shimanoe, K. Catal. Surv. Asia 2003, 7, 63-75. doi:10.1023/a:1023436725457

152. Yamazoe, N. Sens. Actuators, B 1991, 5, 7-19. doi:10.1016/0925-4005(91)80213-4

153. Kim, J.-H.; Zheng, Y.; Mirzaei, A.; Kim, S. S. Korean J. Mater. Res. 2016, 26, 741-750. doi:10.3740/mrsk.2016.26.12.741

154.Katoch, A.; Byun, J.-H.; Choi, S.-W.; Kim, S. S. Sens. Actuators, B 2014, 202, 38-45. doi:10.1016/j.snb.2014.05.050

155.Xu, X.; Fan, H.; Liu, Y.; Wang, L.; Zhang, T. Sens. Actuators, B 2011, 160, 713-719. doi:10.1016/j.snb.2011.08.053

156. Lee, J.-S.; Katoch, A.; Kim, J.-H.; Kim, S. S. Sens. Actuators, B 2016, 222, 307-314. doi:10.1016/j.snb.2015.08.037

157.Xu, X.; Chen, Y.; Zhang, G.; Ma, S.; Lu, Y.; Bian, H.; Chen, Q. J. Alloys Compd. 2017, 703, 572-579. doi:10.1016/j.jallcom.2017.01.348

158.Xu, L.; Xing, R.; Song, J.; Xu, W.; Song, H. J. Mater. Chem. C 2013, 1, 2174-2182. doi:10.1039/c3tc00689a

159.Miao, Y.-E.; He, S.; Zhong, Y.; Yang, Z.; Tjiu, W. W.; Liu, T. Electrochim. Acta 2013, 99, 117-123. doi:10.1016/j.electacta.2013.03.063

160.Ma, S.; Jia, J.; Tian, Y.; Cao, L.; Shi, S.; Li, X.; Wang, X. Ceram. Int. 2016, 42, 2041-2044. doi:10.1016/j.ceramint.2015.09.034

161.Wang, J.; Zou, B.; Ruan, S.; Zhao, J.; Chen, Q.; Wu, F. Mater. Lett. 2009, 63, 1750-1753. doi:10.1016/j.matlet.2009.05.046

162. Kim, J. H.; Abideen, Z. U.; Zheng, Y.; Kim, S. S. Sensors 2016, 16, 1857. doi:10.3390/s16111857

163.Shin, J.; Choi, S.-J.; Lee, I.; Youn, D.-Y.; Park, C. O.; Lee, J.-H.; Tuller, H. L.; Kim, I.-D. Adv. Funct. Mater. 2013, 23, 2357-2367. doi:10.1002/adfm.201202729

164.Jang, B.-H.; Landau, O.; Choi, S.-J.; Shin, J.; Rothschild, A.; Kim, I.-D. Sens. Actuators, B 2013, 188, 156-168. doi:10.1016/j.snb.2013.07.011 
165.Dong, K.-Y.; Choi, J.-K.; Hwang, I.-S.; Lee, J.-W.; Kang, B. H.; Ham, D.-J.; Lee, J.-H.; Ju, B.-K. Sens. Actuators, B 2011, 157, 154-161. doi:10.1016/j.snb.2011.03.043

166.Zheng, W.; Lu, X.; Wang, W.; Li, Z.; Zhang, H.; Wang, Z.; Xu, X.; Li, S.; Wang, C. J. Colloid Interface Sci. 2009, 338, 366-370. doi:10.1016/j.jcis.2009.06.041

167. Cho, N. G.; Woo, H.-S.; Lee, J.-H.; Kim, I.-D. Chem. Commun. 2011, 47, 11300-11302. doi:10.1039/c1cc13876f

168. Choi, S.-J.; Lee, I.; Jang, B.-H.; Youn, D.-Y.; Ryu, W.-H.; Park, C. O.; Kim, I.-D. Anal. Chem. 2013, 85, 1792-1796. doi:10.1021/ac303148a

169.Tang, W.; Wang, J.; Qiao, Q.; Liu, Z.; Li, X. J. Mater. Sci. 2015, 50, 2605-2615. doi:10.1007/s10853-015-8836-0

170.Lin, Y.; Wei, W.; Li, Y.; Li, F.; Zhou, J.; Sun, D.; Chen, Y.; Ruan, S. J. Alloys Compd. 2015, 651, 690-698. doi:10.1016/j.jallcom.2015.08.174

171.Trung, D. D.; Hoa, N. D.; Tong, P. V.; Duy, N. V.; Dao, T. D.; Chung, H. V.; Nagao, T.; Hieu, N. V. J. Hazard. Mater. 2014, 265 , 124-132. doi:10.1016/j.jhazmat.2013.11.054

172.Choi, J.-K.; Hwang, I.-S.; Kim, S.-J.; Park, J.-S.; Park, S.-S.; Jeong, U.; Kang, Y. C.; Lee, J.-H. Sens. Actuators, B 2010, 150 , 191-199. doi:10.1016/j.snb.2010.07.013

173.Zhang, M.; Ning, T.; Zhang, S.; Li, Z.; Yuan, Z.; Cao, Q. Mater. Sci. Semicond. Process. 2014, 17, 149-154. doi:10.1016/j.mssp.2013.09.014

174.Shahreen, L.; Chase, G. G.; Turinske, A. J.; Nelson, S. A.; Stojilovic, N. Chem. Eng. J. 2013, 225, 340-349. doi:10.1016/j.cej.2013.03.102

175.Moon, J.; Park, J.-A.; Lee, S.-J.; Zyung, T.; Kim, I.-D. Sens. Actuators, B 2010, 149, 301-305. doi:10.1016/j.snb.2010.06.033

176.Wei, S.; Yu, Y.; Zhou, M. Mater. Lett. 2010, 64, 2284-2286. doi:10.1016/j.matlet.2010.07.038

177.Jiang, Z.; Jiang, T.; Wang, J.; Wang, Z.; Xu, X.; Wang, Z.; Zhao, R.; Li, Z.; Wang, C. J. Colloid Interface Sci. 2015, 437, 252-258. doi:10.1016/j.jcis.2014.09.056

178.Wang, Z.; Liu, L. Mater. Lett. 2009, 63, 917-919. doi:10.1016/j.matlet.2009.01.051

179. Cheng, J. P.; Wang, B. B.; Zhao, M. G.; Liu, F.; Zhang, X. B. Sens. Actuators, B 2014, 190, 78-85. doi:10.1016/j.snb.2013.08.098

180.Liu, L.; Zhang, T.; Wang, L.; Li, S. Mater. Lett. 2009, 63, 2041-2043. doi:10.1016/j.matlet.2009.06.048

181.Xu, X.; Sun, J.; Zhang, H.; Wang, Z.; Dong, B.; Jiang, T.; Wang, W.; Li, Z.; Wang, C. Sens. Actuators, B 2011, 160, 858-863. doi:10.1016/j.snb.2011.08.072

182.Xiong, Y.; Xue, Q.; Ling, C.; Lu, W.; Ding, D.; Zhu, L.; Li, X. Sens. Actuators, B 2017, 241, 725-734. doi:10.1016/j.snb.2016.10.143

183.Jang, J.-S.; Kim, S.-J.; Choi, S.-J.; Kim, N.-H.; Hakim, M.; Rothschild, A.; Kim, I.-D. Nanoscale 2015, 7, 16417-16426. doi:10.1039/c5nr04487a

184.Wu, J.; Huang, Q.; Zeng, D.; Zhang, S.; Yang, L.; Xia, D.; Xiong, Z.; Xie, C. Sens. Actuators, B 2014, 198, 62-69. doi:10.1016/j.snb.2014.03.012

185.Kou, X.; Wang, C.; Ding, M.; Feng, C.; Li, X.; Ma, J.; Zhang, H.; Sun, Y.; Lu, G. Sens. Actuators, B 2016, 236, 425-432. doi:10.1016/j.snb.2016.06.006

186.Liu, L.; Guo, C.; Li, S.; Wang, L.; Dong, Q.; Li, W. Sens. Actuators, B 2010, 150, 806-810. doi:10.1016/j.snb.2010.07.022
187. Kukkola, J.; Mohl, M.; Leino, A.-R.; Mäklin, J.; Halonen, N.; Shchukarev, A.; Konya, Z.; Jantunen, H.; Kordas, K. Sens. Actuators, B 2013, 186, 90-95. doi:10.1016/j.snb.2013.05.082 188.Koo, W.-T.; Choi, S.-J.; Kim, N.-H.; Jang, J.-S.; Kim, I.-D. Sens. Actuators, B 2016, 223, 301-310. doi:10.1016/j.snb.2015.09.095

189.Kim, K.-H.; Kim, S.-J.; Cho, H.-J.; Kim, N.-H.; Jang, J.-S.; Choi, S.-J.; Kim, I.-D. Sens. Actuators, B 2017, 241, 1276-1282. doi:10.1016/j.snb.2016.09.192

190.Cho, H.-J.; Kim, S.-J.; Choi, S.-J.; Jang, J.-S.; Kim, I.-D. Sens. Actuators, B 2017, 243, 166-175. doi:10.1016/j.snb.2016.11.137

191.Kim, S.-J.; Choi, S.-J.; Jang, J.-S.; Cho, H.-J.; Koo, W.-T.; Tuller, H. L.; Kim, I.-D. Adv. Mater. 2017, 29, 1700737. doi:10.1002/adma.201700737

192.Koo, W.-T.; Jang, J.-S.; Choi, S.-J.; Cho, H.-J.; Kim, I.-D. ACS Appl. Mater. Interfaces 2017, 9, 18069-18077. doi:10.1021/acsami.7b04657

193.Li, W.; Ma, S.; Yang, G.; Mao, Y.; Luo, J.; Cheng, L.; Gengzang, D.; Xu, X.; Yan, S. Mater. Lett. 2015, 138, 188-191. doi:10.1016/j.matlet.2014.09.130

194.Sun, Y.; Zhao, Z.; Li, P.; Li, G.; Chen, Y.; Zhang, W.; Hu, J. Appl. Surf. Sci. 2015, 356, 73-80. doi:10.1016/j.apsusc.2015.08.057

195.Xu, X. L.; Chen, Y.; Ma, S. Y.; Li, W. Q.; Mao, Y. Z. Sens. Actuators, B 2015, 213, 222-233. doi:10.1016/j.snb.2015.02.073

196.Zhao, M.; Wang, X.; Ning, L.; Jia, J.; Li, X.; Cao, L. Sens. Actuators, B 2011, 156, 588-592. doi:10.1016/j.snb.2011.01.070

197.Mao, Y.; Ma, S.; Li, X.; Wang, C.; Li, F.; Yang, X.; Zhu, J.; Ma, L. Appl. Surf. Sci. 2014, 298, 109-115. doi:10.1016/j.apsusc.2014.01.133

198.Liu, L.; Li, S.; Zhuang, J.; Wang, L.; Zhang, J.; Li, H.; Liu, Z.; Han, Y.; Jiang, X.; Zhang, P. Sens. Actuators, B 2011, 155, 782-788. doi:10.1016/j.snb.2011.01.047

199.Zhao, M.; Wang, X.; Cheng, J.; Zhang, L.; Jia, J.; Li, X. Curr. Appl. Phys. 2013, 13, 403-407. doi:10.1016/j.cap.2012.08.019

200. Huang, B.; Zhao, C.; Zhang, M.; Zhang, Z.; Xie, E.; Zhou, J.; Han, W. Appl. Surf. Sci. 2015, 349, 615-621. doi:10.1016/j.apsusc.2015.05.003

201.Park, D.-H.; Son, K.-Y.; Lee, J.-H.; Kim, J.-J.; Lee, J.-S. Solid State lonics 2004, 172, 431-434. doi:10.1016/j.ssi.2004.03.029 202.Lotus, A. F.; Kang, Y. C.; Ramsier, R. D.; Chase, G. G. J. Vac. Sci. Technol., B: Microelectron. Nanometer Struct.-Process., Meas., Phenom. 2009, 27, 2331-2336. doi:10.1116/1.3244588

203.Feng, Y.; Hou, W.; Zhang, X.; Lv, P.; Li, Y.; Feng, W. J. Phys. Chem. C 2011, 115, 3956-3961. doi:10.1021/jp1117745

204. Han, N.; Chai, L.; Wang, Q.; Tian, Y.; Deng, P.; Chen, Y. Sens. Actuators, B 2010, 147, 525-530. doi:10.1016/j.snb.2010.03.082

205.Zhao, C.; Bai, J.; Huang, B.; Wang, Y.; Zhou, J.; Xie, E. Sens. Actuators, B 2016, 231, 552-560. doi:10.1016/j.snb.2016.03.056

206.Shan, H.; Liu, C.; Liu, L.; Li, S.; Wang, L.; Zhang, X.; Bo, X.; Chi, X. Sens. Actuators, B 2013, 184, 243-247. doi:10.1016/j.snb.2013.04.088

207.Su, C.; Zou, Y.; Xu, X.; Liu, L.; Liu, Z.; Liu, L. Colloids Surf., A 2015, 472, 63-68. doi:10.1016/j.colsurfa.2015.01.071

208.Su, C.; Liu, C.; Liu, L.; Ni, M.; Li, H.; Bo, X.; Liu, L.; Chi, X. Appl. Surf. Sci. 2014, 314, 931-935. doi:10.1016/j.apsusc.2014.06.169 
209.Su, C.; Li, Y.; He, Y.; Liu, L.; Wang, X.; Liu, L. Mater. Sci. Semicond. Process. 2015, 39, 49-53. doi:10.1016/j.mssp.2015.04.043

210.Li, Z.; Dzenis, Y. Talanta 2011, 85, 82-85. doi:10.1016/j.talanta.2011.03.033

211.Wang, X.; Li, H.; Ni, M.; Wang, L.; Liu, L.; Wang, H.; Guo, X. J. Electron. Mater. 2017, 46, 363-369. doi:10.1007/s11664-016-4878-6

212.Lian, H.; Wang, G.; Yue, H.; Liu, L.; Guo, X.; Wang, X. Micro Nano Lett. 2016, 11, 825-827. doi:10.1049/mnl.2016.0235

213.Wang, X. S.; Wang, G. G.; Li, H. Y.; Wang, L. Y.; Liu, L.; Guo, X. X.; Wang, H.; Lian, H. W. Wuli Xuebao 2016, 65, 130012. doi:10.7498/aps.65.036802

214.Xu, L.; Dong, B.; Wang, Y.; Bai, X.; Chen, J.; Liu, Q.; Song, H. J. Phys. Chem. C 2010, 114, 9089-9095. doi:10.1021/jp101115v

215.Zhao, C.; Huang, B.; Xie, E.; Zhou, J.; Zhang, Z. Sens. Actuators, B 2015, 207, 313-320. doi:10.1016/j.snb.2014.10.087

216.Wang, X.; Zhang, J.; Wang, L.; Li, S.; Liu, L.; Su, C.; Liu, L. J. Mater. Sci. Technol. 2015, 31, 1175-1180. doi:10.1016/j.jmst.2015.11.002

217.Liu, J.; Guo, W.; Qu, F.; Feng, C.; Li, C.; Zhu, L.; Zhou, J.; Ruan, S.; Chen, W. Ceram. Int. 2014, 40, 6685-6689. doi:10.1016/j.ceramint.2013.11.129

218.Liu, C.; Wang, X.; Xie, F.; Liu, L.; Ruan, S. J. Mater. Sci.: Mater. Electron. 2016, 27, 9870-9876. doi:10.1007/s10854-016-5055-7

219.Lian, H.; Feng, Y.; Wang, Z.; Liu, L.; Guo, X.; Wang, X. Appl. Phys. A: Mater. Sci. Process. 2017, 123, 158. doi:10.1007/s00339-017-0791-y

220.Feng, C.; Wang, C.; Zhang, H.; Li, X.; Wang, C.; Cheng, P.; Ma, J.; Sun, P.; Gao, Y.; Zhang, H.; Sun, Y.; Zheng, J.; Lu, G. Sens. Actuators, B 2015, 221, 1475-1482. doi:10.1016/j.snb.2015.07.114

221.Wang, Y.; Zhang, H.; Sun, X. Appl. Surf. Sci. 2016, 389, 514-520. doi:10.1016/j.apsusc.2016.07.073

222.Wan, G. X.; Ma, S. Y.; Sun, X. W.; Sun, A. M.; Li, X. B.; Luo, J.; Li, W. Q.; Wang, C. Y. Mater. Lett. 2015, 145, 48-51. doi:10.1016/j.matlet.2015.01.085

223.Li, W.; Ma, S.; Li, Y.; Yang, G.; Mao, Y.; Luo, J.; Gengzang, D.; Xu, X.; Yan, S. Sens. Actuators, B 2015, 211, 392-402. doi:10.1016/j.snb.2015.01.090

224.Katoch, A.; Kim, J.-H.; Kim, S. S. J. Nanosci. Nanotechnol. 2015, 15, 8637-8641. doi:10.1166/jnn.2015.11505

225.Xu, L.; Song, H.; Dong, B.; Wang, Y.; Chen, J.; Bai, X. Inorg. Chem. 2010, 49, 10590-10597. doi:10.1021/ic101602a

226.Gao, J.; Wang, L.; Kan, K.; Xu, S.; Jing, L.; Liu, S.; Shen, P.; Li, L.; Shi, K. J. Mater. Chem. A 2014, 2, 949-956. doi:10.1039/c3ta13943c

227.Xu, S.; Gao, J.; Wang, L.; Kan, K.; Xie, Y.; Shen, P.; Li, L.; Shi, K. Nanoscale 2015, 7, 14643-14651. doi:10.1039/C5NR03796D

228. Wu, H.; Kan, K.; Wang, L.; Zhang, G.; Yang, Y.; Li, H.; Jing, L.; Shen, P.; Li, L.; Shi, K. CrystEngComm 2014, 16, 9116-9124. doi:10.1039/C4CE01248H

229.Chi, X.; Liu, C.; Liu, L.; Li, S.; Li, H.; Zhang, X.; Bo, X.; Shan, H. Mater. Sci. Semicond. Process. 2014, 18, 160-164. doi:10.1016/j.mssp.2013.11.016

230.Lee, C.-S.; Kim, I.-D.; Lee, J.-H. Sens. Actuators, B 2013, 181, 463-470. doi:10.1016/j.snb.2013.02.008

231.Liu, J.; Li, X.; Chen, X.; Niu, H.; Han, X.; Zhang, T.; Lin, H.; Qu, F. New J. Chem. 2016, 40, 1756-1764. doi:10.1039/C5NJ02337H
232.Du, H.; Wang, J.; Sun, Y.; Yao, P.; Li, X.; Yu, N. Sens. Actuators, B 2015, 206, 753-763. doi:10.1016/j.snb.2014.09.010

233.Deng, J.; Yu, B.; Lou, Z.; Wang, L.; Wang, R.; Zhang, T. Sens. Actuators, B 2013, 184, 21-26. doi:10.1016/j.snb.2013.04.020

234.Lou, Z.; Li, F.; Deng, J.; Wang, L.; Zhang, T. ACS Appl. Mater. Interfaces 2013, 5, 12310-12316. doi:10.1021/am402532v

235.Lou, Z.; Deng, J.; Wang, L.; Wang, R.; Fei, T.; Zhang, T. RSC Adv. 2013, 3, 3131-3136. doi:10.1039/c2ra22655c

236. Qi, Q.; Wang, P.-P.; Zhao, J.; Feng, L.-L.; Zhou, L.-J.; Xuan, R.-F.; Liu, Y.-P.; Li, G.-D. Sens. Actuators, B 2014, 194, 440-446. doi:10.1016/j.snb.2013.12.115

237. Nikfarjam, A.; Salehifar, N. IEEE Sens. J. 2015, 15, 5962-5970. doi:10.1109/JSEN.2015.2449895

238.Wang, Q.; Dong, X.; Pang, Z.; Du, Y.; Xia, X.; Wei, Q.; Huang, F. Sensors 2012, 12, 17046-17057. doi:10.3390/s121217046

239.Li, Y.; Gong, J.; He, G.; Deng, Y. Mater. Chem. Phys. 2011, 129, 477-482. doi:10.1016/j.matchemphys.2011.04.045

240.Wang, Y.; Jia, W.; Strout, T.; Ding, Y.; Lei, Y. Sensors 2009, 9 , 6752-6763. doi:10.3390/s90906752

241.Li, Y.; Ban, H.; Yang, M. Sens. Actuators, B 2016, 224, 449-457. doi:10.1016/j.snb.2015.10.078

242.Li, Y.; Ban, H.; Jiao, M.; Yang, M. RSC Adv. 2016, 6, 74944-74956. doi:10.1039/C6RA10280H

243.Wang, Z.; Liu, S.; Jiang, T.; Xu, X.; Zhang, J.; An, C.; Wang, C. RSC Adv. 2015, 5, 64582-64587. doi:10.1039/C5RA08863A

244. Yan, S.; Wu, Q. Sens. Actuators, B 2014, 205, 329-337. doi:10.1016/j.snb.2014.08.062

245. Abideen, Z. U.; Park, J. Y.; Kim, H. W.; Kim, S. S. Nanotechnology 2017, 28, 035501. doi:10.1088/1361-6528/28/3/035501

246. Kim, J.-H.; Zheng, Y.; Mirzaei, A.; Kim, H. W.; Kim, S. S. J. Electron. Mater. 2017, 46, 3531-3541. doi:10.1007/s11664-017-5301-7

247.Liu, S.; Sun, H.; Nagarajan, R.; Kumar, J.; Gu, Z.; Cho, J.; Kurup, P. Sens. Actuators, A 2011, 167, 8-13. doi:10.1016/j.sna.2011.02.007

248.Lin, Q.; Li, Y.; Yang, M. Anal. Chim. Acta 2012, 748, 73-80. doi:10.1016/j.aca.2012.08.041

249. He, X.; Arsat, R.; Sadek, A. Z.; Wlodarski, W.; Kalantar-zadeh, K.; Li, J. Sens. Actuators, B 2010, 145, 674-679. doi:10.1016/j.snb.2010.01.013

250.Matatagui, D.; Fernández, M. J.; Santos, J. P.; Fontecha, J.; Sayago, I.; Horrillo, M. C.; Grácia, I.; Cané, C. J. Nanomater. 2014, 2014, 243037. doi:10.1155/2014/243037

251.Liu, Y.; Huang, H.; Wang, L.; Cai, D.; Liu, B.; Wang, D.; Li, Q.; Wang, T. Sens. Actuators, B 2016, 223, 730-737. doi:10.1016/j.snb.2015.09.148

252.Sheng, L.; Dajing, C.; Yuquan, C. Nanotechnology 2011, 22, 265504. doi:10.1088/0957-4484/22/26/265504

253.Lu, C.; Czanderna, A. W. Applications of piezoelectric quartz crystal microbalances; Elsevier: Amsterdam, Netherlands, 2012; Vol. 7.

254.Sauerbrey, G. Z. Phys. 1959, 155, 206-222. doi:10.1007/BF01337937

255.Wang, Z. L.; Wu, W. Angew. Chem., Int. Ed. 2012, 51, 11700-11721. doi:10.1002/anie.201201656

256. Aria, M. M.; Irajizad, A.; Astaraei, F. R.; Shariatpanahi, S. P.; Sarvari, R. Measurement 2016, 78, 283-288. doi:10.1016/j.measurement.2015.10.018

257.Zhang, C.; Wang, X.; Lin, J.; Ding, B.; Yu, J.; Pan, N. Sens. Actuators, B 2011, 152, 316-323. doi:10.1016/j.snb.2010.12.028 
258.Ding, B.; Wang, X.; Yu, J.; Wang, M. J. Mater. Chem. 2011, 21, 12784-12792. doi:10.1039/c1jm11847a

259.Wang, X.; Wang, J.; Si, Y.; Ding, B.; Yu, J.; Sun, G.; Luo, W.; Zheng, G. Nanoscale 2012, 4, 7585-7592. doi:10.1039/c2nr32730a

260.Ding, B.; Yamazaki, M.; Shiratori, S. Sens. Actuators, B 2005, 106, 477-483. doi:10.1016/j.snb.2004.09.010

261.Wang, X.; Ding, B.; Yu, J.; Si, Y.; Yang, S.; Sun, G. Nanoscale 2011, 3, 911-915. doi:10.1039/CONR00783H

262.Jia, Y.; Yan, C.; Yu, H.; Chen, L.; Dong, F. Sens. Actuators, B 2014, 203, 459-464. doi:10.1016/j.snb.2014.06.018

263.Jia, Y.; Yu, H.; Zhang, Y.; Chen, L.; Dong, F. Sens. Actuators, B 2015, 212, 273-277. doi:10.1016/j.snb.2015.02.041

264.Ding, B.; Kim, J.; Miyazaki, Y.; Shiratori, S. Sens. Actuators, B 2004, 101, 373-380. doi:10.1016/j.snb.2004.04.008

265. Hu, Y.; Yu, H.; Yan, Z.; Ke, Q. RSC Adv. 2018, 8, 8747-8754. doi:10.1039/C7RA13006F

266. Huang, W.; Wang, X.; Jia, Y.; Li, X.; Zhu, Z.; Li, Y.; Si, Y.; Ding, B.; Wang, X.; Yu, J. RSC Adv. 2013, 3, 22994-23000. doi:10.1039/c3ra44671a

267. Horzum, N.; Tascioglu, D.; Özbek, C.; Okur, S.; Demir, M. M. New J. Chem. 2014, 38, 5761-5768. doi:10.1039/c4nj00884g

268.Jia, Y.; Chen, L.; Yu, H.; Zhang, Y.; Dong, F. RSC Adv. 2015, 5, 40620-40627. doi:10.1039/C5RA04890G

269. Korotcenkov, G. Mater. Sci. Eng., B 2007, 139, 1-23. doi:10.1016/j.mseb.2007.01.044

270.Sekimoto, S.; Nakagawa, H.; Okazaki, S.; Fukuda, K.; Asakura, S.; Shigemori, T.; Takahashi, S. Sens. Actuators, B 2000, 66, 142-145. doi:10.1016/S0925-4005(00)00330-0

271.Viter, R.; Chaaya, A. A.; latsunskyi, I.; Nowaczyk, G.; Kovalevskis, K.; Erts, D.; Miele, P.; Smyntyna, V.; Bechelany, M. Nanotechnology 2015, 26, 105501. doi:10.1088/0957-4484/26/10/105501

272.Luoh, R.; Hahn, H. T. Compos. Sci. Technol. 2006, 66, 2436-2441. doi:10.1016/j.compscitech.2006.03.012

273.Aydogdu, S.; Ertekin, K.; Suslu, A.; Ozdemir, M.; Celik, E.; Cocen, U. J. Fluoresc. 2011, 21, 607-613. doi:10.1007/s10895-010-0748-4

274.Xue, W.; Zhang, Y.; Duan, J.; Liu, D.; Ma, Y.; Shi, N.; Chen, S.; Xie, L.; Qian, Y.; Huang, W. J. Mater. Chem. C 2015, 3, 8193-8199. doi:10.1039/C5TC00819K

275. Urrutia, A.; Goicoechea, J.; Rivero, P. J.; Matías, I. R.; Arregui, F. J. Sens. Actuators, B 2013, 176, 569-576. doi:10.1016/j.snb.2012.10.009

276.Davis, B. W.; Burris, A. J.; Niamnont, N.; Hare, C. D.; Chen, C.-Y.; Sukwattanasinitt, M.; Cheng, Q. Langmuir 2014, 30, 9616-9622. doi:10.1021/la5017388

277.Xue, R.; Behera, P.; Xu, J.; Viapiano, M. S.; Lannutti, J. J. Sens. Actuators, B 2014, 192, 697-707. doi:10.1016/j.snb.2013.10.084

278. Wolf, C.; Tscherner, M.; Köstler, S. Sens. Actuators, B 2015, 209, 1064-1069. doi:10.1016/j.snb.2014.11.070

279.Wolf, C.; Tscherner, M.; Köstler, S.; Ribitsch, V. Optochemical sensors based on polymer nanofibers with ultra-fast response characteristics. In 2014 IEEE Proceedings of Sensors, IEEE Publishing: Piscataway, NJ, U.S.A., 2014; pp 950-953. doi:10.1109/ICSENS.2014.6985159

280.Zhang, Y.; He, X.; Li, J.; Miao, Z.; Huang, F. Sens. Actuators, B 2008, 132, 67-73. doi:10.1016/j.snb.2008.01.006

281.Park, J.-A.; Moon, J.; Lee, S.-J.; Lim, S.-C.; Zyung, T. Curr. Appl. Phys. 2009, 9, S210-S212. doi:10.1016/j.cap.2009.01.044
282.Liu, Y.; Gao, C.; Pan, X.; An, X.; Xie, Y.; Zhou, M.; Song, J.; Zhang, H.; Liu, Z.; Zhao, Q.; Zhang, Y.; Xie, E. Appl. Surf. Sci. 2011, 257, 2264-2268. doi:10.1016/j.apsusc.2010.09.085

283. Sowti Khiabani, P.; Hosseinmardi, A.; Marzbanrad, E.; Ghashghaie, S.; Zamani, C.; Keyanpour-Rad, M.; Raissi, B. Sens. Actuators, B 2012, 162, 102-107. doi:10.1016/j.snb.2011.12.043

284. Karimi, E. Z.; Esmaeilzadeh, J.; Marzbanrad, E. Bull. Mater. Sci. 2015, 38, 209-214. doi:10.1007/s12034-014-0800-0

285.Liang, X.; Kim, T.-H.; Yoon, J.-W.; Kwak, C.-H.; Lee, J.-H. Sens. Actuators, B 2015, 209, 934-942. doi:10.1016/j.snb.2014.11.130

286. Qi, Q.; Zou, Y.-C.; Fan, M.-H.; Liu, Y.-P.; Gao, S.; Wang, P.-P.; He, Y.; Wang, D.-J.; Li, G.-D. Sens. Actuators, B 2014, 203, 111-117. doi:10.1016/j.snb.2014.06.082

287.Song, X.; Liu, L. Sens. Actuators, A 2009, 154, 175-179. doi:10.1016/j.sna.2009.06.010

288.Zhang, H.-D.; Tang, C.-C.; Long, Y.-Z.; Zhang, J.-C.; Huang, R.; Li, J.-J.; Gu, C.-Z. Sens. Actuators, A 2014, 219, 123-127. doi:10.1016/j.sna.2014.09.005

289.Bai, H.; Zhao, L.; Lu, C.; Li, C.; Shi, G. Polymer 2009, 50, 3292-3301. doi:10.1016/j.polymer.2009.04.066

290.Low, K.; Horner, C. B.; Li, C.; Ico, G.; Bosze, W.; Myung, N. V.; Nam, J. Sens. Actuators, B 2015, 207, 235-242. doi:10.1016/j.snb.2014.09.121

291.Patil, P. T.; Anwane, R. S.; Kondawar, S. B. Procedia Mater. Sci. 2015, 10, 195-204. doi:10.1016/j.mspro.2015.06.041

292.Pang, Z.; Nie, Q.; Wei, A.; Yang, J.; Huang, F.; Wei, Q. J. Mater. Sci. 2017, 52, 686-695. doi:10.1007/s10853-016-0362-1

293. Pinto, N. J.; Ramos, I.; Rojas, R.; Wang, P.-C.; Johnson, A. T., Jr. Sens. Actuators, B 2008, 129, 621-627. doi:10.1016/j.snb.2007.09.040

294.Pinto, N. J.; Rivera, D.; Melendez, A.; Ramos, I.; Lim, J. H.; Johnson, A. T. C. Sens. Actuators, B 2011, 156, 849-853. doi:10.1016/j.snb.2011.02.053

295. Feng, Q.; Li, X.; Wang, J.; Gaskov, A. M. Sens. Actuators, B 2016, 222, 864-870. doi:10.1016/j.snb.2015.09.021

296. Han, L.; Andrady, A. L.; Ensor, D. S. Sens. Actuators, B 2013, 186, 52-55. doi:10.1016/j.snb.2013.05.069

297.Lv, Y.-Y.; Wu, J.; Xu, Z.-K. Sens. Actuators, B 2010, 148, 233-239. doi:10.1016/j.snb.2010.05.029

298.Zhou, Q.; Sussman, A.; Chang, J.; Dong, J.; Zettl, A.; Mickelson, W. Sens. Actuators, A 2015, 223, 67-75. doi:10.1016/j.sna.2014.12.005 


\section{License and Terms}

This is an Open Access article under the terms of the Creative Commons Attribution License (http://creativecommons.org/licenses/by/4.0). Please note that the reuse, redistribution and reproduction in particular requires that the authors and source are credited.

The license is subject to the Beilstein Journal of Nanotechnology terms and conditions:

(https://www.beilstein-journals.org/bjnano)

The definitive version of this article is the electronic one which can be found at:

doi:10.3762/bjnano.9.202 